\title{
REOPERATIVE CORONARY ARTERY BYPASS GRAFTING
}

Frans M. van Eck 
Eck van Frans,

Reoperative coronary artery bypass surgery

Omslagtekening Lucas en Lisa van Eck 


\title{
REOPERATIVE CORONARY ARTERY BYPASS GRAFTING
}

\author{
Een wetenschappelijke proeve op het gebied van de
}

MEDISCHE WETENSCHAPPEN

Proefschrift

Ter verkrijging van de graad van doctor

aan de Katholieke Universiteit Nijmegen

op gezag van de Rector Magnificus

Professor Dr. C.W.P.M. Blom,

volgens besluit van het College van Decanen

in het openbaar te verdedigen op woensdag 18 februari 2004

des namiddags om 3.30 uur precies

door

\section{Frans Matthijs van Eck}

geboren op 4 februari 1972

te Ede 
Promotor:

Prof. Dr. M.H.J. Brouwer

Co-promotor:

Dr. L. Noyez

Manuscriptcommissie:

Prof. Dr. A. Stalenhoef, voorzitter

Prof. Dr. J.C. van der Hoeven

Prof. Dr. B. Mochtar, AZ Maastricht

Prof. Dr. G.J. Scheffer

Prof. Dr. P. Sergeant, KU Leuven (Belgie) 


\section{CONTENTS}

$\begin{array}{ll}\text { General Introduction } & 7\end{array}$

Chapter I On Reoperations 9

Chapter II Changing profile of patients undergoing redo-coronary artery 23

surgery

European Journal of Cardio-thoracic Surgery

2002; 21: 205-211.

Chapter III Coronary reoperations in patients with a patent internal mammary

artery graft.

Cardiovascular Surgery 2001; 9: 179-183.

Chapter IV Analysis of mortality within the first six months after coronary

reoperation.

The Annals of Thoracic Surgery 2002; 74: 2106-2112

Chapter V Preoperative prediction of early mortality in redocoronary artery surgery.

European Journal of Cardio-thoracic Surgery 2002; 21:1031-1036.

Chapter VI Identification of patients at risk for early out-of-hospital mortality

after redocoronary artery surgery.

Netherlands Heart Journal 2003; 11: 394-400.

Chapter VII Long term cardiac survival after reoperative coronary artery

bypass grafting

European Journal of Cardio-thoracic Surgery In press

Chapter VIII Evaluation of long term quality of life after reoperative coronary

artery surgery. Preliminary results.

Netherlands Heart Journal 2003; 11: 500-505.

Chapter IX Summary and conclusions

Samenvatting en besluiten

Dankwoord

Curriculum vitae 


\section{General Introduction.}

Over the last fifteen years, reoperative coronary artery bypass grafting (RECABG) has become one of the major areas of interest in the department of Thoracic and Cardiac Surgery of the University Medical Center Nijmegen, St. Radboud, The Netherlands. Not only was there increasing surgical experience, but also several papers concerning RECABG were published in national and international journals. In 1996 several of these papers were summarized in a book called "Coronaire Heroperaties. Een evaluatie"*.

The publications of results can be seen as a kind of quality control of the surgery performed and can spur the authors to update their knowledge and confront the new problems and questions of RECABG. Such surgery can be described as disastrous, adventurous, frustrating, trying and presents many challenges to the surgical team. Two essential points must, however, be remembered. Firstly, RECABG is the consequence of primary coronary artery bypass surgery (CABG) and secondly, whereas modern cardiac surgery has become relatively safe, RECABG continues $\mathrm{t}$ have a high morbidity and mortality compared to CABG.

This thesis consists of several articles related to two major points:

- The influence of the evolution in CABG on RECABG.

- Analysis of the early postoperative mortality.

Chapter I gives a general review of problems of RECABG. In Chapter II the changing profile of patients undergoing RECABG is presented. In chapter III the short and long term results, of RECABG in patients, with a patent internal mammary artery are discussed. The chapters IV to VI deal with the problem of early (six months) mortality. Chapter IV analyses determinants associated with early mortality following RECABG. In Chapter V and VI the results of the study presented in chapter IV are used to construct a preoperative (Chapter V) and a postoperative (Chapter VI) predictive model of early mortality in RECABG. Chapter VII presents the results of the long-term survival after RECABG, and confirms again the importance of the first six months for the long-term survival. Our preliminary results on quality of life after RECABG are presented in Chapter VIII. Summaries and general conclusions in English and Dutch are presented in Chapter IX

\footnotetext{
* Coronaire Heroperaties. Een Evaluatie. Noyez L. (eds). ISBN 90-803014-1-8, NUGI 742, Universiteits drukkerij Nijmegen, 1996
} 
CHAPTER I

ON REOPERATIONS. 


\section{Incidence.}

In 1983, Loop postulated that about $7 \%$ of patients undergoing primary coronary arterial bypass grafting $(\mathrm{CABG})$ in time would need a second operation for recurrent angina [1]. During the last decade, much has changed in the fields of cardiac surgery, anesthesia and intensive care, which have resulted in lower mortality rates and a shift away from cardiac related mortality and morbidity after CABG to non-cardiac related mortality and morbidity [2-4]. Loop's postulation, however, has turned out to be true because the percentage of reoperative coronary artery bypass grafting (RECABG) currently varies between $6-10 \%$ of the patient population. $[1,5,6]$ There seems to be a paradox here. On the one hand the results of CABG have improved remarkably with longer life expectation of the overall population even with the acceptance of older patients for cardiac surgery. On the other hand, more patients with suboptimal distal coronary arteries undergo $\mathrm{CABG}$ with a higher risk of recurrent angina. (table 1)

Table 1 Factors which may increase or decrease the rate of RECABG

\begin{tabular}{|l|l|}
\hline \multicolumn{1}{|c|}{ Increase } & \multicolumn{1}{c|}{ Decrease } \\
\hline Use of saphenous vein grafts only & Use of arterial grafts \\
\hline Failure of operative technique & Complete revascularization \\
\hline Progression of atherosclerosis & Antiplatelet drugs \\
\hline Incomplete revascularization & Statines \\
\hline Younger age at the primairy operation & Balloon Angioplasty - Stenting \\
\hline Older age at the reoperation & \\
\hline Hyperlipidemia & \\
\hline Diffuse coronary pathology & \\
\hline
\end{tabular}

\section{Early and late return of angina - early and late graft failure}

Coronary artery bypass surgery is a well-recognized treatment for coronary artery disease. The use of arterial grafts have improved long-term results in terms of survival as well as in return of ischemic symptoms. [7-10] However, the process of atherosclerosis cannot be stopped and the return of angina pectoris seems inevitable. This return seems to be biphasic: an early return of angina pectoris within six months after $\mathrm{CABG}$, and a late return more than six months after CABG. Early graft failure, due to intimal fibroplasia, [11] and incomplete 
revascularization are the main reasons for the early return. Late return is due to progression of atherosclerosis in the native coronary artery system, in the vein grafts, or both (table 2).

Table 2 Return of angina post myocardial revascularization

\begin{tabular}{|l|ll|}
\hline Return of angina & \multicolumn{1}{|c|}{ Cause } \\
\hline Early $(<6$ months) & - & Surgicalrelated problem \\
& - & Incomplete revascularization \\
& - & Intima fibroplasia \\
& & \\
\hline Late $(>6$ months) & - & Progression of atherosclerosis in the native coronary system (PA) \\
& - & Atherosclerosis in grafts (AG) \\
& - & Combination of PA + AG \\
& - & Incomplete revascularization \\
\hline
\end{tabular}

It seems that the reason for RECABG is time related: in the early seventies, the majority of the patients underwent a RECABG because of progression of atherosclerosis in the native coronary system or due to incomplete revascularization at the CABG. Later in the eighties, the reason for RECABG had shifted to predominantly failure of the graft. Furthermore, in the seventies the mean interval between the CABG and RECABG for graft failure alone was approximately 25 months and 45 months for the combination of graft failure and progression of the atherosclerosis in the native coronary system. Later with more experience, these intervals increased up to 66 months and 90 months respectively. These data indicate that even after a successful CABG, the patency of grafts is compromised predominantly by vein graft atherosclerosis. [12]

Currently, the interval between the CABG and RECABG is still increasing because of the better patency of arterial grafts compared to vein grafts, and due to the acceptance of older patients for RECABG. [5,13] However, the use of arterial grafts will not hold back the process of atherosclerosis; it only prolongs the interval free of angina pectoris. As a result, the biphasic pattern will flatten because the early return of angina pectoris will decline and the late return will occur later. The need for a RECABG, therefore, cannot be abolished simply because the process of atherosclerosis cannot be stopped in spite of the use of arterial grafts and other precautions to improve the patency of the grafts.

Another unexpected reason for an early return of angina pectoris is the popularization of the offpump surgery. With the off-pump technique, the anastomosis are made on the beating heart with 
the aid of special tools to stabilize the anastomotic region without hampering the heart function. It is a striking phenomenon that in several cardiac-surgery centers, with the off-pump technique, significantly less distal anastomoses, are performed compared to classic on-pump surgery. This incomplete revascularization could provoke an increase of predominantly early return of angina pectoris en thereby the need for a re-intervention e.g. a Percutaneous Transluminal Coronary Angioplasty (PTCA) or even RECABG. [14-17]

\section{Patient selection}

The two major indications for CABG are 1) improvement of the prognosis especially in patients with a significant stenosis of the ostium of the left coronary artery or the left main, three vessel disease with impaired left ventricular function and 2) relieve of complaints due to reversible myocardial ischemia not responding on medication. [18,19]

For RECABG the indications for surgery are actually similar. Improvement of the prognosis after RECABG is especially seen in patients with late vein graft stenosis to the left anterior descending coronary artery (LAD) more than five years after CABG with revasculariztion of the LAD with the Left Internal Mammary Artery (LIMA)[20]. In the last two decades nearly all patients have received a LIMA graft to the LAD, so this cohort gradually has become rare. In patients with complaints not responding to medical treatment and proof of reversible myocardial ischemia, the indications for RECABG are thus similar as the indication for CABG [19] albeit that the perioperative mortality of the RECABG is higher (2-18\%) compared to CABG (1-4\%) [21-24]

Although angiography is an important tool in evaluating coronary anatomy and status of the previous constructed grafts, it remains debatable whether the operability on the basis of the visualization of the coronary vessel alone is enough. To determine the diameter of the coronary vessels with angiography can be difficult, especially when these vessels are critically narrowed or totally occluded with insufficient perfusion.

The mortality rate of emergency RECABG is high and varies between $25 \%-45 \%$. [1-5,21-25] It is, therefore, wise to avoid emergency RECAGB, as much as possible. [5] Medical therapy, intra aortic balloon counter pulsation (IABP) or even angioplasty of the culprit lesion can be used to stabilize these patients in order to perform the RECABG in a more stable situation. 


\section{Resternotomy.}

The risk of a resternotomy is related to fibrosis and scarring of the pericardium and mediastinum.[26] Hemorrhagic complications due to laceration of the right ventricle during resternotomy can be life threatening. In 1983, Loop concluded that control and management of the mediastinal adhesions, was the prime reason for the improved results in RECABG. [1] With increasing experience, repeat median sternotomy is no longer considered as an incremental risk factor for mortality for RECABG.[12] To avoid the potential problems of resternotomy, alternative approaches were introduced as an alternative to the resternotomy such as the posterolateral thoracotomy, [27] a left anterior small thoracotomy for minimal invasive procedures, [28] or even laparotomy [29] These approaches have the advantage that they enter the chest by a non-operated route. However, the drawback is that they offer only a limited exposure of the heart, which can compromise total myocardial revascularization [30] Thus, a resternotomy is a demanding, challenging procedure and more than just reopening the chest.

A point of discussion is if groin vessels must be exposed or not, and/or cannulated before resternotomy. In our department groin vessels are not exposed routinely, but are always checked before the sternotomy is performed. Exceptions are: second and third redo's, patients with a history of sternal infection, grafts adherent to the sternum, IMA-grafts crossing the midline and patients with tricuspid valve regurgitation, and right atrial, ventricle dilatation, because a lesion to a dilated, thin right atrium or ventricle is difficult to repair.

\section{Grafts, old and new}

Certainly in RECABG, vessel identification can be difficult, and lack of bypass conduits may contribute to incomplete revascularization. Specific for RECABG is the presence of old vein grafts. Progression of atherosclerosis involves not only the native coronary artery system, but also the vein graft. A study from the Cleveland Clinic reported that 5 to 12 years after CABG, $40 \%$ of the vein grafts were stenotic or totally occluded.[31] In spite of the use of antiplatelet medication which is said to delay this artherosclerotic process, the time of occurrence remains unpredictable [32]. Furthermore coronary angiography underestimates the severity of the atherosclerotic degeneration in vein grafts.[1-5] 
Of clinical importance is that vein graft atherosclerosis is more dangerous than native vessel coronary artery disease. The mechanism by which late vein grafts occlude, produces clinical events such as embolization of atherosclerotic debris and graft failure. Furthermore it differs distinctly compared to native coronary artery atherosclerosis. Coronary artery atherosclerosis is focal, with eccentric plaques that have a fibrous cap overlying a center of lipid debris whereas vein graft atherosclerosis has not with the result that the debris is exposed directly to the blood stream. [33] These lesions are friable and fragile and might result in embolization by manipulations of the heart, arterial pressure fluctuations and antegrade delivery of cardioplegic solution during reoperations. [34,35] It seems logical to speculate that naturally occurring embolization may account for unstable angina or myocardial infarction, due to the spreading of debris in the distal coronary arteries. This is also a reason for the high perioperative myocardial infarction rates and mortality rates in unstable RECABG patients.

To decreases the risk of embolization during manipulation, the patient should be put on bypass with the so called 'no-touch' technique, retrograde delivery of cardioplegia and cardiac dissection when the heart is still and flaccid. Ligation of diseased vein grafts is dangerous because this might result in squeezing debris to the distal coronary circulation. Some advocate graft division or favor replacement of the old vein grafts but even these options are debatable. $[31,32,36]$

An argument against ligation or division of the old graft is the so-called 'hypoperfusion syndrome', This means that when a patent with a diseased vein graft to the LAD artery is disconnected and replaced by an IMA-graft, hypoperfusion of the coronary area might occur manifested as ST-segment changes, arrthymia or hypotension. This problem could be avoided by adding a new vein graft to the LAD, or with preservation of the old and diseased vein graft. [20] With the increased use of the IMA-grafts during $\mathrm{CABG}$, reoperations in patients with a patent IMA-graft is challenging in terms of preservation of the patent IMA and myocardial protection of the IMA -dependent myocardium[37]. These problems can be adequately solved with the use of retrograde delivered cardioplegia. A patent IMA should not be considered as a risk factor for mortality or morbidity in reoperations. [5,13,37]

Most RECABGs can be done using the classic conduits like the saphenous veins, the internal mammary arteries, the gastro-epiploic, radial and even the inferior epigastic artery. [38] Alternative conduits, used infrequently, are the lesser saphenous vein, cubital veins and homografts. The use of bovine heterograft arteries has now been abandoned due to unacceptable 
low patency rates. In some patients however there will be just enough length of conduits, so that maximal use is important. Also Y- or T graft constructions can be performed. In patients with a patent IMA-graft, a recycling of this IMA graft can be done successfully without compromising this graft. This recycling technique was first described by the Nijmegen group. [39]

\section{Myocardial protection}

The mortality of a RECABG exceeds the mortality of a CABG [1-5,21-23]. Also, the difference between RECABG and CABG with regard to perioperative myocardial infarction is another striking finding. [1-5,21-23,40] Furthermore in CABG, there is a shift away from cardiac-related postoperative morbidity and mortality in contrast to RECABG.

The inefficiency of myocardial protection in RECABG is related to several problems. First, the complex anatomy, mostly expanded with a collateral circulation of the myocardial blood supply, the routes of myocardial perfusion with patent and diseased vein grafts, and the blood flow through patent IMA-grafts are the reasons that the antegrade delivered cardioplegia is suboptimal in protecting the heart. Secondly, embolization of debris from atherosclerotic vein grafts during antegrade infusion of cardioplegia jeopardizes the run-off of the distal coronary arteries which might lead to a perioperative myocardial infarction. In order to prevent this, one could argue that it might be wise to disconnect the diseased vein graft before cardioplegic delivery is given. The drawback with this option is that it might provoke hypoperfusion of the myocardium. Therefore, retrograde transatrial perfusion of cardioplegia through the coronary sinus seems to be the most effective alternative.[41,42]. The advantages are that there is no atherosclerosis in the venous system, the debris in the coronary arteries will be washed out and the cardioplegia can be delivered independently of the position of the heart. With this preservation technique, the Cleveland group has shown a significant decrease in perioperative myocardial infarction and postoperative morbidity thereby underscoring the effectiveness of the retrograde transatrial delivery of cardioplegia in RECABG. [40-43].

\section{Perioperative mortality and morbidity}

Perioperative mortality and morbidity such as myocardial infarction after RECABG are still troublesome and higher than in CABG. Mortality rates vary between $418 \%$ for RECABG 
versus $1-4 \%$ for $\mathrm{CABG}$, and the incidence of perioperatieve myocardial infarction varies from 6$15 \%$ in RECABG versus 2-6\% in CABG [1,2,5,6,12,21-23] In 1987, Lytle et al [12] already mentioned these striking differences between CABG and RECABG.

There is no doubt that advances in perioperative anesthetic management, myocardial protection and surgical techniques in the last decades have reduced the risks of RECABG. However, in spite of these changes, the prevalence of risk factors for hospital mortality and morbidity has further increased over the years $[6,44,45]$. A clearer insight into the demographic profile of the cardiac patients for RECABG is crucial to unravel the problem of a persistent high mortality and morbidity in RECABG [1,5,6,20,31,36-47]. Non-elective procedures, perioperative myocardial infarction and retrograde delivery of cardioplegia are all identified as independent variables for mortality and morbidity rates [5,6,40-52]. Still, it is difficult to compare these studies and come to a definitive conclusion because the endpoints 'mortality' an 'morbidity' are not defined consequently. Some series use in-hospital mortality and morbidity and others 30 -days mortality and morbidity. In our series we advocate a six months mortality and morbidity, because it is known that the operative risk, certainly in high-risk patients, is prolonged. [25, 53-55].

\section{Long-term results}

Ten-year survival after successful RECABG is about 80\%. [5,20,21,48,50,51] A number of these patients return with symptomatic coronary disease, as coronary artery sclerosis is a progressive disease in both the native coronary system and the conduits. It is generally accepted that with each subsequent reintervention, the probability of an "angina-free period" as well as the interval between these periods diminish. [55]. The long-term results after revascularization of the coronary vessels are not only influenced by graft choice and completeness of the revascularization but also by older age, impairment of the left ventricle, hypertension, diabetes mellitus and congestive heart failure [5,20,49-52] For RECABG, it seems that the long-term results are predominantly determined by the perioperative risk and that survival of the postoperative period is the first step in long-term survival. 


\section{Conclusion}

RECABG has become an increasing challenge for the cardiac surgeon. The increasing incidence of the procedure itself and the persistently elevated rates of morbidity and mortality all add to the challenge. RECABG is technically more complicated than CABG. Most of these complications are related to each other, and are the consequence of our strategies at the primary CABG. Therefore, at every RECABG, the cardiac surgeon may face the limitations of coronary artery bypass surgery.

\footnotetext{
* On reoperations is based on the article 'The challenges of redocoronary artery surgery.' by L. Noyez published in Cardiology 2000;7:73-75.

** Dr. Eric N. Robertson, Anesthesiologist, is thanked for his correction of the English text.
}

\section{References}

1. Loop FD, Lytle BW, Gill CC et al. Trends in selection and results of coronary artery reoperations. Ann Thorac Surg 1983; 36: 380-388.

2. Abramov D, Tamariz MG, Fremes SE et al. Trends in coronary artery bypass surgery results: a recent, 9-year study. Ann Thorac Surg 2000; 70: 84-90.

3. Noyez L, Janssen DPB, Druten van JAM, Skotnicki SH, Lacquet LK. Coronary bypass surgery: what is changing? Analysis of 3834 patients undergoing primary isolated myocardial revascularization. Eur J Cardiothorac Surg 1997; 13: 365-369.

4. Pintor PP, Colango S, Bobboi M. Evolution of case- mix in heart surgery: from mortality risk to complication risk. Eur J Cardiothorac Surg 2002; 22: 927-933.

5. Akins CW, Buckley MJ, Dagget WM, et al. Reoperative coronary grafting: changing patient profiles, operative indications, techniques, and results. Ann Thorac Surg 1994; 58: 359-365.

6. Yau TM, Borger MA, Weisel RD, Ivanov J. The changing pattern of reoperative coronary surgery: trends in 1230 consecutive reoperations J Thorac Cardiovasc Surg 2000; 120: 156163.

7. Loop FD, Lytle BW, Cosgrove DM, et al. Influence of the internal mammary artery graft on 10-years survival and other cardiac events. N Eng. J. Med. 1986; 314:1-6. 
8. Noyez L, Werf T van der, Remmen GHJ, Kaan GL, Lacquet LK. Importance of the internal mammary artery for coronary bypass grafting in patients aged $\geq 70$ years . Am J Cardiol 1995; 75: 734-736.

9. Sergeant P, Blackstone E, Meyns B. Validation and interdependence with patient-variables of the influence of procedural variables on early and late survival after CABG. KU Leuven Coronary Surgery Program. Eur J Cardiothorac Surg 1997;12: 1-19.

10. Dion R, Etienne PY, Verhelst R et al. Bilateral mammary grafting: clinical, functional and angiographic assessment in 400 consecutive patients. Eur J Cardiothoracic Surg 1993; 7: 287-293.

11. Ratliff NB, Myles JL, Rapidly progressive atherosclerosis in aortocoronary saphenous vein grafts. Arch Pathol Lab Med 1989; 113: 772.

12. Lytle BW, Loop FD, Cosgrove DM, et al. Fifteen hundred coronary reoperations. J Thorac Cardiovasc Surg 1987; 93: 847-859.

13. Joyce FS, McCarthy PM, Taylor P, et al. Cardiac reoperation in patients with bilateral internal thoracic artery grafts. Ann Thorac Surg 1994; 58: 80-85.

14. Mack MJ. Pro: Beating-heart surgery for coronary revascularization: Is it the most important development since the introduction of the heart lung machine? Ann Thorac Surg 2000; 70: 1774-1778.

15. Bedi HS, Suri A, Kalkat MS, et al. Global myocardial revascularization without cardiopulmonary bypass using innovative techniques for myocardial stabilization and perfusion. Ann Thorac Surg 2000; 69: 156-164.

16. Tasdemir O, Vural KM, Karagoz H, Bayazit K. Coronary artery bypass grafting on the beating heart without the use of extracorporeal circulation: review of 2052 cases. J Thorac Cardiovasc Surg 1998; 116: 68-73.

17. Bonchek LI. Off-pump coronary bypass: is it for everyone? J Thorac Cardiovasc Surg 2002; 124: 431-414.

18. CASS principal investigators and their associates: Coronary Artery Surgery Study (CASS), a randomized trial of coronary artery bypass surgery survival data. Circulation 1983; 68: 939950.

19. Werkgroep richtlijnen voor coronaire revascularisatie van de Nederlandse Vereniging voor Thoraxchirurgie en de Nederlandse Vereniging voor Cardiologie. Richtlijnen indicatiestelling voor coronaire revascularisatie. Cardiologie 1998; 5; 511-534. 
20. Lytle BW, Loop FD, Taylor PC, et al. The effect of coronary reoperation on the survival of patients with stenoses in saphenous vein bypass grafts to coronary arteries. J Thorac Cardiovasc Surg 1993; 105: 605-614.

21. Salomon NW, Page US, Bigelow JC, et al. Comparative analysis of 6591 patients undergoing primary bypass and 508 patients undergoing reoperative coronary bypass. J Thorac Cardiovasc Surg 1990; 100: 250-260.

22. Schmuziger M, Christenson JT, Maurice J, et al. Myocardial revascularization for the second time. Analysis of 458 reoperations and 2645 single operations. Cardiovasc Surg 1994; 2: 623-629.

23. Noyez L, Skotnicki SH, Kaan GL, et al. Primaire myocardrevascularisaties versus heroperaties. Een evaluatie van periopertieve morbiditeit en mortaliteit. Cardiologie 1996; 3: $18-21$

24. Sergeant P, Blackstone E, Meyns B, et al. First cardiological or cardiosurgical reintervention for ischemic heart disease after primary coronary artery bypass grafting. Eur J Cardiothoracic Surg 1998; 14: 480-487.

25. Eck van FM, Noyez L, Verheugt FWA, Brouwer RMHJ. Preoperative prediction of early mortality in redocoronary artery surgery. Eur J Cardiothoracic Surg 2002; 21: 1031-1036.

26. Londe S, Sugg WL. The challenge of reoperation in cardiac surgery. Ann Thorac Surg 1974; 17: 157-162.

27. Grosner G, Lajos TZ, Schimert G, et al. Left thoracotomy reoperation for coronary artery disease. J Cardiac Surg 1990; 5: 304-308.

28. Subramanian VA. Clinical experience with minimal invasive reoperative coronary bypass surgery. Eur J Cardiothorac surg 1996; 10: 1058-1063.

29. Grandjean JG, Mariani MA, Ebels T. Reoperative coronary surgery via small laparotomy using gastroepiploic artery without CPB. Ann Thorac Surg 1996; 61: 1853-1855.

30. Czerny M, Zimpfer D, Kilo J, et al. Coronary reoperations: recurrence of angina and clinical outcome with and without cardiopulmonary bypass. Ann Thorac Surg 2003: 75: 847-852.

31. Lytle BW, Loop FD, Taylor PC, Simpfendorfer C, Kramer JR, Ratliff NB, Goormastic M, Cosgrove DM, Vein graft disease: The clinical impact of stenoses in saphenous vein bypass grafts to coronary arteries. J Thorac Cardiovasc Surg 1992; 103: 831-840. 
32. Metha ID, Weinberg J, Jones MF. Should angiographically disease-free saphenous vein grafts be replaced at the time of redo coronary artery bypass grafting? Ann Thorac Surg 1998; 65: 17-23.

33. Kouz S, Campeau L, Lesperance J, et al. The role of early graft changes attributed to intimal fibrous hyperplasia in late aortocoronary saphenous vein graft closure. J Am Coll Cardiol 1986; 7: 34A.

34. Keon WJ, Heggtveit HA, Leduc J. Perioperative myocardial infarctions caused by atheroembolization. J Thorac cardiovasc surg 1982; 84: 849-855.

35. Gonzales-Santos JM, Ennabli K, Grondin C: Repeated coronary artery bypass grafting in patients with patent atherosclerotic grafts: a special challenge. Thorac Cardiovasc Surg 1984; 32: 346-349.

36. Noyez L. van der Werf T, Klinkenberg TJ, Janssen DBP, Kaan GL, Lacquet LK. Experience and early results of re-re-operations for coronary artery disease. Should patent vein grafts be replaced during reoperation? J Thorac Cardiovasc Surg 1994; 107: 684-689.

37. Noyez L, Lacquet LK. Cardiac reoperations with a patent internal mammary artery graft. A double challenge? Cardiovascular Surgery 1995; 36: 13-15.

38. Schmid C, Scheld HH. Trends and strategies for myocardial revascularization. Thorac. Cardiovasc. Surgeon 1996; 44: 113-117.

39. Noyez L, Lacquet LK. Recycling of the internal mammary artery in coronary reoperation. Ann Thorac Surg 1993; 55: 597-599.

40. Loop FD, Lytle BW, Cosgrove DM, et al. Reoperation for coronary atherosclerosis. Changing practice in 2059 consecutive patients. Ann Surg 1990; 212: 378-386.

41. Noyez L. Retrograde delivery of cardioplegic solution in adult cardiac surgery. A clinical evalution. L. Noyez (eds) Universiteits drukkerij Nijmegen, 1993.

42. Noyez L, Skotnicki SH, Lacquet LK. Morbidity and mortality in 200 consecutive coronary reoperations. Eur J Cardiothoracic Surg 1998; 14: 480-487.

43. Borger MA, Rao V, Weisel RD, Floh AA, Cohen G, Feindel CM, Scully HE, Mickleborough LL, Yau TM. Reoperative coronary bypass surgery: effect of patent grafts and retrograde cardioplegia. J Thorac Cardiovasc Surg 2001; 121: 83-90.

44. Rao V, Ivanov J, Weisle RD, et al. Predictors of low cardiac output syndrome after coronary artery bypass. J Thorac Cardiovasc Surg 1996; 112: 38-51. 
45. Christakis GT, Ivanov J, Weisel RD, et al. The changing pattern of coronary bypass surgery. Circulation 1989;80(suppl):I-151-161.

46. Brener SJ, Loop FD, Lytle BW,et al. A profile of candidates for repeat myocardial revascularization: implications for selection of treatment. J Thorac Cardiovasc Surg 1997; 114: 153-161.

47. Eck van FM, Noyez L, Verheugt FWA, Brouwer RMHJ. Changing profile of patients undergoing redo-coronary artery surgery. Eur J Cardiothoracic Surg 2002; 21: 205-211.

48. Christenson JT, Schmuzinger M, Simonet F. Peoperative coronary artery bypass procedures: risk factors for early mortality and late survival. Eur J Cardiothoracic Surg 1997; 11: 129133.

49. He GW, Acuff TE, Ryan WH, He YH, Mack MJ. Determinants of operative mortality in reoperative coronary artery bypass grafting. J Thorac Cardiovasc Surg 1995; 110: 971-978.

50. Weintraub WS, Jones EL, Craver JM, Grosswald R, Guyton RA. In-hospital and long-term outcome after reoperative coronary artery bypass surgery. Circulation 1995;92[suppl II]:II5-II-57.

51. Yamamuro M, Lytle BW, Sapp SK, et al. Risk factors and outcomes after coronary reoperation in 739 elderly patients. Ann Thorac Surg 2000; 69: 464-474.

52. Blanche C, Kahn SS, Chaux A, et al. Cardiac reoperations in octogenarians: Analysis of outcomes. Ann Thorac Surg 1999; 67: 93-98.

53. Eck van FM, Noyez L, Verheugt FWA, Brouwer RMHJ. Analysis of mortality within the six months after coronary reoperation. Ann Thorac Surg 2002; 74: 2106-2112.

54. Blackstone Eh. Outcome analysis using hazard functional methodology. Ann Thorac Surg 1996; 61(2 suppl):S2-7.

55. Accola KD,Craver JM, Weintraub WS, et al. Multiple reoperative coronary artery bypass grafting. Ann Thorac Surg 1991; 52: 738-744. 


\title{
CHAPTER II
}

\section{CHANGING PROFILE OF PATIENTS UNDERGOING REDO-CORONARY ARTERY SURGERY.}

\author{
Frans M. van Eck, Luc Noyez, Freek W.A. Verheugt, Rene M.H.J. Brouwer
}

European Journal of Cardio -thoracic Surgery 2002; 21: 205-211

\section{Paper presented at:}

- Fourth International Symposium On Redo Cardiac Surgery in Adults, San Diego, California, May 4\&5, 2001

- The European Society for Cardiovascular Surgery, Budapest, June 20-23, 2001. 


\begin{abstract}
Objective: To Outline the changes of the patient population undergoing redo-coronary artery bypass surgery (RECABG).
\end{abstract}

Methods: Preoperative data of 582 first RECABG's, January 1987- June 2000 were analyzed. Group A: 1987-1991 ( $\mathrm{n}=193)$; group B: 1992-1995 ( $\mathrm{n}=201)$; and group C: 1996- June 2000 $(n=188)$.

Results: These 582 RECABG's represent about $8.5 \%$ of the performed bypass surgeries during this period. Mean age $(\mathrm{P}=<0.001)$, percentage of patients with kidney disease $(\mathrm{P}=0.001)$, a preoperative PTCA $(\mathrm{P}<0.001)$ increased. Significant more elective operations $(\mathrm{P}<0.001)$ and lesser urgent operations $(\mathrm{P}=0.001)$ were performed in group $\mathrm{C}$. There is a significant different distribution of vessel disease over the three periods $(\mathrm{P}=0.04)$. Significant more patients had a patent IMA graft $(\mathrm{P}<0.001)$. The angina-free period after CABG $(\mathrm{P}<0.001)$, the time period between both operations $(\mathrm{P}<0.001)$ and the period between the new onset of angina and the RECABG $(p=0.012)$ increased significantly. Despite the importance of progression of atherosclerosis of any sort decrease significantly $(\mathrm{P}<0.001)$ over the whole study, there is a significant increase of patients reoperated for isolated progression of the disease in the native coronary arteries $(\mathrm{P}<0.001)$ in group $\mathrm{C}$. The impact of late graft failure was not different for the total group ( $\mathrm{P}=0.82)$, however, the percentage of RECABG's for isolated late graft failure increased significantly between group $\mathrm{A}$ and $\mathrm{B}(\mathrm{P}<0.001)$ but there was a decrease from $\mathrm{B}$ to $\mathrm{C}$, however, not significant $(\mathrm{P}=0.067)$.

Conclusion: During the past years there is a trend in RECABG of older patients, with more coexisting disease. There are an increasing number of patients with patent arterial grafts, an increase of the event-free period after the CABG, the period between the CABG and RECABG and of the time period between the onset of new angina and the RECABG. Although the impact of atherosclerosis, as angiographic indication, decreased over the total group, there is the significant increase of the percentage of patients reoperated because of isolated progression of atherosclerosis in the native coronary arteries.

\title{
Key words:
}

Reoperation, Corona ry artery bypass, Atherosclerosis, Graft failure. 


\section{Introduction}

As in primary coronary artery bypass surgery $(\mathrm{CABG})$, the patient's population undergoing first redo-coronary artery surgery (RECABG) has changed during the last years $[1,2]$. However, in the RECABG-population, also the changed strategies of primary myocardial revascularization take part in this evolution. The purpose of this paper is to study the evolutionary trends in the patient population undergoing RECABG. Therefore operative and postoperative data are only presented and discussed in relation to this changes.

\section{Material and methods}

\subsection{Patients}

With the aid of our database, Coronary Surgery Database Radboud Hospital (CORRAD), a registry that stores pre-, peri-, postoperative data as well as follow-up data on all patients undergoing myocardial revascularization, we identified a series of 582 patients undergoing a RECABG from January 1987 to June 2000. The total group was subdivided into three time cohorts: group A (193 patients) operated between January 1987 and December 1991, group B (201 patients) operated between January 1992 and December 1995, and group C (188 patients) operated between January 1996 and June 2000.

Table 1 presents the studied general variables. Diabetes was defined when there was dietcontrolled, oral therapy or insulin dependency. Hypertension was defined as systolic blood pressure of greater than $160 \mathrm{mmHg}$ or diastolic pressure of greater than $100 \mathrm{mmHg}$. Hyperlipidemia was defined as having a total cholesterol level of greater than $250 \mathrm{mg} / \mathrm{dl}$ or a triglyceride level of greater than $200 \mathrm{mg} / \mathrm{dl}$. Cerebrovascular disease was registered in patients with cerebrovascular accidents and/or transient ischaemic attack in their histories. Kidney disease was defined as having a documented renal failure (creatinine $\geq 150 \mu \mathrm{mol} / \mathrm{l}$ ), preoperative dialysis, or renal transplantation. Lung disease was registered in patients with chronic obstructive pulmonary disease, and/or a history of previous lung disease. Successful PTCA was defined as a successful PTCA as well before the CABG as before the RECABG. Impaired left ventricular function was noted when there was an ejection fraction of $\leq 30 \%$. It must be noted that ejection fraction is not routinely calculated for all patients, however for patients with bad ventricular function, this is mostly done. 
Table 1. General preoperative variables

\begin{tabular}{|c|c|c|c|c|}
\hline Variable & $\begin{array}{c}\text { Group A } \\
\text { N=193 (\%) }\end{array}$ & $\begin{array}{c}\text { Group B } \\
\text { N=201 (\%) }\end{array}$ & $\begin{array}{c}\text { Group C } \\
\mathbf{N}=\mathbf{1 8 8}(\%)\end{array}$ & P-value \\
\hline Sex & & & & 0.31 \\
\hline Men & $148(77)$ & $165(82)$ & $154(82)$ & \\
\hline Women & $45(23)$ & $36(18)$ & $34(18)$ & \\
\hline Age (mean \pm S.D.) (years) & $60 \pm 8.7$ & $64 \pm 7.8$ & $66 \pm 8.3$ & $<0.001$ \\
\hline Range & $32-91$ & $35-83$ & $45-82$ & \\
\hline Diabetes & $26(14)$ & $41(20)$ & $36(19)$ & 0.16 \\
\hline Hypertension & $123(64)$ & $135(67)$ & $100(53)$ & 0.01 \\
\hline Hyperlipidemia & $112(58)$ & $126(63)$ & $105(56)$ & 0.37 \\
\hline Family history of cardiovascular disease & $133(69)$ & $122(61)$ & $102(54)$ & 0.01 \\
\hline Peripheral vascular disease & $37(19)$ & $50(25)$ & $42(22)$ & 0.39 \\
\hline Cerebrovascular disease & $11(6)$ & $15(7.5)$ & $15(8)$ & 0.65 \\
\hline Kidney disease & $1(0.5)$ & $5(2.5)$ & $14(7.4)$ & 0.001 \\
\hline Lung disease & $33(17)$ & $46(23)$ & $33(18)$ & 0.26 \\
\hline Previous successful PTCA & $19(10)$ & $22(11)$ & $47(25)$ & $<0.001$ \\
\hline \multicolumn{5}{|l|}{ Myocardial infarction } \\
\hline Before the CABG & $122(63)$ & $129(64)$ & $109(58)$ & 0.40 \\
\hline Between CABG and RECABG & $46(24)$ & $62(31)$ & $49(26)$ & 0.27 \\
\hline Impaired left ventricular function & $3(1.5)$ & $5(2)$ & $4(2)$ & 0.3 \\
\hline Clinical indication & & & & 0.006 \\
\hline Elective & $96(50)$ & $93(46)$ & $122(64)$ & $<0.001$ \\
\hline Urgent & $79(41)$ & $82(41)$ & $47(25)$ & 0.001 \\
\hline Emergency & $18(9)$ & $26(13)$ & $19(11)$ & 0.6 \\
\hline Vessel disease & & & & 0.04 \\
\hline One-vessel & $12(6)$ & $9(4)$ & $17(9)$ & 0.18 \\
\hline Two-vessel & $39(20)$ & $21(10)$ & $31(17)$ & 0.04 \\
\hline Three-vessel & $142(74)$ & $171(86)$ & $140(74)$ & 0.007 \\
\hline
\end{tabular}

Clinical indication for RECABG was angina and proven ischemia (treadmill test, sintigraphy) despite medical therapy with $\beta$ blockers, calcium antagonists or nitrates, or a combination. 
We distinguish three groups. Elective operations, patients with stable cardiac function, usually scheduled at least one day prior to the surgical procedure. Urgent operations, when surgery is required within 24 hours after admission. Emergency operations: in case of operation for evolving infarction, ischemia not responding to medical therapy, or cardiogenic shock.

Vessel-disease is also presented in Table 1. Important is that, in case of a diseased native coronary artery with a patent, not diseased, graft, this coronary artery was not coded as a diseased vessel. So a patient with a patent IMA-graft on a diseased LAD, and an occluded circumflex- and right coronary artery without, or with diseased grafts is registered as a twovessel disease.

Table 2 presents the specific RECABG variables. Patent internal mammary artery graft (IMA), and different time periods. The angiographic indication for RECABG is divided in five groups. Early graft failure, as documented graft failure within the first six months after the CABG. Late graft failure $(\mathrm{GF})$, graft failure later than six months after CABG. Progression of athersoclerosis in the native coronary artery system (PA). The combination of GF and PA, and incomplete revascualarization, in case of a documented not- or wrong-bypassed vessel during the CABG.

The presented mortality is the hospital mortality, defined as the operative mortality and mortality during hospital stay after RECABG, independent of the time.

\subsection{Surgical technique}

Our surgical technique is described in previous papers [3,4]. Of the total number of patients 79\% (459/582) received at least one new arterial graft. In group A, 80\% (154/193), group B, 82\% (164/201) and in group C, $75 \%$ (141/188). Table 3 present the total number of new grafts and distal anastomoses, new arterial and vein grafts performed in the different groups.

\subsection{Statistical analysis}

The characteristics of patients in group $\mathrm{A}, \mathrm{B}$, and $\mathrm{C}$ is presented as percentages for dichotome variables and as mean \pm S.D. for age, and time intervals. Differences between the groups were tested with F-test (one way analysis of variance) or with the $\chi^{2}$-test when appropriate. Statistical significance was assumed at $\mathrm{P} \leq 0.05$. 
Table 2. Specific preoperative variables

\begin{tabular}{lcccc}
\hline Variable & $\begin{array}{c}\text { Group A } \\
\text { N=193 (\%) }\end{array}$ & $\begin{array}{c}\text { Group B } \\
\text { N=201 (\%) }\end{array}$ & $\begin{array}{c}\text { Group C } \\
\text { N=188 (\%) }\end{array}$ & P-value \\
& $11(6)$ & $26(13)$ & $55(30)$ & $<0.001$ \\
\hline Patent IMA & & & & $<0.001$ \\
Angina-free period after CABG (months) & $68.2 \pm 51.6$ & $90.0 \pm 50.8$ & $108.7 \pm 61.2$ & \\
Mean \pm S.D. & $0-240$ & $0-246$ & $0-276$ & \\
Range & & & & $<0.001$ \\
Time between CABG - RECABG (months) & $90.3 \pm 52.9$ & $118.5 \pm 53.4$ & $140.6 \pm 61.3$ & \\
Mean \pm S.D. & $0-300$ & $0-276$ & $0-283$ & \\
Range & & & & 0.012 \\
Time between return of angina and RECABG & & & & \\
(months) & $22.0 \pm 24.4$ & $28.4 \pm 30.4$ & $31.1 \pm 36.8$ & \\
Mean \pm S.D. & $0-144$ & $0-140$ & $0-188$ & \\
Range & & & & $<0.001$ \\
Angiographic indication & $18(9)$ & $16(8)$ & $9(5)$ & 0.2 \\
Early graft failure & $17(9)$ & $68(34)$ & $48(26)$ & $<0.001$ \\
Late graft failure & $10(5)$ & $13(6)$ & $36(18)$ & $<0.001$ \\
Progression of atherosclerosis in the native & & & & \\
system & $3(2)$ & $3(1)$ & $1(1)$ & 0.6 \\
Incomplete revascularization & $145(75)$ & $101(51)$ & $94(50)$ & $<0.001$ \\
Combination of GF and PA & & & & \\
\hline
\end{tabular}

GF: Graft failure, PA: Progression of atherosclerosis in the native coronary artery system

Table 3. Distribution of new constructed grafts (no significant difference)

\begin{tabular}{lccc}
\hline $\begin{array}{l}\text { Variable } \\
\text { Number of }\end{array}$ & $\begin{array}{c}\text { Group A } \\
\text { N=193 }\end{array}$ & $\begin{array}{c}\text { Group B } \\
\text { N=201 }\end{array}$ & $\begin{array}{c}\text { Group C } \\
\text { N=188 }\end{array}$ \\
\hline New constructed grafts & $2.4 \pm 0.8(1-5)$ & $2.6 \pm 0.8(1-5)$ & $2.1 \pm 0.8(1-4)$ \\
New constructed distal anastomoses & $3.0 \pm 1.2(1-6)$ & $3.3 \pm 1.2(1-7)$ & $2.9 \pm 1.3(1-6)$ \\
New arterial grafts & $0.9 \pm 0.3(0-2)$ & $1.2 \pm 0.3(0-2)$ & $0.8 \pm 0.5(0-2)$ \\
New vein grafts & $1.5 \pm 0.7(0-4)$ & $1.7 \pm 0.3(0-4)$ & $1.5 \pm 0.6(0-4)$ \\
\hline
\end{tabular}




\section{Results}

The 582 RECABG-patients represent $8.5 \%$ (582/6837) of the performed myocardial revascularizations during this time period. There is a difference, not significant $(\mathrm{P}=0.6)$, between the three time periods, group 193/2254 (8.5\%) group B 201/2020 (9.9\%) and 7.3\% ( 188/2553) in group C. The overall mortality is $42 / 582$ patients $(7.2 \%)$. There is a no statistical significant difference $(\mathrm{P}=0.07)$ between the three groups, group $\mathrm{A} ; 11 \%(21 / 193)$, group $\mathrm{B} ; 6.4 \%(13$ /201), group C; $4.2 \%(8 / 188)$. However, the decrease from $11 \%$ in group $\mathrm{A}$ to $4.2 \%$ in group $\mathrm{C}$ is statistical significant $(\mathrm{P}=0.03)$.

Table 1 shows that there is a statistical significant increase of the mean age of the patients $(\mathrm{P}<0.001)$, with the significant step from group A to group $\mathrm{B}$. The percentage of patients with kidney disease $(\mathrm{P}=0.001)$ increased significantly over the whole studied period and the percentage of preoperative successful PTCA $(\mathrm{P}<0.001)$ increased significantly from period $\mathrm{B}$ to C. On the other hand there is a significant decrease of patients with a family history of cardiovascular disease $(\mathrm{P}=0.01)$ during the whole period, and in the last period a decrease of patients with hypertension $(\mathrm{P}=0.01)$.

There is no statistical significant difference in the percentage of diabetes, hyperlipidemia, peripheral vascular disease, cerebrovascular disease, lung disease, the occurrence of myocardial infarctions and percentage of patients with an impaired left ventricular function.

There is a significant difference $(\mathrm{P}=0.006)$ in the clinical indication for RECABG, this statistical significance is due to the significant decrease of urgent patients in the last period $(25 \%$ versus $41 \%$ in group $\mathrm{A}$ and $\mathrm{B}, \mathrm{P}=<0.001$ ) and consequently an increase of elective patients in group $\mathrm{C}(64 \%$ versus $50 \%$ and $46 \%$ in group $\mathrm{A}$ and $\mathrm{B}, \mathrm{P}=0.001)$. The percentage of emergency RECABG, remains about $10 \%$ during the study.

There is a statistical significant difference in the distribution of the vessel disease over period ( $\mathrm{P}=0.04)$. There is an increase of patients operated for one vessel disease during period $\mathrm{C}$ ( $9 \%$ versus $6 \%$ and $4 \%$ ), however not significant. The decrease of patients operated in period B is statistical significant $(\mathrm{P}=0.04)$ and also the higher number of patients operated for three vessel disease in period $\mathrm{B}$ is statistical significant different from the other two periods. $(\mathrm{P}=0.007)$

Table 2 presents the specific RECABG variables. There is a significant increase of patients with patent arterial grafts, IMA-graft $(\mathrm{P}<0.001)$. Also, the angina-free period after the primary operation $(\mathrm{P}<0.001)$, the time between CABG and RECABG $(\mathrm{p}<0.001)$, and also the 
time period between the new onset of angina and the RECABG $(p=0.012)$ increased significantly.

There is a statistical significant difference in angiographic indication over the years. Analyzing the different classes of angiographic indication, there is a decrease, not significant $(\mathrm{P}=0.22)$ of patients operated for early graft failure (5\% in group $\mathrm{C}$ versus $9 \%$ and $8 \%$ ) There is a statistical significant $(\mathrm{P}<0.001)$ increase of patients reoperated for late graft failure in group $\mathrm{B}$ and $\mathrm{C}$ versus group A $(34 \%, 26 \%$ versus $9 \%)$, The decrease of group C (26\%) did not reach significance $(\mathrm{P}=0.067)$ versus the $34 \%$ in group $\mathrm{B}$. There is a statistical significant increase $(\mathrm{P}<$ $0.001)$ of patients operated for progression of atherosclerosis in the native coronary arteries $(18 \%$ in group $\mathrm{C}$ versus $5 \%$ and $6 \%$ ). Since period $\mathrm{A}$ there is a statistical significant decrease $(\mathrm{P}<0.001)$ of patients reoperated for combined graft failure and progression of atherosclerosis in the coronary arteries (75\% in group A versus 51\% and 50\%). The percentage of patients operated for incomplete revascularizations remains small (1\%) and was not different over the years.

Analyzing the patients reoperated for progression of atherosclerosis of any sort, there is a statistical significant difference $(\mathrm{P}=<0.0001)$ over the studied period. The decrease from $80 \%$ $(155 / 193)$ in group A versus 57\% (114/201) in group B and versus 69\% (130/188) in Group C is significant $(\mathrm{P}=0.001 \mathrm{~A}-\mathrm{B}, \mathrm{P}=0.01 \mathrm{~A}-\mathrm{C})$. However, the increase from $\mathrm{B}$ to $\mathrm{C}$ is also significant $(\mathrm{P}=0.01)$. For late graft failure of any sort, there is no statistical significant difference over the study $(\mathrm{P}=0.82)$. The increase from $84 \%(162 / 193)$ in group A versus $89 \%(169 / 201)$ in group $\mathrm{B}$ is not significant $(\mathrm{P}=0.1)$, the decrease from $89 \%$ in group $\mathrm{B}$ to the $76 \%(142 / 188)$ in group $\mathrm{C}$ reaches statistical significance $(\mathrm{p}=0.02)$.

There is a decrease (from $80 \%$ to $75 \%$ ), however, not significant $(\mathrm{P}=0.7)$ of patients receiving a new arterial graft. The number of new grafts, distal anastomoses, new arterial and venous grafts is not statistical significant different $(\mathrm{P}=0.2)$ between the three groups (table 3$)$.

\section{Discussion}

It must be clear that the aim of this paper is to outline the changes in the population of patients undergoing RECABG over the years. The number of RECABG's over the studied period remains stable; the decrease in the last period is not significant. It is known that RECABG has a higher mortality than CABG $[3,5,6]$. Despite there is not a significant decrease of the mortality over the studied period, our mortality of the last period $4.2 \%$ is statistical significant lower than 
the $11 \%$ of the first studied period (group A). Mortality is not an endpoint in this paper, however, since our and other previous studies identified -urgent and emergency RECABG- as dominant pred ictors of mortality, [3,5,6] we avoid to do urgent/emergency RECABG. The statistical significant decrease of urgent RECABG, in this study is certainly one, and an important one, in the decrease of mortality in the last studied period.[3]

As in CABG, the trend to operate older patients with more coexisting disease, is also visible in the RECABG population [1,2]. There is an increase of age in our study (group A versus B and C). That this increase of age is not continuous over the whole studied period can be related to several factors. There is use of arterial grafts during $\mathrm{CABG}$, even in elderly patients, since the eighties. [7] Because these older patients received arterial grafts, at the CABG, the event-free period after $\mathrm{CABG}$ increased, which means that they were even older at the moment of the RECABG. It is certain that older patients are not so frequently presented for RECABG, or died already before, because of their age and before we have a statistical significant increase of the mean age of a group, we need a lot of older patients in this group. There is a significant increase of patients with kidney disease That there is an increase of patients with kidney disease undergoing $\mathrm{CABG}$ the last decade is known, and this is also a result of the aging of the patient population. [8] There is a significant increase of successful PTCA's over the studied period (group C). This is similar as in CABG [2], and we know that a lot of patients underwent a PTCA between CAGB and RECABG. Our strategy, to stabilize urgent/ emergency patients, eventually by PTCA of the culprit lesion, is probably one of the reasons for this increased percentage in group C. However, because this is not registered separately, we cannot prove that there is a specific increase of PTCA between CABG and RECABG.

The percentage of patients with hypertension and a family history of cardiovascular disease decreased significantly. Hypertension is a comorbidity factor with an incremental risk for death in the late phase (more than 6 years after $\mathrm{CABG}$ ), so because the increase of the time between the CABG and the RECABG, more than 10 years in group C, [9] a number of patients with hypertension died already.

It may be remarkable that there is a slight, not significant, increase of patients with diabetes $(14 \%$ to $19 \%)$, and cerebrovascular disease $(6 \%$ to $8 \%)$. Here again we can suppose that a several of these patients died already, due to this comorbidity. But probably a lot of these patients were even not presented for RECAGB, because of the perioperative risk for morbidity and mortality. Diabetic patients have mostly diffuse and distal pathology, not so suitable for 
surgery and diabetes is also a risk factor for perioperative myocardial infarction and mortality in RECABG. [3] Also patients with a history of a œrebrovascular disease have a higher risk for neurological morbidity during cardiac surgery. [10]

So, the increase of co-morbidity with RECABG seems to be of lesser importance than in CABG. However, it must be clear, that the RECABG population is only a part of the population with an insufficient result of the CABG. Some of them died already, due the importance of several co-morbidity factors over the years, or were not presented for RECABG, because they have not enough symptoms, can be managed with medication, by interventional procedures, or because the procedural risk seems to high in relation with the expected benefit. On the other hand, because of the interval between CABG and RECABG, we can expect a further increase of co-morbidity variables in the RECABG-group over the years. If we compare our series of CABG between 1987 and 1995 we note an increase of patients with diabetes, and these with cerebrovascular disease in particular in the years 1992-1995 [2]. The interval between CABG and RECABG at this moment is about 12 years, so some of these patients will be reoperated over about five years.

There is no significant difference in myocardial infarct percentage before CABG or between CABG and RECABG, neither of the percentage of patients with an impaired left ventricular function, over the years.

There is a significant difference in the clinical indication for RECABG, especially a significant decrease of urgent RECABG, and an increase of elective RECABG (group C). Since our study identifying urgent and emergency RECABG, [3] as dominant independent variables in predicting the occurrence of a perioperative myocardial infarction and mortality, we try to avoid urgent- emergency RECABG since 1996. The number of emergency RECABG, is constant over the studied period $(10 \%)$, this were patients that we could not stabilize.

There is a significant difference in vessel disease over the studied periods. Because of the complex blood supply of the myocardium by native coronary arteries, grafts, collaterals, it is sometimes difficult and arbitrary to distinguish one-two- three vessel disease in redo-patients. Therefore our specific registration of one-two-three-vessel disease in redo-patients as already defined, and also this is the reason why we do not register left main in these patients.[3] The percentage of patients undergoing RECABG for one-vessel disease is low, and remains stable over the years $(\mathrm{P}=0.18)$ The statistical significant difference in vessel disease is caused by the significant lower percentage of patients with two vessel disease and the higher percentage of 
patients with three-vessel disease in group B versus A and C. However there is a different reason for the trend seen from $\mathrm{A}$ to $\mathrm{B}$ and the trend from $\mathrm{B}$ to $\mathrm{C}$. That in group $\mathrm{C}$ a lower percentage of patients is reoperated for three-vessel disease is certainly related to the use on arterial grafts. Most patients received at the CABG an IMA-graft to the LAD. The percentage of about $30 \%$ of patients with a patent IMA in group $C$ (table 2) is corresponding well with $74 \%$ of patients reoperated for three-vessel disease. Also in group B the percentage of $12 \%$ patients with a patent IMA graft is complementary to about $86 \%$ patients reoperated for three-vessel disease. In group A, there are only a small number of patients with a patent IMA-graft at the moment of the RECABG. But about $25 \%$ of the patients were reoperated for early/late graft failure, progression of atherosclerosis in the native coronary arteries, and incomplete revascularization (table2). Several of these patients had patent venous grafts at the moment of the RECABG and were therefore not registered as three-vessel disease.

Despite the significant difference in vessel disease of the three groups, there is no statistical significant difference in the number of new constructed grafts or distal anastomoses (table 3). The reason is that the percentage of patients with two-and three-vessel disease remains quit stable over the three periods, the higher number of distal anastomoses in group B is an indication that more vessels were bypassed (not significant).

The statistical significant increase of a patent IMA is of course a result of our own surgical work. The effect of an internal mammary artery graft on survival and the event-free period after CABG is well known. [11] The significant increase of angina-free period, time interval between $\mathrm{CABG}$ and RECABG confirms this. The group of patients undergoing RECABG with a patent arterial graft offers a double challenge: the problem of protection in the myocardial region supplied by the arterial graft, and the preservation of the patent arterial graft. Certainly because preservation of a patent arterial graft results in a decrease of morbidity and mortality of the RECABG, but damage of this arterial graft results in a increase of morbidity and mortality of RECAGB [12]. Despite surgeons experienced in performing RECABG, who are used to handling patent arterial grafts, this challenge can be partially responsible for the slight, but significant, increase of the time period between the new onset of angina and the RECABG, because several people are more conservative in patients with return of angina but with (a) patent arterial graft(s), mostly an internal mammary graft to the anterior site. [13]

Despite the significant higher percentage of patent IMA-grafts over the years, the number of patients receiving a new arterial graft, and the number of new constructed arterial grafts did 
not change. This is because in a lot of patients with one patient arterial graft a second new, mostly the right IMA, but also the gastroepiploic artery is used. In some patients a patent IMA graft is recycled to another vessel $[4,14]$.

The percentage of patients reoperated for early graft failure and incomplete revascularization decreased, not significant, over the years, but is a small percentage.

On the whole, there is a decrease of patients re-operated for progression of atherosclerosis of any sort. The high, and statistical significant $(\mathrm{P}<0.001)$ percentage of patients in group A, reoperated for progression of atherosclerosis of any sort in combination with graft failure, is partially explaining the global decrease. However, further analysis shows a statistical significant increase for patients reoperated for atherosclersosis of any sort in group C versus group B, and this is only related to the increase $(\mathrm{P}<0.001)$ of patients reoperated for isolated progression of the disease in the native system. There is no statistical significant difference in the percentage of patients reoperated for late graft failure of any sort $(\mathrm{P}=0.82)$. That there is no significant difference between group $\mathrm{A}$ and $\mathrm{B}$, despite there is an statistical difference for patients reoperated for the combination of graft failure and progression of atherosclerosis, is due to the statistical significant increase $(\mathrm{P}<0.001)$ of patients reoperated for isolated late graft failure in group B. That the decrease of patients reoperated for late graft failure of any sort between group $\mathrm{B}$ and $\mathrm{C}$ reaches significance $(\mathrm{P}=0.02)$ is due to the complementary effect of the decrease of isolated late graft failure $(\mathrm{P}=0.06)$ and in combination with progression of atherosclerosis in group C. These results are interesting, in group B, there is a high percentage of patients reoperated for isolated late graft failure, we can suppose that these patients had an initial good revascularization, however due to the vein graft pathology they need a reoperation. This in contrast with group A, were a lot of patients were reoperated for combined graft failure and progression of atherosclerosis, but significant shorter after the CABG. This trend was already described by Lytle et al. [15] In group C, there is a significant decrease of patients reoperated for isolated late graft failure ( $\mathrm{P}=0.02)$, this is due to extensive use of arterial grafts during the $\mathrm{CABG}$ (patent IMA $=30 \%$ ) and probably also to the use of platelet-inhibiting medication [16], this evolution is also reflected in the increased time between CABG and RECABG. However, there is in group $\mathrm{C}$ a significant increase of patients reoperated for progression of atherosclerosis of any sort, but as a consequence of the increasing number of patients reoperated for isolated progression of atherosclerosis in the native coronary arteries $(\mathrm{P}<0.001)$. This means that despite surgical evolution, the increasing use of arterial grafts, certainly resulting in an increase of the 
event-free period, and increasing the time before a RECABG, the disease is still going on. The knowledge that in group $\mathrm{C}$, we have patients with total arterial revacularization at the $\mathrm{CABG}$, and new lesions in native coronary arteries, in some patients, even distal of a patent arterial graft, let us suppose that total arterial revascularization is not excluding RECABG. These RECABG's, with several patent arterial grafts, offer again new surgical challenges: preservation of the arterial grafts, mobilization of the heart, recycling of arterial grafts, use of veins, or other alternative grafts.

In conclusion there have been, during the last years, an increasing number of older patients, with more coexisting disease, and more patent arterial grafts, undergoing RECABG. This is not only due to demographic changes, but also in part the result of the different strategies used at the CABG. The extensive use of arterial grafts at CABG, results in an increase of the event-free period and of the period between CAGB and RECABG. The increasing number of patients reoperated for progression of the disease in the coronary arteries, confirms again the palliative aspect of bypass surgery and in our aging population, we can expect a further increase of this trend.

\section{References}

1. Abramov D, Tamariz MG, Fremes SE, Guru V, Borger MA, Christakis GT, Bhatnagar G, Sever JY, Goldman BS. Trends in coronary artery bypass surgery results: A recent, 9-year study. Ann Thorac Surg 2000; 70: 84-90.

2. Noyez L, Janssen DPB, Druten van JAM, Skotnicki SH, Lacquet LK. Coronary Bypass surgery: What is changing? Analysis of 3834 patients undergoing primary isolated myocardial revascularization. Eur J Cardiothorac Surg 1998; 13: 365-369.

3. Noyez L, Skotnicki SH, Lacquet LK. Morbidity and mortality in 200 consecutive coronary reoperations. Eur J Cardiothorac Surg 1997; 11: 528-532.

4. Noyez L, Eck van FM, Skotnicki SH, Brouwer MHJ. Coronary reoperations in patients with a patent internal mammary artery graft. Cardiovascular Surgery 2001; 9:179-183.

5. Brener S, Loop FD, Lytle BW, Ellis SG, Cosgrove DM, Topol EJ. A profile of candidates for repeat myocardial revascularization: Implications for selection of treatment. J Thorac Cardiovasc Surg 1997;114: 153-161. 
6. Akins CW, Buckley MJ, Daggett WM, Hilgenberg Ad, Vlahakes GJ, Torchiana DF, Austen WG. Reoperative coronary grafting: Changing patients profiles, operative indications, techniques, and results. Ann Thorac Surg 1994; 58: 359-365.

7. Noyez L, van der Werf T, Remmen GH, Kaan GL, Lacquet LK. Importance of the internal mammary artery for coronary bypass grafting in patients aged $\geq 70$ years. American Journal of Cardiology 1995; 75: 734-736.

8. Janssen DPB, Noyez L, van Druten JAM, Skotnicki SH, Lacquet LK. Predictors of nefrological morbidity after coronary artery bypass surgery. Cardiovascular Surgery 2002; 10: $222-227$.

9. Sergeant P, Blackstone E, Meyns B, Validation and interpendence with patient-variables of the influence of procedurables on early and late survival after CABG. Eur J Cardiothorac Surg 1997; 12: 1-19.

10. Janssen DPB, Noyez L, van Druten JAM, Skotnicki SH, Lacquet LK. Predictors of neurological morbidity after coronary artery bypass surgery. Eur J Cardiothorac Surg 1999; 15: 166-172.

11. Loop FD, Lytle BW, Cosgrove DM. Influence of the internal mammary artery graft on survival and other cardiac events. New England Journal of Medicine. 1986; 314: 2-6.

12. Gillinov Am, Casselman FP, Lytle BW, Blackstone E, Parson EM, Loop FD, Cosgrove DM. Injury to a patent left internal thoracic artery graft at coronary reoperation. Ann Thorac Surg 1999; 67: 382-386.

13. Sergeant P, Blacstone E, Meyns B, Stockman B, Jashari R. First cardiological and cardiosurgical reintervention for ischemic heart disease after primary coronary artery bypass grafting. Eur J Cardiothorac Surg 1998; 14: 480-487.

14. Noyez L, Lacquet LK. Recycling of the internal mammary artery in reoperations. Annals Thoracic Surgery 1993; 55: 597-599.

15. Lytle BW, Loop FD, Cosgrove DM, Taylor PC, Goormastic M, Peper W, Gill CC. Fifteen hunderd coronary reoperations. J Thorac Cardiovasc Surg 1987; 93: 847-859.

16. Chesebro JH, Fuster V, Elreback LT. Effect of dipyrimadole and aspirin on late vein-graft patency after coronary bypass operations. N Eng J Med 1984; 310: 209-214. 


\title{
CHAPTER III
}

\section{CORONARY REOPERATIONS IN PATIENTS WITH A PATENT INTERNAL MAMMARY ARTERY GRAFT.}

\author{
Luc Noyez, Frans M. van Eck, Stefan H. Skotnicki, René M.H. J. Brouwer
}

Cardiovascular Surgery 2001; 9: 179-183 


\begin{abstract}
Objective: Analysis of short- and long- term results, clinical functional- and subjective status of patients, with a patent arterial graft, after RECABG.

Methods: Perioperative and follow - up data of 71 patients, undergoing RECABG (1987 - 1998) were studied. A cross-sectional follow-up was conducted, functional evaluation by the Duke Activity Status Index (DASI), and patients evaluation of his life situation were registered.

Results: Perioperative mortality was 7\%. Eleven patients died during follow-up. The 12-month and 60 -month survival was $96 \%$ and $80 \%$. Event-free survival was $86 \%$ and $51 \%$. Family doctors declared that 55/66 (83\%) had benefit of the RECABG. NYHA decreased significantly from $3.4 \pm 0.5$ preoperative versus $1.5 \pm 0.4$ postoperative. The mean DASI was $38.06 \pm 10.42$. At the moment of the cross-sectional follow-up, $45 / 55$ patients $(82 \%)$ declared to have a benefit of the RECABG.
\end{abstract}

Conclusion: Improvement in NYHA-class, good postoperative functional capacity, and patients positive evaluation, justify RECABG in patients with a patent IMA graft.

\title{
Key-words
}

Coronary reoperations, Internal mammary artery, Mortality, Morbidity, Functional evaluation, Follow-up. 


\section{Introduction}

The number of coronary reoperations (RECABG) continues to increase. Despite this, RECABGs have higher perioperative mortality and also at long term the results, mortality, return of ischemic events are higher than in patients undergoing a primary myocardial revascularization (CABG) [1-4]. Moreover, there is a good survival rate with a patent arterial graft, with only a recuurence of angina without reintervention $[5,6]$. This makes that the decision between medical treatment and RECABG for this group of patients is difficult.

In this study we evaluate short- and long- term the results, clinical- functional and subjective status of patients, with a patent arterial graft, after RECABG.

\section{Patients and Methods}

\section{Patients}

We took our information from the Coronary Surgery Database-Radboud Hospital (CORRAD), which is a registry that stores pre-, per-, and postoperative (in hospital) data regarding all patients undergoing isolated myocardial revascularization, we identified a consecutive series of 71 patients, with a patent IMA-graft, undergoing a RECABG from January 1987, through December 1998. During the same time cohort 6083 isolated myocardial revascularizations were carried out, 590 (9.7\%) were first RECABG, so these 71 patients represent $12 \%$ of the total number of first RECABG's performed at our institution.

Table I. shows the preoperative data of the studied patient group. This was concluded by carrying out the following tests. Diabetes mellitus was detected with a positive glucose tolerance test, peroral antidiabetec medication or insulin dependency, Hypertension was defined as systolic blood pressure $>160 \mathrm{mmHg}$ or diastolic pressure $>100 \mathrm{mmHg}$. Hyperlipidemia was defined as total cholesterol level $>6.4 \mathrm{mmol} / \mathrm{L}$ or triglyceride level $>2 \mathrm{mmol} / \mathrm{L}$, and renal dysfunction as a creatinine level $>150 \mu \mathrm{mol} / \mathrm{L}$ or preoperative dialysis. Neurological pathology was registered in patients with a cerebrovascular accident and/or a transient ischemic attack in their history. Pulmonary pathology was registered in patients with chronic obstructive pulmonary disease, and/or a history of previous lung disease. 
Table I. Preoperative data

\begin{tabular}{lc}
\hline Variable & $\begin{array}{l}\text { No. of } \\
\text { patients } \\
(\mathbf{n = 7 1 )} \mathbf{( \% )}\end{array}$ \\
\hline Sex & $50(70)$ \\
Men & $21(30)$ \\
Women & $62 \pm 8.29$ \\
Age (mean+S.D.) (years) & $45-82$ \\
Range & $18(25)$ \\
Diabetes & $48(68)$ \\
Systemic hypertension & $42(59)$ \\
Hyperlipidemia & $53(76)$ \\
Family history of cardiovascular disease & $17(10)$ \\
Peripheral vascular atherosclerosis & $4(5.5)$ \\
Neurological pathology & $5(7)$ \\
Renal dysfunction & $11(15)$ \\
Pulmonary pathology & \\
Myocardial infarction & $39(55)$ \\
Before the initial operation & $9(12.5)$ \\
Between the initial and the reoperation & $18(25)$ \\
PTCA & \\
& $70 \pm 54,5$ \\
Mean interval ( \pm ) S.D. between the operations (mos) & $1-180$ \\
Range &
\end{tabular}

The localization of the used IMA-grafts at the initial operation is summarized in Table II. In 66 patients one IMA was used, in five patients both IMAs were used. One patient with a left IMA to the left anterior descending coronary artery (LAD) and the right IMA to the circumflex coronary artery $(\mathrm{CX})$, two patients with the left IMA to the LAD and the right IMA to the right coronary artery (RC), and two patients with the left IMA to the CX and the right IMA to the LAD.

Table II. Localisation of the used IMA-grafts at the initial operation.

\begin{tabular}{lcc}
\hline Localisation & Left IMA & Right IMA \\
\hline LAD & 56 & 3 \\
LAD-D & 3 & \\
CX & 10 & 1 \\
RC & \multicolumn{3}{l}{ IMA: internal mammary artery, LAD: left anterior descending coronary artery, D: diagonal branch, CX: } \\
circumflex coronary artery, RC: right coronary artery.
\end{tabular}




\section{Indications for reoperation}

The clinical and angiographic indication is summarized in Table III. The clinical indication in all patients was angina of at least New York Heart Association (NYHA) class III despite medical therapy with $\beta$ blockers, calcium antagonists or nitrates, or a combination.

Table III. Clinical and angiographic indication for reoperation

\begin{tabular}{lc}
\hline Variable & $\begin{array}{c}\text { Patients } \\
\mathbf{n = 7 1}(\mathbf{\%})\end{array}$ \\
\hline Clinical indication & $39(55)$ \\
NYHA < IV & $29(41)$ \\
NYHA = IV & $3(4)$ \\
Emergency & \\
Angiographic indication & $23(32)$ \\
Graft failure & $14(20)$ \\
Progression of atherosclerosis in native coronary vessels & $31(44)$ \\
Late graft failure and progression of atherosclerosis in native & \\
coronary vessels & $3 \quad(4)$ \\
Incomplete revascularisation & \\
\hline
\end{tabular}

NYHA= New York Heart Association

Patients with angina at rest were registered as NYHA=IV, and patients with ischemia not responding to medical therapy, as emergency operation. The mean NYHA for the total group was $3.4 \pm 0.5(3-4)$. Twelve patients (17\%) were operated for a single vessel, 15 patients $(21 \%)$ for two vessels, and 44 patients (62\%) for three vessel disease. Forty-four patients (66\%) had preoperatively a sinus rhythm and 1 patient had a left ventricular ejection fraction below $30 \%$.

\section{Surgical technique}

Sixty-four $(90 \%)$ patients were operated using standard cardiopulmonary bypass, as described in a previous paper [7]. Three patients (4.5\%) were put on bypass, and were operated on an empty beating heart without aortic-cross clamping, and 4 (5.5\%) patients were operated on a beating heart without use of the cardiopulmonary bypass.

For the patients operated on with cardiopulmonary bypass the mean bypass time was $149.8 \pm 81,2$ minutes (range 46-485), and the mean duration of aortic cross-clamping was $65.8 \pm$ 43.0 minutes (range 15-227). Myocardial protection during aortic cross-clamping was performed with cold $\left(4^{\circ} \mathrm{C}\right)$ St.Thomas'Hospital cardioplegia, and since 1995 with blood cardioplegia. In 48 
(77 \%) cardioplegia was delivered initial retrograde, in $14(21 \%)$ patients antegrade. Two patients $(2 \%)$ were operated using the technique of intermittent aortic cross clamping.

At reoperation there was a mean of $1.8 \pm 0.8$ (range 1-4) grafts, and $2.1 \pm 1.0$ (range 1-5) distal anastomoses constructed. Thirty-six new arterial grafts were constructed. The left IMA was used for 14 grafts (39\%), the right IMA for 19 grafts (53\%) and the gastroepiploic artery for 3 grafts (8\%). In 14 patients (20\%) we recycled the left IMA graft [8], 6 times to the anterior descending coronary artery, 8 times to the circumflex coronary artery with a right IMA to the left anterior descending coronary artery.

\section{Follow-up}

The follow-up of all cardiac patients is registered in our follow-up databank. This databank contains reports of referring cardiologists and family doctors, mostly medical information, For the studied group cross-sectional follow-up was conducted in December 1998, at that time an additional functional evaluation by the Duke Activity Status Index (DASI) and information was obtained by telephone contact with the patients and their family and their family doctor. The DASI is a 12 -item questionnaire that determines a patient's ability to participate in a spectrum of activity without difficulty and correlates strongly with maximal oxygen consumption during exercise, and this index has been validated in patients with several cardiac disorders [9]. All patients and their family doctors were asked to answer the question "are you feeling better, worse and is there improvement since the RECABG.?"

\section{Statistical analysis}

Data are presented as frequency distribution and percentages. Values of continuous variables are expressed as mean \pm S.D. Data were analyzed with the Student's $t$ test and the chi square test. Survival curves and event-free survival were obtained by the method of Kaplan Meier. Statistical significance was assumed when the $p$ value was less than 0.05 .

\section{Results}

During the 12 years of the study, the number of RECABGs with a patent IMA-graft increased significantly from $0 \%$ during the time cohort ' $87-$ ' 89 over $8.1 \%$ in the time cohort ' 90 ' $92,12 \%$ in the time cohort '93-' 95 , to $28 \%$ in the time cohort ' $96-' 98(p<0.05)$ (figure 1). 
Figure 1. Distribution of the reoperations over four time cohorts $(p<0.05$ for the trend).

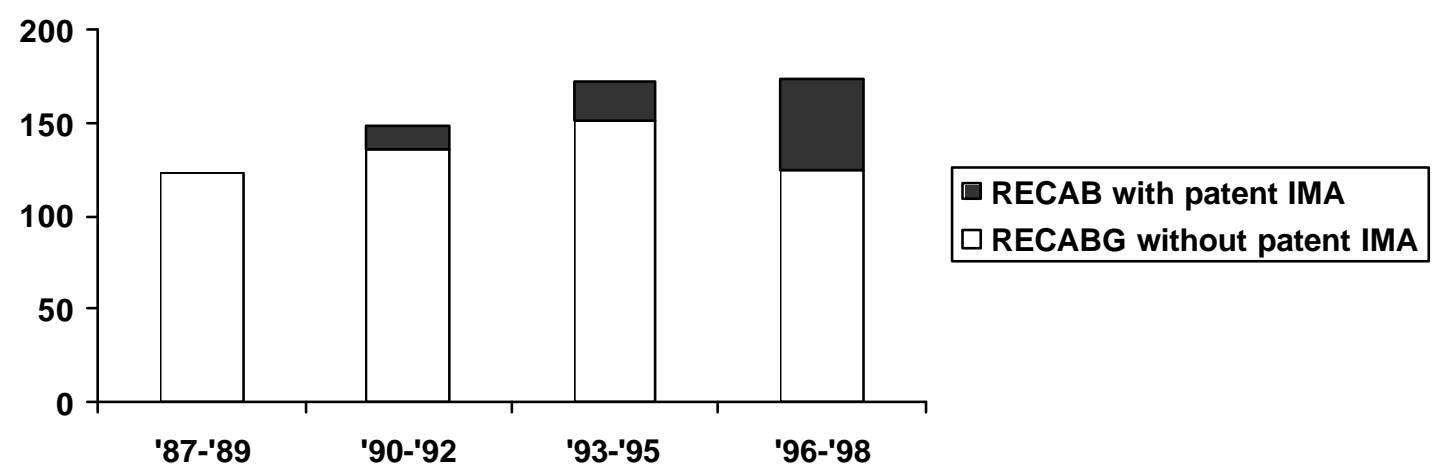

In 6 patients the arterial graft was damaged, five times a left IMA and one right IMA pedicle, crossing the median line. In all these patients the pedicle was not covered with pericardium and was adherent to the sternum. The perioperative mortality (operative and hospital mortality) was $7 \%$ (5/71). Perioperative myocardial infarction (defined as new pos toperative Q waves or T wave changes accompanied by increased cardiac enzymes) occurred in 8 patients and was the major cause death in $3 / 5$ patients. The other postoperative morbidity is presented in table IV.

Table IV. Postoperative morbidity

\begin{tabular}{lc}
\hline Variable & $\begin{array}{c}\text { No. of patients } \\
\text { (n=71) }\end{array}$ \\
\hline Ventilatory support $>$ 2 days & 1 \\
Reoperation for bleeding and other problems & 10 \\
Sternal wound problems & 1 \\
Neurological problems & 0 \\
Nefrological problems & 1 \\
Pulmonary problems & 7 \\
\hline
\end{tabular}

The follow-up of the 66 hospital survivors was complete. The mean survival time was $88,5 \pm 5.5$ months. And the actuarial survival of the hospital survivors is presented in figure 2 . At 12 months the survival was $96 \%$, at 36 months $88 \%$ and $80 \%$ at 60 months. Family doctors declared that 55/66 hospital survivors were better after the RECABG than before. During followup 11 patients died, 9 deaths were cardiac related, 2 were not cardiac-related. Figure 2 present also the event-free actuarial curve of these patients. The first ischemic event is defined as return of angina; cardiac related death, a new myocardial myocardial infarction, new arrhythmia, 
congestive heart failure, and an intervention for angina. The event- free group at 12 months was $86 \%$, at 36 months $70 \%$ and at 60 months $51 \%$.

Figure 2. Actuarial and event-free survival

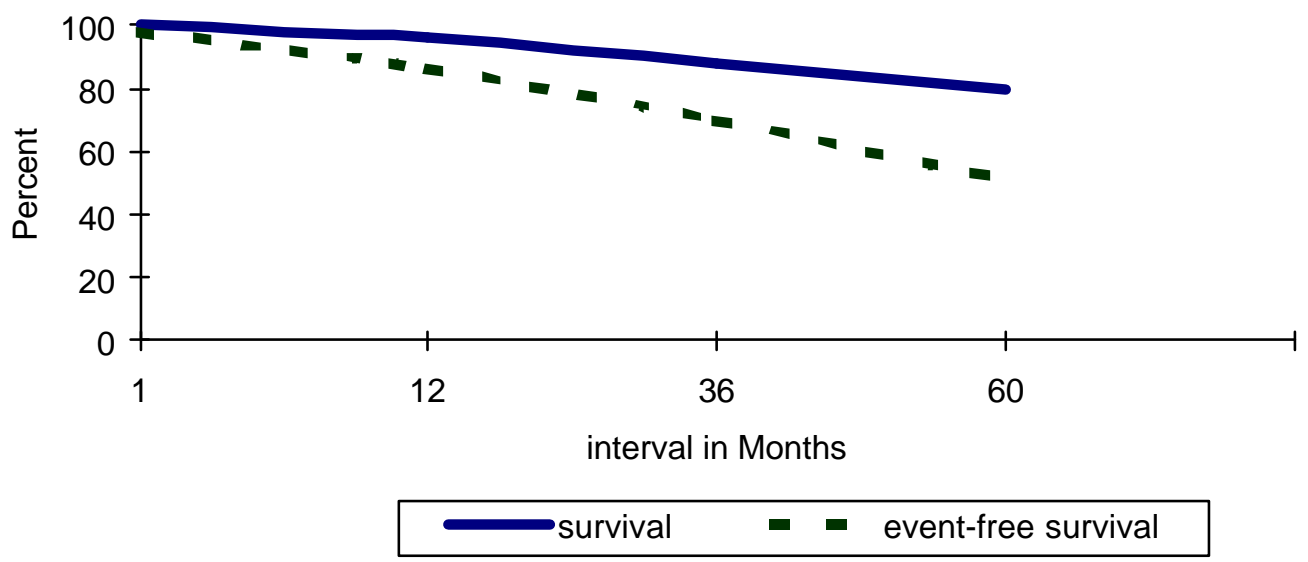

The registered first ischemic events were presented in Table V.

Table V. First ischemic events

\begin{tabular}{lc} 
Variable & No. of patients $(\mathbf{n}=\mathbf{6 6})$ \\
\hline Myocardial infarction & 2 \\
Rithm problems & 2 \\
Dyspnae & 12 \\
Return of angina & 12 \\
PTCA & 1 \\
RE-RE-CABG & 2 \\
\hline
\end{tabular}

The 55 patients at the moment of the cross-sectional follow up, there is a statistical significant improvement of NYHA classification for the total group, preoperative $3.4 \pm 0.5$ versus $1.5 \pm 0.4$ postoperative $(\mathrm{p}<0.05)$. Twenty-four patients $(44 \%)$ were in NYHA class I, 20 patients (37\%) in NYHA class II, 4 patients $(7.2 \%)$ in NYHA III, and 1 patient $(1.8 \%)$ in NYHA IV. The mean DASI was $38.06 \pm 10.42$ with a range from 12.5 to 52.5 .

To the question: are you feeling better, worse, or is there no improvement since the REC ABG, 45 patients (82\%) answered that they were better since the operation, 7 patients (13 $\%$ ) were feeling worse and 3 patients (5\%) answered that there was no improvement. On the same question, but independently, the family doctors answered for 46 patients (83\%) that they 
were better since the RECABG, for 8 patients (14\%) that they were worse, and for one patient (3\%) that there was no improvement.

\section{Discussion}

The number of RECABGs is still increasing. Vein graft atherosclerosis and progression of atherosclerosis in native coronary vessels are the leading angiographic indication for reoperation. This progression of atherosclerosis takes mostly 10-15 years and is an indication that angina will return [1-4]. Angina, not responding with medical therapy, is the primary indication for RECABG. Only patients with late stenoses in saphenous vein grafts to the left anterior descending coronary artery has an improved late survival when this diseased graft is replaced by an arterial graft $[10,11]$.

With the extensive use of arterial grafts since 1987 [12], there is less of a chance that angina will return, however, progression of atherosclerosis is not stopped. So more and more patients with a patent arterial graft (mostly to the LAD), with return of angina, are presented for RECABG. Important for this patient group is the knowledge that return of angina has minimal impact on survival [6] and RECABG has a high perioperative risk, and did not improve survival $[5,1-4]$.

In this study, perioperative mortality is $7 \%$, which is comparable with other series reporting mortality rates between $3,5 \%$ and $12,5 \%$ [1-4,13]. In this series, there was the specific problem of patients with a patent arterial graft. It is documented that a patent arterial graft is not a predictor of perioperative mortality $[7,14,15]$. However this patent arterial graft gives this RECABG a double challenge [16]. First this type of graft may not be damaged. In this series, 6 IMA's were damaged, al these pedicles were not covered by pericardium and adherent to the sternum. The placement and covering of the IMA-pedicle at the primary operation is essential [16]. The second challenge is myocardial protection of the area supply by the patent IMA. The use of retrograde delivered cardioplegia is advocated to reach this myocardium [14]. But retrograde delivery of cardioplegic solutions is important in RECABG, in order to prevent spreading of debris from diseased venous grafts; retrograde cardioplegia is a significant variable in avoiding perioperative myocardial infarction [7]. The use of other techniques, as intermittent aortic cross-clamping, or beating heart procedures may be helpful in specific patients. Our group 
first described the possibility of recycling a patent IMA in 1993, which was later confirmed by others $[8,17-19]$.

Our survival rate is comparable with other series and also our event-free survival rate $[3,4,6,13]$. Interesting is that the recurrence of angina is not the only important event, but also dyspnae, a sign of congestive heartfailure. More than $80 \%$ of the patients, however, declared to have benefitted from the RECAGB, what is confirmed by the family doctors. The significant improvement of the NYHA-class and the good functional status of these patients is confirmed by the DASI-result of $38,6 \pm 10.42$ what is correlating with a maximal oxygen uptake of approximately $28 \mathrm{ml} / \mathrm{min} / \mathrm{kg}$, indicating a normal functional capacity [20].

In conclusion, perioperative mortality, long-term survival and event-free survival of this group of RECABG are not different from other series with or without patent arterial graft. This confirms that a patent arterial graft is not an additional risk factor for the operation. The good clinical, functional and subjective status of the patients justify this RECABG in patients with unacceptable angina.

\footnotetext{
*We thank Mrs. Lisette Peters for her work in the secretarial function of the CORRAD database.
}

\section{References}

1. Loop FD, Lytle BW, Cosgrove DM, Woods EL, Stewart RW, Golding LAR, Goormastic M, Taylor PC. Reoperation for coronary atherosclerosis. Changing practice in 2509 consecutive patients. Ann Surg 1990; 212: 378-386.

2. Akins CW, Buckley MJ, Daggett WM, Hilgenberg AD, Vlahekes GJ, Torchiana DF, Austen WG. Reoperative coronary grafting: changing patient profiles, operative indications, techniques, and results. Ann Thorac Surg 1994; 58: 359-365.

3. Schmuziger M, Christenson JT, Maurice J, Mosimann E, Simonet F, Velebit V. Reoperative myocardial revascularization: an analysis of 458 reoperations and 2645 single operations. Cardiovascular Surgery 1994; 2: 623-629.

4. Weintraub WS, Jones EL, Craver JM, Grosswald R, Guyton RA. In-hospital asnd long-term outcome after reoperative coronary artery bypass surgery. Circulation 1995; 92 [suppl II]:II$50-57$. 
5. Sergeant P, Blackstone E, Meyns B, Stockman B, Jashari R. First cardiological or cardiosurgical reintervention for ischemic heart disease after primary coronary artery bypass grafting. Eur J Cardiothoracic Surg 1998; 14: 480-487.

6. Sergeant P, Blackstone E, Meyns B. Is return of angina after coronary artery bypass grafting immutable, can it be delayed, and is it important? J Thorac Cardiovasc Surg 1998; 116: 440-453.

7. Noyez L, Skotnicki SH, Lacquet LK. Morbidity and mortality in 200 consecutive coronary reoperations. Eur J Cardiothoracic Surg 1997; 11: 528-532.

8. Noyez L, Lacquet LK. Recycling of the internal mammary artery in coronary reoperations. Ann Thorac Surg 1993; 55: 597-599.

9. Hyatky MA, Boineau RE, Higgenbotham MB, Lee KL, Mark DB, Califf RM, Cobb FR, Pryor DB. A brief self-administered questionnaire $\mathfrak{b}$ determine functional capacity ( The Duke Activity Status Index) Am J Cardiol 1998; 64: 651-654.

10. Lytle BW, Loop FD, Taylor PC, Simpfendorfer C, Kramer JR, Ratliff NB, Goormastic M, Cosgrove DM, Vein graft disease: the clinical impact of stenoses in saphe nous vein bypass grafts to coronary arteries. $J$ Thorac Cardiovasc surg 1992; 103: 831-840.

11. Lytle BW, Loop FD, Taylor PC, Goormastic M, Stewart RW, Novoa R, McCarthy P, Cosgrove DM. The effect of coronary reoperation on the survival of patients with stenoses in saphenous vein bypass grafts to coronary arteries. J Thorac Cardiovasc Surg 1992; 103: 831-840.

12. Loop FD, Lytle BW, Cosgrove DM. Et al. Influence of the internal mammary artery graft on survival and other cardiac events. N Eng J Med 1986; 314: 2-6.

13. Salomon NW, Page US, Bigelow JC, Krause AH, Okies JE, Metzdorff MT. Reoperative coronary surgery. J Thorac Cardiovasc Surg 1990; 100: 250-260.

14. Lytle BW, McElroy D, McCarthy P, Loop FD, Goormastic M, Stewart RW, Cosgrove DM. Influence of arterial coronary bypass grafts on the mortality in coronary reoperations. $J$ Thorac Cardiovasc Surg 1994; 107: 675-683.

15. He GW, Acuff TE, Ryan WH, Ryan WH, He YH, Mack MJ. Determinants of operative mortality in reoperative coronary artery bypass grafting J Thorac Cardiovasc Surg 1995; 110: $971-978$.

16. Noyez L, Lacquet LK. Cardiac reoperations with a patent internal thoracic artery graft. A double challenge. J Cardiovasc Surg 1995; 36: 13-15. 
17. Antonia C, Parolari A, Zanobini M, Arena V, Biglioli P. Mid-term angiographic study of five recycled mammary arteries during four coronary redos. Ann Thorac Surg 1996; 61: 702-705.

18. Noirhomme PH, Underwood MJ, El Khoury GA, Glineur D, Elias B, d'Udekem Y, Dion RA. Recycling of arterial grafts during reoperative coronary artery operations. Ann Thorac Surg 1999; 67: 641-644.

19. Velebit V, Maurice JP Recycling of the internal mammary artery in coronary reoperation. Ann Thorac Surg 1996; 62: 947-948.

20. Weber KT, Janicki JS, and Mc Elroy PA. Cardiopulmonary exercise testing. In Weber KT and Janicki JS (eds) Cardiopulmonary Exercise Testing, Philadelphia, WB Saunders Company 1986, p153. 


\section{CHAPTER IV}

\section{ANALYSIS OF MORTALITY WITHIN THE FIRST SIX MONTHS AFTER CORONARY REOPERATION.}

Frans M. van Eck, Luc Noyez, Freek W.A. Verheugt, Rene M.H.J. Brouwer.

The Annals of Thoracic Surgery 2002; 74: 2106-2112 


\begin{abstract}
Background. Identify risk factors associated with mortality following repeat coronary revascularization (redoCABG) within the first 6 months following surgery.

Methods. Five hundred forty-one redoCABG patients (1987-1998) were studied by uniand multivariant analysis. Mortality was assessed at three different points: hospital mortality (A) (36/541, 6.7\%); mortality at six months (C) 75/541, 13.9\%); and outpatient perioperative mortality, which is a death occurring from the time of hospital discharge to six months postoperatively (B) 39/541, 7.2\%).

Results. Diabetes, hypertension, peripheral vascular disease, renal insufficiency, lung disease, myocardial infarction (MI) before the first operation, MI between the first and redoCABG, lack of sinus rhythm, No- IMA-graft, acute/emergency operation, perfusion time, and perioperative MI were all identified as risk factors related to early mortality. MI before the first operation, antegrade cardioplegia, and the time period 1987 to 1992 all influenced hospital mortality (A). Diabetes, hypertension, renal insufficiency, lung disease, and valvular heart disease all influenced the outpatient mortality up to six months. Independent predictive factors for early mortality were: age $>69$ years; diabetes; vascular insufficiency; chronic lung disease; MI between first and redoCABG; No-IMA-graft; acute preoperative MI; emergency operation; perfusion time; perioperative MI; and the time period 1987 to 1992. Risk factors for in-hospital death included MI between the first and redoCABG, cardiopulmonary bypass time, and the time period 1987 to 1992 . Diabetes is an important risk factor during the outpatient perioperative phase. Emergency surgery and perioperative MI predict mortality regardless of the time period
\end{abstract} (A, B or C).

Conclusion. Early mortality after redoCABG is influenced by many variables during the first 6 months following surgery. Understanding these factors and their time course may better help to assess the true risk associated with reoperation for recurrent coronary insufficiency.

Key words : Coronary reoperations; Early mortality; Hospital mortality 


\section{Introduction}

Mortality after coronary reoperations (redoCABG) is still higher than for the initial revascularization procedure (CABG). Several studies have attempted to analyze operative, 30day, and hospital mortality following coronary reoperations [1-8]. In reviewing these studies, there is no consensus as to predictors of early mortality. The purpose of the present study is to identify risk factors for early mortality within the first six months following redoCABG, and also to analyze those risk factors and patient characteristics that may be associated with an increased risk following repeat revascularization.

\section{Materials and methods}

\section{Patients}

The Coronary Surgery Database at Radboud Hospital (CORRAD), a registry that stores pre-, peri-, postoperative 6llow-up data on all patients undergoing isolated coronary bypass surgery at the University Medical Center St. Radboud, Nijmegen (UMC St. Radboud) was used to identify 541 patients undergoing a first coronary reoperation (redoCABG) from January 1987 to December 1998. All patients underwent isolated coronary revascularization. No patients with combined procedures were included. A number of different variables were analyzed and are presented in Table 1. A six-month period of follow-up was selected. The information placed in our database is based on data from cardiologists, family doctors, and an annual survey sent directly to the patients. In addition a cross-sectional follow-up was performed in the first months of 2000. This follow-up was performed by a survey sent directly to the patients. If there was no response from the patient, the information was traced by telephone contact with the patient, family, doctor, or government records. The six-month follow-up in this study was $100 \%$. In case of death, the cardiologist, family doctor, or patient's family was contacted to identify the cause of death.

\section{Perioperative and six-month mortality}

Hospital mortality (A) was defined as an operative death or mortality at the University Hospital anytime during the hospitalization for the redo coronary artery bypass. Six-month mortality (C) was defined as all mortality within the first six months from the time of surgery. This is consistent with the early phase mortality described by Blackstone [9]. Blackstone's study 
Table 1. Variables analyzed in patients undergoing reoperative coronary artery bypass.

\begin{tabular}{|c|c|}
\hline Age (years) & 3 groups: age $<60,60 \geq$ age $<70$, age $\geq 70$ years \\
\hline Sex & Male, Female \\
\hline Obesity & Body Surface Area $(\mathrm{BSA})>2.1$ \\
\hline Diabetes & Diet-controlled, oral therapy or insulin dependent diabetes \\
\hline Hypertension & $\begin{array}{l}\text { Systolic blood pressure }>160 \mathrm{mmHg} \text {, or diastolic pressure }>100 \mathrm{mmHg} \text {. } \\
\text { Or antihypertensive medication. }\end{array}$ \\
\hline Hyperlipidemia & Total cholesterol $>250 \mathrm{mg} / \mathrm{dl}$ or triglyceride level $200 \mathrm{mg} / \mathrm{dl}$ \\
\hline Vascular disease & Peripheral -, abdominal vascular pathology or operation \\
\hline Neurological disease & Cerebrovascular accidents and /or transient ischemic attack \\
\hline Renal disease & $\begin{array}{l}\text { Renal failure (creatinine } \geq 150 \mu \mathrm{mol} / \mathrm{L} \text { ) preoperative dialysis, renal } \\
\text { transplantation }\end{array}$ \\
\hline Lung disease & $\begin{array}{l}\text { Chronic obstructive pulmonary disease and/or history of previous lung } \\
\text { disease }\end{array}$ \\
\hline PTCA & History of previous percutaneous transluminal coronary angioplasty \\
\hline $\begin{array}{l}\text { Preoperative myocardial } \\
\text { infarction (MI) }\end{array}$ & History of myocardial infarction before the first operation \\
\hline $\begin{array}{l}\text { Myocardial infarction (MI) } \\
\text { between operations. }\end{array}$ & $\begin{array}{l}\text { History of myocardial infarction between the first operation and the } \\
\text { reoperation. }\end{array}$ \\
\hline Rhythm & Preoperative sinus rhythm \\
\hline $\begin{array}{l}\text { Internal mammary artery } \\
\text { graft (IMA-graft) }\end{array}$ & Patent IMA graft at the reoperation \\
\hline Operative status & $\begin{array}{l}3 \text { groups: Elective: patients with stable cardiac function, usually } \\
\text { scheduled at least one day prior to the surgical procedure. Urgent: } \\
\text { surgery is required within } 24 \text { hours after admission, Emergency: } \\
\text { operation for evolving infarction, ischemia not responding to medical } \\
\text { therapy, or cardiogenic shock. }\end{array}$ \\
\hline Mild valve pathology & Combined valve disease, not requiring surgical intervention \\
\hline $\mathrm{ECC}$ & ECC: extra corporal circulation, duration in minutes \\
\hline AoX & AoX; aortic cross clamp, duration in minutes \\
\hline $\begin{array}{l}\text { Perioperative myocardial } \\
\text { infarction (peri-MI) }\end{array}$ & A new $\mathrm{Q}$ wave and a CPK-MB $\% \geq 10 \%$ \\
\hline
\end{tabular}


only describes mortality up to six months following the operation. In addition, we defined outpatient perioperative mortality as the difference between the hospital and six-month mortality (B).

\section{Discharge policy}

Patients are either sent home or transferred to the referring cardiac center from UMC. St. Radboud Nijmegen. Patients are not discharged or transferred unless they are ambulatory and require minimal levels of care. The mean hospital stay the UMC St. Radboud for redoCABG is ten days. Patients with postoperative complications such as wound problems remain at UMC St. Radboud until they are ambulatory and require minimal care. Thus patients who died in the perioperative period were all in good condition and functioning at the time they were discharged from the UMC St. Radboud center. In the 541 patients studied, all hospital deaths occurred within the first five months after surgery. None of the deaths occurring during the post-discharge perioperative period died after transfer to their referring cardiac center and thus would not be considered a hospital death directly related to the surgery.

\section{Surgical technique}

Our surgical technique has been described previously [7,8]. It is important to note that since 1993 cardioplegia has been delivered using retrograde techniques in redoCABG procedures. Of the 541 patients, 230 (42\%) patients had antegrade, and 305 patients (67\%) had retrograde delivery of their cardioplegia. Six other patients (1\%) were operated without cardioplegic arrest (intermittent aortic cross-clamping; two patients, off-pump, four patients).

The mean bypass time was $140 \pm 60.8$ minutes (range 25-485), and the mean duration of aortic cross-clamping was $70 \pm 33.6$ minutes (range 10-227). There were $2.4 \pm 0.8$ grafts (range 1-5), per patient, and $3.2 \pm 1.2$ (range 1-7) distal anastomoses. On average, $1.0 \pm 0.6$ (range 1-2) arterial grafts were used in the patients, and resulted in $1.2 \pm 0.9$ (range 1-5) distal anastomoses. 428 patients (79.1\%) received at least one new arterial graft.

\section{Statistical analysis}

To test which variables were associated with increased perioperative risk and six-month mortality, a Fisher's exact test (univariant analysis) was used. Multiple logistic regression 
Table 2a. Univariant analysis of preoperative variables.

A: hospital mortality, B: early out-hospital mortality, C: early six-month mortality

\begin{tabular}{|c|c|c|c|c|c|c|c|c|}
\hline \multirow[b]{3}{*}{ Variable } & \multirow[b]{3}{*}{ Category } & \multirow{3}{*}{$\begin{array}{l}\text { Patients } \\
\mathrm{N}=541 \\
\mathrm{~N}(\%)\end{array}$} & \multicolumn{6}{|c|}{ Mortality } \\
\hline & & & \multicolumn{2}{|c|}{$\begin{array}{c}\mathrm{A} \\
\mathrm{N}=36(6.7)\end{array}$} & \multicolumn{2}{|c|}{$\begin{array}{c}\mathrm{B} \\
\mathrm{N}=39(7.2)\end{array}$} & \multicolumn{2}{|c|}{$\begin{array}{c}\mathrm{C}=\mathrm{A}+\mathrm{B} \\
\mathrm{N}=75(13.9)\end{array}$} \\
\hline & & & N (\%) & $\mathrm{p}$-value & $\mathrm{N}(\%)$ & $\mathrm{p}$-value & $\mathrm{N}(\%)$ & p-value \\
\hline \multirow[t]{3}{*}{ Age (years) } & $<60$ & $156(31)$ & $9(5.5)$ & 0.70 & $11(6.7)$ & 0.07 & $20(12)$ & 0.12 \\
\hline & $\geq 60-<70$ & $248(46)$ & $17(6.9)$ & & $13(5.2)$ & & $30(12)$ & \\
\hline & $\geq 70$ & $128(24)$ & $10(7.8)$ & & $15(12)$ & & $25(20)$ & \\
\hline \multirow[t]{2}{*}{ Sex } & Female & $107(20)$ & $8(7.5)$ & 0.67 & $11(10)$ & 0.21 & $19(18)$ & 0.21 \\
\hline & Male & $434(80)$ & $28(6.5)$ & & $28(6)$ & & $56(13)$ & \\
\hline \multirow[t]{2}{*}{ Obesity } & No & $407(75)$ & $24(5.9)$ & 0.23 & $29(7.1)$ & 0.85 & $53(13)$ & 0.32 \\
\hline & Yes & $134(25)$ & $12(9.0)$ & & $10(7.5)$ & & $22(16)$ & \\
\hline \multirow[t]{2}{*}{ Diabetes } & No & $445(82)$ & $31(7.0)$ & 0.66 & $18(4.00$ & $10^{-7}$ & $49(11)$ & $10^{-4}$ \\
\hline & Yes & $96(18)$ & $5(5.2)$ & & $21(22)$ & & $26(27)$ & \\
\hline \multirow[t]{2}{*}{ Hipertens ión } & No & $208(38)$ & $14(6.7)$ & 1.00 & $6(2.9)$ & 0.002 & $20(9.6)$ & 0.03 \\
\hline & Yes & $333(62)$ & $22(6.6)$ & & $33(9.9)$ & & $55(17)$ & \\
\hline \multirow[t]{2}{*}{ Hyperlipidemia } & No & $224(41)$ & $12(5.4)$ & 0.38 & $17(7.6)$ & 0.87 & $29(13)$ & 0.71 \\
\hline & Yes & $317(59)$ & $24(7.6)$ & & $22(6.9)$ & & $46(15)$ & \\
\hline \multirow[t]{2}{*}{ Vascular disease } & No & $423(78)$ & $23(5.4)$ & 0.04 & $20(4.7)$ & $10^{-4}$ & $43(10)$ & $10^{-5}$ \\
\hline & Yes & $118(22)$ & $13(11)$ & & $19(16)$ & & $32(27)$ & \\
\hline \multirow[t]{2}{*}{ Neurological dis. } & No & $507(94)$ & $32(6.3)$ & 0.27 & $35(6.9)$ & 0.30 & $67(13)$ & 0.12 \\
\hline & Yes & $34(6)$ & $4(12)$ & & $4(12)$ & & $8(24)$ & \\
\hline \multirow[t]{2}{*}{ Renal disease } & No & $528(98)$ & $35(6.6)$ & 0.60 & $35(6.6)$ & 0.01 & $70(13)$ & 0.02 \\
\hline & Yes & $13(2)$ & $1(7.7)$ & & $4(31)$ & & $5(39)$ & \\
\hline \multirow[t]{2}{*}{ Lung disease } & No & $436(81)$ & $27(6.2)$ & 0.39 & $19(4.4)$ & $3.10^{-6}$ & $46(11)$ & $3.10^{-5}$ \\
\hline & Yes & $105(19)$ & $9(8.6)$ & & $20(19)$ & & $29(28)$ & \\
\hline \multirow[t]{2}{*}{ PTCA } & No & $466(86)$ & $34(7.3)$ & 0.21 & $34(7.3)$ & 1.00 & $68(15)$ & 0.28 \\
\hline & Yes & $75(14)$ & $2(2.7)$ & & $5(6.7)$ & & $7(9.3)$ & \\
\hline \multirow[t]{2}{*}{ Pre-M.I. } & No & $207(38)$ & $7(3.4)$ & 0.02 & $10(4.8)$ & 0.12 & $17(8.2)$ & 0.003 \\
\hline & Yes & $334(62)$ & $29(8.7)$ & & $29(8.7)$ & & $58(17)$ & \\
\hline \multirow[t]{2}{*}{ Between M.I. } & No & $397(73)$ & $16(4.00$ & $10^{-4}$ & $23(5.8)$ & 0.04 & $39(9.8)$ & $2.10^{-5}$ \\
\hline & Yes & $144(27)$ & $20(14)$ & & $16(11)$ & & $36(25)$ & \\
\hline \multirow[t]{2}{*}{ Sinus rhythm } & No & $32(6)$ & $4(13)$ & 0.16 & $5(16)$ & 0.07 & $9(28)$ & 0.03 \\
\hline & Yes & $509(94)$ & $32(6.3)$ & & $34 * 6.7)$ & & $66(13)$ & \\
\hline \multirow[t]{2}{*}{ IMA-graft } & No & $467(86)$ & $35(7.5)$ & 0.05 & $38(8.1)$ & 0.03 & $73(16)$ & 0.003 \\
\hline & Yes & $74(14)$ & $1(1.4)$ & & $1(1.4)$ & & $2(2.7)$ & \\
\hline \multirow[t]{2}{*}{ Time period } & ’87-'92 & $230(42)$ & $24(10)$ & 0.003 & $15(6.5)$ & 0.62 & $39(17)$ & 0.08 \\
\hline & '92-'98 & $311(58)$ & $12(3.90$ & & $24(7.7)$ & & $36(12)$ & \\
\hline
\end{tabular}

PTCA: percutane transluminal coronary angioplasty, M.I.: myocardial infarction, IMA: internal mammary artery. 
analysis was used to identify risk factors that independently predicted an increased or decreased risk of death. A p-value of 0.05 or less was considered significant. All mortality data are presented with $95 \%$ confidence interval $(\mathrm{CI})$.

\section{Results}

The overall risk for hospital, perioperative, and six-month mortality is $36 / 541(6.7 \%$, 95\% CI 4.6-6.8), 39/541 (7.2\%, 95\% CI 5.1-9.3), and 75/541 (13.9\%, 95\% CI 11.0-16.8 respectively). Cardiovascular causes were the reasons for mortality at six months in 64 patients $(85 \%)[10]$.

Univariant analysis

The results of the univariant analysis are presented in Table $2(a+b)$.

Risk factors for hospital mortality (A) include: peripheral vascular pathology $(\mathrm{p}=0.04)$; myocardial infarction $(\mathrm{p}=0.02)$; myocardial infarction between initial CABG and redoCABG $(\mathrm{p}$ $\left.=10^{-4}\right)$; No- IMA graft $(\mathrm{p}=0.05)$; operative status $(\mathrm{p}=0.003)$; perfusion time $\geq 120$ minutes $(\mathrm{p}$ $=0.001)$; antegrade delivery of cardioplegia $(\mathrm{p}=0.008)$; perioperative myocardial infarction $(\mathrm{p}=$ $\left.7.10^{-6}\right)$; and the earlier time period 1987 to $1992(\mathrm{p}=0.003)$.

Risks for perioperative outpatient mortality (B) include: diabetes $\left(\mathrm{p}=10^{-7}\right)$; hypertension $(\mathrm{p}=0.002)$; peripheral vascular disease $\left(\mathrm{p}=10^{=5}\right)$; renal insufficiency $(\mathrm{p}=0.01)$, pulmonary disease $\left(p=3.10^{-6}\right)$; infarction between initial CABG and redoCABG $(p=0.04)$; No- IMA graft $(\mathrm{p}=0.03)$; operative status $\left(\mathrm{p}=10^{-7}\right)$; mild valvular disease $(\mathrm{p}=0.04)$; perfusion time $\geq 120$ minutes $(p=0.04)$, and perioperative myocardial infarction $\left(p=2.10^{-8}\right)$.

Risk factors for six-month mortality $(C)$ include: diabetes $\left(p=10^{-4}\right)$; hypertension $(p=$ $0.03)$; peripheral vascular disease $\left(\mathrm{p}=10^{-5}\right)$; renal insufficiency $(\mathrm{p}=0.02)$; pulmonary disease $(\mathrm{p}$ $\left.=3.10^{-5}\right)$; myocardial infarction $(\mathrm{p}=0.003)$; myocardial infarction between initial CABG and redoCABG $\left(p=2.10^{-5}\right)$; cardiac rhythm other than sinus $(\mathrm{p}=0.03)$; No-IMA graft $(\mathrm{p}=0.003)$; operative status $\left(\mathrm{p}=8.10^{-12}\right)$; mild valvular heart disease $(\mathrm{p}=0.02)$; perfusion time $\geq 120$ minutes $\left(\mathrm{p}=6.10^{-5}\right)$; and perioperative myocardial infarction $\left(\mathrm{p}=2.10^{-14}\right)$. 
Table 2b. Univariant analysis of perioperative variables

A: hospital mortality, B: early out-hospital mortality, C: early six months mortality

\begin{tabular}{|c|c|c|c|c|c|c|c|c|}
\hline \multirow[b]{3}{*}{ Variable } & \multirow[b]{3}{*}{ Category } & \multirow{3}{*}{$\begin{array}{l}\text { Patients } \\
\mathrm{N}=541 \\
\mathrm{~N}(\%)\end{array}$} & \multicolumn{6}{|c|}{ Mortality } \\
\hline & & & \multicolumn{2}{|c|}{$\begin{array}{c}\mathrm{A} \\
\mathrm{N}=36(6.7)\end{array}$} & \multicolumn{2}{|c|}{$\begin{array}{c}\mathrm{B} \\
\mathrm{N}=39(7.2)\end{array}$} & \multicolumn{2}{|c|}{$\begin{array}{c}\mathbf{C}=\mathbf{A}+\mathbf{B} \\
\mathrm{N}=75(13.9)\end{array}$} \\
\hline & & & N (\%) & p-value & N (\%) & p-value & N (\%) & $\mathrm{p}$-value \\
\hline \multirow[t]{3}{*}{$\begin{array}{l}\text { Operative } \\
\text { status }\end{array}$} & Elective & $289(53)$ & $11(3.8)$ & 0.003 & $9(3.1)$ & $10^{-7}$ & $20(6.9)$ & $8.10^{-12}$ \\
\hline & Acute & $198(37)$ & $14(7.1)$ & & $15(7.6)$ & & $29(15)$ & \\
\hline & Emergency & $54(10)$ & $11(20)$ & & $15(28)$ & & $26(48)$ & \\
\hline \multirow[t]{2}{*}{$\begin{array}{l}\text { Mild valve } \\
\text { disease }\end{array}$} & No & 495 (91) & $31(6.3)$ & 0.22 & $32(6.5)$ & 0.04 & $63(13)$ & 0.02 \\
\hline & Yes & $46(9)$ & $5(10.9)$ & & $7(15)$ & & $12(26)$ & \\
\hline \multirow[t]{2}{*}{$\begin{array}{l}\text { ECC-time } \\
(\mathrm{min})\end{array}$} & $<120$ & 212 (39) & $5(2.4)$ & 0.001 & $9(4.2)$ & 0.04 & $14(6.6)$ & $6.10^{-5}$ \\
\hline & $\geq 120$ & $329(61)$ & $31(9.4)$ & & $30(9.1)$ & & $61(19)$ & \\
\hline \multirow[t]{2}{*}{$\begin{array}{l}\text { AoX-time } \\
\text { (min) }\end{array}$} & $<60$ & $198(37)$ & $10(5.1)$ & 0.29 & $14(7.1)$ & 1.00 & $24(12)$ & 0.43 \\
\hline & $\geq 60$ & $343(63)$ & $26(7.6)$ & & $25(7.3)$ & & $51(15)$ & \\
\hline \multirow{3}{*}{$\begin{array}{l}\text { Myocardial } \\
\text { protection }\end{array}$} & Retrograde & 305 (57) & $12(4.0)$ & 0.008 & $23(7.4)$ & 0.87 & 35 (12) & 0.08 \\
\hline & Antegrade & $230(42)$ & $23(10)$ & & $16(7.0)$ & & 39 (17) & \\
\hline & Other* & $6(1)$ & 1 & & 0 & & 1 & \\
\hline \multirow[t]{2}{*}{$\begin{array}{l}\text { Perioperative } \\
\text { MI }\end{array}$} & No & $452(84)$ & $20(4.3)$ & $7.10^{-6}$ & $19(4.1)$ & $2.10-8$ & $39(8.4)$ & $2.10^{-14}$ \\
\hline & Yes & $89(16)$ & $16(20)$ & & $20(25)$ & & $36(46)$ & \\
\hline
\end{tabular}

*Other technique, not incorporated in the analysis concerning myocardial protection, because of the limited number of patients.

ECC: extra corporal circulation, AoX; aortic cross clamp, MI: myocardial infarction 
Multivariant analysis

Table 3 shows the results of the multiple logistic regression analysis.

Table 3. Multivariant risk analysis

A: hospital mortality, B: early out-hospital mortality, C: early six months mortality

\begin{tabular}{|c|c|c|c|c|c|c|}
\hline \multirow[b]{3}{*}{ Preoperative variable } & \multicolumn{6}{|c|}{ Mortality } \\
\hline & \multicolumn{2}{|c|}{$\begin{array}{c}\mathbf{A} \\
\mathrm{N}=36(6.7)\end{array}$} & \multicolumn{2}{|c|}{$\begin{array}{c}\mathbf{B} \\
\mathrm{N}=39(7.2)\end{array}$} & \multicolumn{2}{|c|}{$\begin{array}{c}\mathrm{C}=\mathrm{A}+\mathrm{B} \\
\mathrm{N}=75(13.9)\end{array}$} \\
\hline & Odds Ratio & p-value & Odds Ratio & p-value & Odds Ratio & p-value \\
\hline Age $<60$ years & 0.56 & 0.21 & 1.2 & 0.71 & 0.83 & 0.56 \\
\hline Age $>69$ years & 1.56 & 0.34 & 2.0 & 0.13 & 2.0 & 0.05 \\
\hline Sex (female/male) & 0.90 & 0.81 & 0.27 & 0.62 & 0.72 & 0.34 \\
\hline Obesity (yes/no) & 1.8 & 0.14 & 0.83 & 0.67 & 1.3 & 0.38 \\
\hline Diabetes (yes/no) & 0.76 & 0.64 & 4.1 & 0.0005 & 2.5 & 0.008 \\
\hline Hypertension (yes/no) & 0.73 & 0.43 & 2.1 & 0.15 & 1.1 & 0.73 \\
\hline Hyperlipidemia (yes/no) & 1.6 & 0.24 & 1.1 & 0.85 & 1.3 & 0.33 \\
\hline Vascular disease(yes/no) & 1.9 & 0.13 & 1.8 & 0.15 & 2.1 & 0.02 \\
\hline Neurological disease (yes/no) & 1.4 & 0.60 & 1.0 & 0.99 & 1.2 & 0.68 \\
\hline Renal disease (yes/no) & 2.1 & 0.51 & 1.9 & 0.47 & 2.8 & 0.17 \\
\hline Lung disease (yes/no) & 1.4 & 0.49 & 2.6 & 0.02 & 2.0 & 0.02 \\
\hline PTCA (yes/no) & 0.45 & 0.31 & 1.4 & 0.57 & 0.86 & 0.75 \\
\hline Previous M.I. (yes/no) & 1.2 & 0.70 & 1.5 & 0.41 & 1.3 & 0.45 \\
\hline Between M.I. (yes/no) & 4.0 & 0.003 & 1.5 & 0.39 & 3.0 & 0.002 \\
\hline Sinus rhythm (yes/no) & 0.79 & 0.72 & 1.1 & 0.84 & 1.0 & 0.95 \\
\hline Patent-IMA-graft (yes/no) & 0.40 & 0.39 & 0.15 & 0.07 & 0.21 & 0.04 \\
\hline Time period '87-'92 /'93-'98 & 0.26 & 0.002 & 0.90 & 0.81 & 0.43 & 0.007 \\
\hline \multicolumn{7}{|l|}{ Perioperative variable } \\
\hline Acute operation (versus elective) & 2.6 & 0.06 & 1.7 & 0.28 & 2.2 & 0.05 \\
\hline $\begin{array}{l}\text { Emergency operation (versus } \\
\text { elective) }\end{array}$ & 11.1 & $10^{-4}$ & 7.5 & 0.001 & 14.9 & $10^{-4}$ \\
\hline Mild valve disease (yes/no) & 1.3 & 0.70 & 0.90 & 0.88 & 1.2 & 0.77 \\
\hline Perfusion time $(<120 / \geq 120)$ & 3.7 & 0.03 & 1.7 & 0.34 & 3.2 & 0.007 \\
\hline AoX time $(<60 / \geq 60)$ & 0.88 & 0.79 & 0.41 & 0.09 & 0.48 & 0.07 \\
\hline $\begin{array}{l}\text { Myocardial protection } \\
\text { (retro/ante) }\end{array}$ & 2.6 & 0.08 & 0.90 & 0.83 & 1.6 & 0.25 \\
\hline Perioperative M.I. (yes/no) & 4.1 & 0.003 & 8.1 & $10-4$ & 10.3 & $10^{-4}$ \\
\hline
\end{tabular}


For hospital mortality (A) a myocardial infarction $(\mathrm{p}=0.003)$, the time period of surgery 1987 to $1992(\mathrm{p}=0.002)$, emergency operation $\left(\mathrm{p}=10^{-4}\right)$, perfusion time $\geq 120$ minutes $(\mathrm{p}=$ $0.03)$, a perioperative myocardial infarction $(p=0.003)$ are all identified as independent variables predicting hospital death. For patients, their outpatient perioperative mortality (B) was predicted by diabetes $(p=0.0005)$, pulmonary disease $(p=0.02)$, emergency operation $(p$ $=0.001)$, and perioperative myocardial infarction $\left(\mathrm{p}=10^{-4}\right)$.

Predictors for six-month mortality $(C)$ include: age $>69$ years $(p=0.05)$; diabetes mellitus $(\mathrm{p}=0.008)$; peripheral vascular disease $(\mathrm{p}=0.02)$; pulmonary disease $(\mathrm{p}=0.02)$; myocardial infarction between initial CABG and redoCABG $(p=0.002)$; occluded IMA graft $(p=0.04)$; and also the time period of surgery 1987 to $1992(p=0.007)$. Independent perioperative variables include: acute operation $(p=0.05)$; emergency operation $\left(p=10^{-4}\right)$, perfusion time $\geq 120$ minutes $(\mathrm{p}=0.007)$; and perioperative myocardial infarction $\left(\mathrm{p}=10^{-4}\right)$.

\section{Comment}

Redo coronary bypass surgery is known to be high-risk surgery. High mortality and morbidity rates are described in several reports [1-8]. This study is focused on mortality within the first six months following operation. The choice for this time interval is based on the work of Blackstone [9], who describes a prolonged early phase in high-risk patients. Several clinical studies have also highlighted the importance of analysis of this period $[11,12]$. Hospital mortality is defined as any death occurring during their hospitalization at the UMC St. Radboud where the patient underwent redoCABG. Thus hospital mortality included not only surgical deaths, but also patients who died after a complicated postoperative recovery. All hospital deaths are included. The perioperative outpatient mortality is the period between hospitalization and six months. This includes all patients who died after discharge from the UMC St. Radboud. All of these patients were in good condition at the time of discharge from the UMC St. Radboud. An event then occurred within the first six months after their redoCABG that lead to their death. It is important to note that none of these patients died after transfer to their referring cardiac center, which would have to have been considered as part of their hospitalization. A number of variables were selected for study, but the list was not all-inclusive. Certain variables such as left ventricular function, identified as a predictor for hospital and late mortality in several reports $[1,3,4]$ were not included because the data was not available in our database. Ejection fraction is not routinely calculated for all patients, except for those with severe decrease in their left ventricular 
function. Seven patients had a documented ejection fraction lower than $30 \%$. Because of the limited number of patients with documented, impaired left ventricular function, we excluded this variable in our analysis. Myocardial infarction may influence left ventricular function and survival, thus infarction before the initial CABG and infarction occurring between the initial procedure and the reoperation are included. The presence of a patent IMA graft is included in our analysis; however, the patency and the degree of disease in old vein grafts is not. Perioperative variables such as lack of graft material and completeness of revascularization during redoCABG are also not included in this analysis.

Over the study period, the percentage of redoCABG's increased from 10\% in 1987 to $12 \%$ in 1998 . In this study, only patients who had isolated myocardial revascularization at both operations were included. Our hospital mortality of $6.7 \%$ and six-month mortality of $13.9 \%$ is comparable with other reports [1-6]. The finding of an additional $7.2 \%$ perioperative outpatient mortality is alarming and confirms again the importance of a longer follow-up period for the evaluation of early mortality in high-risk patients [9, 11, 12]. Simply looking at hospital mortality may not give an accurate picture as to a patient's true risk after a complicated procedure.

Looking at the univariant analysis of these patients, we have found that their hospital mortality is influenced by the presence of peripheral vascular disease, myocardial infarction between the initial operation and redo, and occluded IMA grafts, operative status (emergency vs. elective), ECC time $\geq 120$ minutes, antegrade delivery of cardioplegia, occurrence of perioperative myocardial infarction, and also the time period of their surgery 1987 to 1992.

Several factors also help define the mortality at 6 months. The presence of diabetes, hypertension, peripheral vascular disease, renal insufficiency, pulmonary disease; myocardial infarction between operations, lack of sinus rhythm, No-IMA grafts, operative status (emergency vs. elective), mild valvular disease, time on cardiopulmonary bypass, perioperative myocardial infarction, and the time period 1987 to 1992 all were associated with increased mortality.

Most of these same variables have been identified as risk factors for mortality in previous reports [1-6]. In these reports, however, there are different definitions of mortality as it relates to the procedure. With our distinction between hospital and six-month mortality, we see the importance of different risk factors during the first six months. By looking at perioperative mortality, we have been able to look at three distinct time periods within the first six months. The importance of the identified risk factors is demonstrated in Table 4 
Table 4. Risk factors related to mortality , (univariant and multivariant analysis) after first redo-coronary artery bypass, and the phase in which they exert their effect.

\begin{tabular}{|c|c|c|c|}
\hline \multirow[t]{2}{*}{ Risk factor } & \multicolumn{3}{|c|}{ Mortality } \\
\hline & $\begin{array}{c}\text { A } \\
\text { Hospital } \\
\end{array}$ & $\begin{array}{c}\text { B } \\
\text { Early out-hospital } \\
\end{array}$ & $\begin{array}{c}\mathrm{C}=\mathbf{A}+\mathbf{B} \\
\text { Early six-month }\end{array}$ \\
\hline \multicolumn{4}{|l|}{ UNIVARIANT ANALYSIS } \\
\hline Diabetes & & + & + \\
\hline Hypertension & & + & + \\
\hline Vascular disease & + & + & + \\
\hline Renal disease & & + & + \\
\hline Lung disease & & + & + \\
\hline Pre-MI & + & & + \\
\hline Between MI & + & + & + \\
\hline No sinus rhythm & & & + \\
\hline No-patent-IMA-graft & + & + & + \\
\hline Acute-emergency & + & + & + \\
\hline Valve disease & & + & + \\
\hline ECC-time & + & + & + \\
\hline Antegrade Cardioplegia & + & & \\
\hline $\begin{array}{l}\text { Perioperative myocardial } \\
\text { infarction }\end{array}$ & + & + & + \\
\hline Time period ' $87-' 92$ & + & & \\
\hline \multicolumn{4}{|c|}{ MULTIVARIANT ANALYSIS } \\
\hline Age $>69$ years & & & + \\
\hline Diabetes & & + & + \\
\hline Vascular disease & & & + \\
\hline Lung disease & & + & + \\
\hline Between MI & + & & + \\
\hline No-IMA-graft & & & + \\
\hline Acute operation & & & + \\
\hline Emergency operation & + & + & + \\
\hline ECC time & + & & + \\
\hline Perioperative MI & + & + & + \\
\hline Time period '87-'92 & + & & + \\
\hline
\end{tabular}

$\mathrm{ECC}=$ extracoporal circulation; IMA = internal mammary artery; MI=myocardial infarction.

Vascular disease, as a mirror of the extent of atherosclerosis for the patient, myocardial infarction and subsequent myocardial infarction after the first $\mathrm{CABG}$, as well as the influence of ventricular function, are all important predictors of hospital mortality. The presence of a 
patent IMA graft has been shown to decrease the mortality and morbidity of redo surgery [8, 13, 14]. The importance of a patent IMA graft is further illustrated by reports that show that an injury to a patent IMA graft increases mortality [13]. The importance of retrograde cardioplegia is well known [6], and it seems logical that the influence of operative myocardial protection is reflected in the hospital mortality. The effect of a prolonged period of cardiopulmonary bypass $\ell 120$ minutes) may be relative; a technically difficult operation often leads to a longer pump time. Patients with difficulty in coming off of bypass may also have a longer pump time. Thus, the influence of prolonged extracorporeal circulation time may be related to other factors that increase extracorporeal circulation time and not the time per se. The fact that patients operated on before $1992 \mathrm{had}$ an increased risk is likely due to improved myocardial protection and retrograde cardioplegia, as well as more experience with redo operations by our group. The influence of an emergency operation, and the presence of a perioperative myocardial infarction are both important risks, and have been confirmed by several others [1-7]. This report, however, also demonstrates that the influence is not only on hospital mortality, but also for the early six-month mortality (emergency/acute operations, perioperative myocardial infarction) and is balanced over the whole first six months (early post-discharge mortality for emergency procedures and perioperative myocardial infarction). In coronary artery bypass graft surgery, unstable angina is an incremental risk factor for death during the early hazard phase [11]. No-IMA grafts have a balanced influence, however, of lesser importance. The influence of initial myocardial infarction and perioperative myocardial infarction between operations, cardiopulmonary bypass time $(\geq 120$ minutes, on the six-month mortality seems to be a consequence of their importance on the hospital mortality. On the other hand, the influence of vascular disease, mild valvular heart disease, on the six-month mortality is related to the early perioperative mortality. Diabetes, hypertension, renal insufficiency, and pulmonary disease are indicated as risk factors for sixmonth mortality, but their influence is mainly in the early discharge perioperative mortality. The way of delivery of cardioplegia, and the time the operation was performed does not seem to be related to the six-month mortality. The absence of sinus rhythm, however, is a significant risk factor for the six-month mortality, but not for the hospital mortality, and for early discharge perioperative mortality; however, there is a trend toward significance. The limited number of patients without sinus rhythm undergoing a redo operation $(6 \%)$ is probably a reason that significance is not reached in the outpatient perioperative mortality. 


\section{Multivariant analysis}

Multivariant analysis identified age $>69$ years, diabetes, peripheral vascular disease, pulmonary disease, myocardial infarction between operations, No-IMA grafts, time period 1987 to 1992 , emergency operations, cardiopulmonary bypass time $\geq 120$ minutes, and perioperative myocardial infarction as independent risk factors for early six-month mortality. As in the univariant analysis, there are differences in these factors during the first six months following surgery (Tables 2 and 3). Age $>69$ years, peripheral vascular disease, No-IMA grafts, and emergency surgery were all significant predictors for six-month mortality, with a spread risk over the whole time period. Diabetes and pulmonary disease, however, were important in the early outpatient perioperative period, and did not appear to influence mortality in the immediate postoperative period. Acute myocardial infarction between operations, the time period 1987 to 1992, and the ECC time influenced the inpatient mortality. The same factors that may have affected the prolonged extracorporeal circulation time that were discussed in the univariant analysis also apply to the multivariant analysis as well. Emergency operations and a perioperative myocardial infarction are, however, the strongest independent risk factors for early mortality for both the hospital and the outpatient perioperative mortality. It seems strange that the way of delivery of cardioplegia is not identified as an independent predictor of hospital mortality. This is of interest because of the time period 1987 to 1992 was significant. The use of retrograde cardioplegia has increased since 1992 and since 1993, cardioplegia is delivered in a retrograde fashion predominantly. Since the time period 1987 to 1992 appears to be an independent predictor for early six-month mortality, especially for hospital mortality, means that factors not incorporated in this risk analysis, related to the time cohort, are important. Growing surgical experiences in period 1993 to 1998 may be part of the explanation. Most of the redoCABG's were performed by one surgeon (LN), the changing profile of the patient population [15], and completeness of revascularization are all possible variables. Another possibility is that retrograde delivery of cardioplegia alters the occurrence of a perioperative myocardial infarction, which is an independent predictor of hospital outpatient perioperative and six-month mortality. Renal disease, identified in several reports as an independent predictor [4, 5], was not identified as an independent risk factor in our analysis. However, renal disease has an odds ratio of 2.8 for early mortality, indicating a higher risk for these patients. That we did not reach statistical significance is probably related to the limited number of patients with renal disease $(6.6 \%)$ in our series. 
The aim of this study was to identify risk factors for early six-month mortality. Therefore, statistical analysis in this study is limited to a univariant and multivariant analysis. The finding that different variables, or the same variables, have a different importance at different times as a risk factor for early six-month mortality is the conclusion of the study. At the same time there is also the confirmation of the mortality rates when the early outpatient perioperative mortality is superimposed on the hospital mortality. This fact may be helpful in counselling surgeons and patients about the true risk of redo coronary bypass surgery, and eventually allow the construction of models that may allow for a reduction of mortality. These models, however, would be limited to preoperative variables and will not likely include perioperative ones, such as cardiopulmonary bypass times, or completeness of revascularization during the reoperations [10].

In conclusion, the present study emphasizes that early mortality after a redo coronary artery surgery is influenced by several variables at different times. Insight into this timerelated influence of variables associated with an increased risk may explain the different results of risk analysis in several reports and help point out factors that contribute to death soon after surgery, and death that occurs after hospital discharge. Emergency operation and the occurrence of a perioperative myocardial infarction, however, are the crucial independent risk factors for early mortality after redo surgery.

\footnotetext{
*Johannes AM van Druten, Ph.D., Department of Medical Informatics, Epidemiology and Statistics, University of Nijmegen, for the statistical analysis.

**Dr. Eric N. Robertson, Anesthesiologis t, is thanked for his correction of the English text.

***The authors thank Dr. Follette for language editing this manuscript
}

\section{References}

1. He G-W, Acuff TE, He Y-H, Ryan WH, Mack MJ. Determinants of operative mortality in reoperative coronary bypass grafting. J Thorac Cardiovasc Surg 1995; 110: 971-8.

2. Yau TM, Borger MA, Weisel RD, Ivanov $J$, The changing pattern of reoperative coronary surgery: trends in 1230 consecutive reoperations. J Thorac Cardiovasc Surg 200; 120: 156-63. 
3. Weintraub WS, Jones EL, Craver JM, Grosswald R, Guyton RA. In-hospital and longterm outcome after reoperative coronary artery bypass graft surgery. Circulation 1995; 92 [suppl II]:II-50-7.

4. Christenson JT, Schmuziger M, Simonet F. Reoperative coronary artery bypass procedures : risk factors for early mortality and late survivial. Eur J Cardiothoracic Surg 1997; 11: 129-33.

5. Yamamuro M, Lytle BW, Sapp SK, Cosgrove DM, Loop FD, McCarthy PM. Risk factors and outcomes after coronary reoperation in 739 elderly patients. Ann Thorac Surg 2000; 69: 464-74.

6. Borger MA, Rao V, Weisel RD, Floh A, Cohen G, Feindel CM, Scully HE, Mickleborough LL, Yau TM. Reoperative coronary bypass surgery: effect of patent grafts and retrograde cardioplegia. J Thorac Cardiovasc Surg 2001; 121: 83-90.

7. Noyez L, Skotnicki SH, Lacquet LK. Morbidity and mortality in 200 consecutive coronary reoperations. Eur J Cardiothoracic Surg 1997; 11: 528-32.

8. Noyez L, Eck van FM, Skotnicki SH, Brouwer RMHJ. Coronary reoperations in patients with a patent internal mammary artery graft. Cardiovascular Surgery, 2001; 9: 179-83.

9. Blackstone EH. Outcome analysis using hazard function methodology. Ann Thorac Surg, 61, 1996,(2 Suppl):S2-7.

10. Eck van FM, Noyez L, Verheugt FWA, Brouwer RMHJ. Preoperative prediction of early mortality in redocoronary artery surgery. Eur J Cardiothoracic Surg 2002; 21: 1031-36.

11. Sergeant P. Blackstone E, Meyns B. Validaton and interpendence with patient-variables of the influence of procedural variables on early and late survival after CABG. Eur J Cardiothoracic Surg 1997, 12; 1-19.

12. Osswald BR, Blackstone EH, Tochtermann, Thomas G, Vahl CF, Hagl S. The meaning of early mortality after CABG. Eur J Cardiothoracic Surg 1999, 15; 401-7.

13. Gillinov AM, Casselman FP, Lytle BW, Blackstone EH, Parson EM, Loop FD, Cosgrove DM. Injury to a patent left internal thoracic artery graft at coronary reoperation. Ann Thorac Surg 1999; 67: 382-6.

14. Lyttle BW, McElroy D, McCarthy P, Loop FD, Goormastic M, Stewart RW, Cosgrove DM. Influence of arterial coronary bypass grafts on the mortality in coronary reoperations. J Thorac Cardiovasc Surg 1994, 107; 675-83.

15. Eck van FM, Noyez L, Verheugt FWA, Brouwer RMHJ. Changing profile of patients undergoing redo-coronary artery surgery. Eur J Cardiothoracic Surg 2002, 21; 205-11. 


\section{CHAPTER V}

\section{PREOPERATIVE PREDICTION OF EARLY MORTALITY IN REDOCORONARY ARTERY SURGERY.}

Frans M. van Eck, Luc Noyez, Freek W.A. Verheugt, Rene M.H.J. Brouwer.

European Journal of Cardio-thoracic Surgery 2002; 21: 1031-1036. 


\section{Abstract}

Objective: Construct a predictive model for early mortality in coronary reoperations (RECABG).

Methods: Five hundred and forty one RECABG (1987-1998) were studied by univariate and multivariate analysis. Stepwise selective procedure $(p<0.05)$ was used to identify a subset of variables with prognostic value for early mortality. This subset was used to calculate a prognostic score ' $\mathrm{S}$ ' and a predicted probability ' $\mathrm{P}$ ' for early mortality, $\mathrm{P}=1 / 1+\mathrm{e}^{-\mathrm{S}}$. Sensitivity analysis was used for evaluation.

Results: The best predictive variables for early mortality were diabetes, vascular-, lungdisease, a myocardial infarction between the primary and the RECABG, acute- and emergency operation, and the operative period. The prognostic accuracy (ROC area) was $80 \%$. Observed probabilities compare well with the predicted probabilities, and patients were classified in low risk (5\%), intermediate risk (15\%), high risk (30\%) and very high risk (40\%). A predicted probability of $\geq 0.40$ was used as cut-off point for the prognostic test. The specificity of this test was $97 \%$, sensitivity $33 \%$, predictive value of a positive test $63 \%$, and $90 \%$ for a negative test.

Conclusion: The results show that individual patients presented for RECABG, can be stratified according to their early mortality risk. This information can be used, to inform the patient, but also to discus the opportunity of the RECABG.

\section{Key words}

Reoperation, Early mortality, Prediction, Myocardial revascularization 


\section{Introduction}

Mortality of coronary reoperations (RECABG) is still higher than in primary myocardial revascularization [1-6]. As in all surgical procedures, to improve the results, progress has to be made in the preoperative, perioperative and postoperative phase. A better, evidence based, patient selection can be a first step in the improvement of the results of RECABG. The intention of this study is to construct a predictive model of early mortality of RECABG, using preoperative variables. In the study, early mortality is the end-point. Early mortality, 6 months postoperative, is related to patient-variables and the surgical procedure [7], and is therefore a more honourable endpoint than surgical-, hospital- or 30-day-mortality, which are used as endpoint in most other reports.

\section{Material and Methods}

\subsection{Patients}

With the aid of our database, Coronary Surgery Database Radboud Hospital (CORRAD), a registry that stores pre-, peri-, postoperative and follow-up data on all patients undergoing isolated coronary bypass grafting, we identified a series of 541 patients undergoing a first coronary reoperation (RECABG) from January 1987 to December 1998 at the UMC St.Radboud Nijmegen. Only patients with an isolated myocardial revascularization at the primary operation were included in this study.

The studied variables and their definition are presented in table 1.

\subsection{Surgical technique}

Our surgical technique is described in previous papers [5,6]. The mean bypass time was $140 \pm 60.8$ minutes (range 25-485), and the mean duration of aortic cross-clamping was $70 \pm 33.6$ minutes (range 10-227). There was a mean of $2.4 \pm 0.8$ grafts (range 1-5), and a mean of $3.2 \pm 1.2$ (range 1-7) distal anastomoses. Of the used grafts $1.0 \pm 0.6$ (range 1-2) were arterial grafts with $1.2 \pm 0.9$ (range 1-5) distal anastomoses and 428 patients (79.1\%) received at least one new arterial graft. 
Table 1. Unifactor risk analysis for early mortality

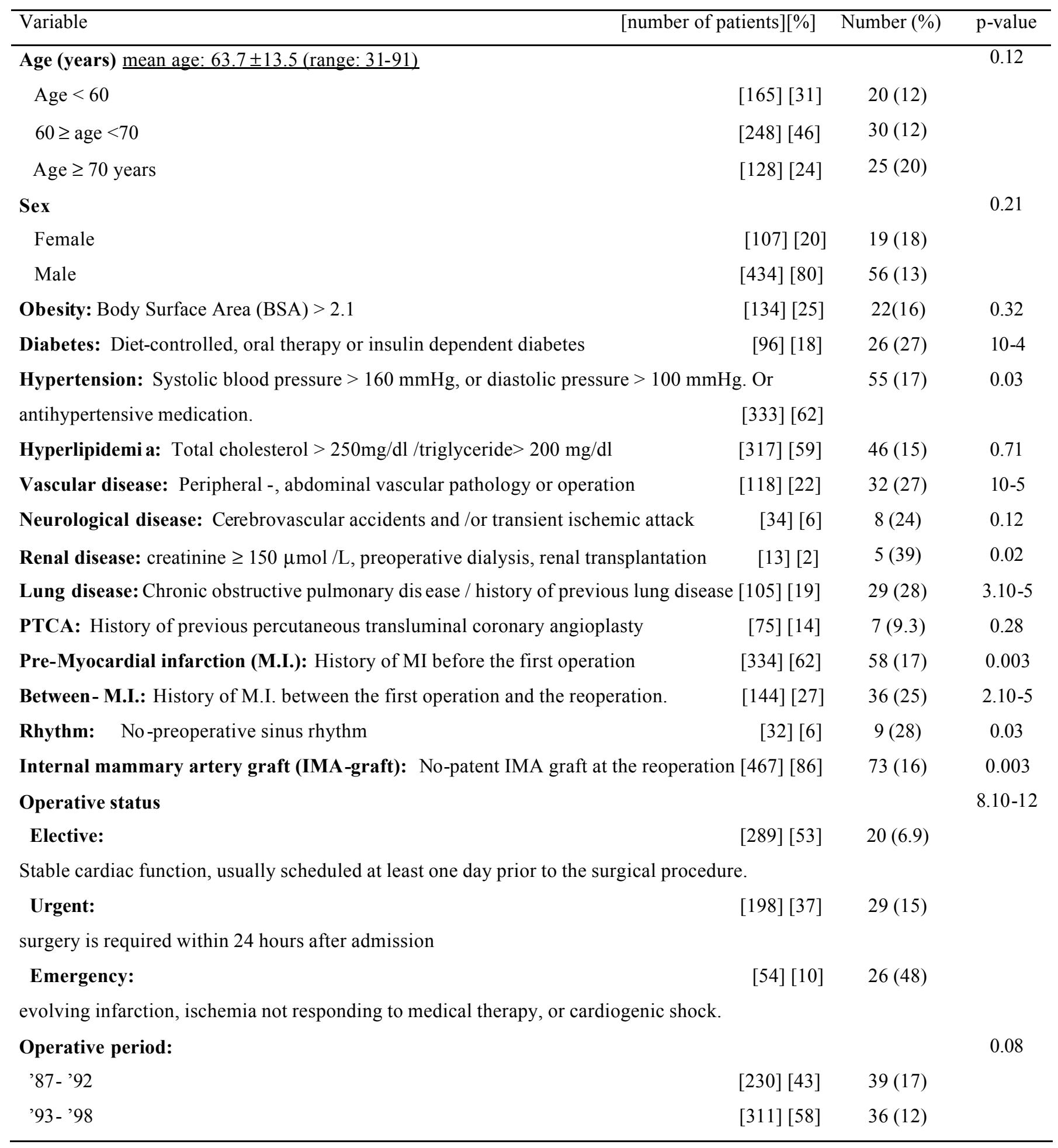

\subsection{Statistical analysis}

To test which variables can be considered risk factors for early mortality, Fisher's exact test (unifactor analysis) was used. Multiple logistic regression analysis was used to identify risk factors that independently contributed to increased or decreased risk. The odds ratio's derived from the parameter estimates in the logistic regression analysis can be 
considered estimates of relative mortality risk. To identify a subset of variables with prognostic value for early mortality a stepwise selective procedure was used at a significance level $\mathrm{p} \leq 0.05$ (significant level for entry respectively stay into the prognostic model). A receiver operating characteristics curve (ROC) was calculated to measure the prognostic value of this subset. This subset was then used to calculated a prognostic score ' $\mathrm{S}$ ' and a predicted probability ' $\mathrm{P}$ ' for early mortality. The prognostic score ' $\mathrm{S}$ ' is a linear function of the variables included in the selected subset. If the variables are selected the ' $\mathrm{S}$ '-score is represented by $\mathrm{S}=\mathrm{b} 0+\mathrm{b} 1 \mathrm{X} 1+\mathrm{b} 2 \times 2+\ldots . . \mathrm{bhxh}$. The predicted probability $(\mathrm{P})$ for early mortality is calculated by $\mathrm{P}=1 / 1+\mathrm{e}^{-\mathrm{s}}$. Sensitivity analysis, $(2 \times 2$ table) was used for evaluating the effect of the initial estimate on the final decision.

\section{Results}

The a priori (average) risk for early mortality is 75/541 (13.9\%). Myocardial infarction was the direct cause of death in 25 patients, and in five patients the cause of death was not clear (Table2).

Table 2. Causes of 75 early deaths .

\begin{tabular}{ccc}
\hline Cause & $\mathrm{N}=75$ & $\%$ \\
\hline Myocardial infarction & 25 & 33 \\
Low cardiac output & 21 & 28 \\
Arrhythmia & 10 & 14 \\
Respiratory & 3 & 4 \\
Sepsis & 3 & 4 \\
Stroke & 4 & 5 \\
Heart failure & 4 & 5 \\
Unknown & 5 & 7 \\
\hline
\end{tabular}

Results of the unifactor risk analysis are presented in table 1. Risk factors for early mortality are: diabetes $(p=10-4)$, hypertension $(p=0.03)$, vascular disease $(p=10-5)$, renal disease $(p=0.02)$, lung disease $(p=3.10-5)$, pre-myocardial infarction $(p=0.003)$, between-myocardial infarction $(p=2.10-5)$, no-sinus rhythm $(p=0.03)$, no patent IMA graft $(p=0.003)$ and Noelective operation ( $\mathrm{p}=8.10-12)$. If the latter risk factor is present then the risk of early mortality amount to $48 \%$. Multifactor risk analysis (table 3 ) Identified the operative period, diabetes, lung disease, between-myocardial infarction, acute-, and emergency operation, as 
Table 3. Multifactor risk analysis, logistic regression analysis, for early mortality

\begin{tabular}{lll}
\hline & $\mathrm{N}=75$ (13.9) \\
\hline Preoperative variable & Odds Ratio & P-value \\
Age $<60$ years & 0.87 & 0.69 \\
Age $>$ 69 years & 1.6 & 0.22 \\
Sex (female/male) & 0.76 & 0.44 \\
Obesity (yes/no) & 1.1 & 0.83 \\
Diabetes (yes/no) & 2.5 & 0.01 \\
Hypertension (yes/no) & 0.8 & 0.51 \\
Hyperlipidemia (yes/no) & 1.2 & 0.47 \\
Vascular disease(yes/no) & 1.7 & 0.11 \\
Neurological disease (yes/no) & 1.8 & 0.24 \\
Renal disease (yes/no) & 2.6 & 0.22 \\
Lung disease (yes/no) & 1.9 & 0.05 \\
PTCA (yes/no) & 0.70 & 0.47 \\
Previous M.I. (yes/no) & 1.3 & 0.44 \\
Between M.I. (yes/no) & 2.6 & 0.009 \\
Sinus rhythm (yes/no) & 1.0 & 0.99 \\
Patent-IMA-graft (yes/no) & 0.31 & 0.13 \\
Acute operation (versus elective) & 2.0 & 0.05 \\
Emergency operation (versus elective) & 10.9 & $1.10-4$ \\
Time period '87-'92/'93-'98 & 0.31 & $5.10-4$ \\
\hline
\end{tabular}

independent risk factors for early mortality. The odds ratio's (estimates of relative risk) are respectively: $0.31,2.5,1.9,2.6,2.0$ and 10.9 .

Using stepwise logistic regression analysis, the following variables were selected for prediction of early mortality: operative period, diabetes, vascular-, lung-disease, between myocardial infarction, acute and emergency operation. The associated regression coefficients (bi), odds ratio's, and p-values are presented in table 4.

Table 4. Stepwise logistic regression analysis. Variables selected for prediction of early mortality.

\begin{tabular}{llll}
\hline Preoperative variable & $\begin{array}{l}\text { Regression } \mathrm{b}_{\mathrm{i}} \\
\text { coefficient }( \pm \mathrm{SE})\end{array}$ & Odds Ratio & P-value \\
\hline Intercept & $-2.89(0.29)$ & & \\
Diabetes (yes/no) & $0.88(0.34)$ & 2.4 & 0.009 \\
Vascular disease(yes/no) & $0.69(0.320$ & 2.0 & 0.03 \\
Lung disease (yes/no) & $0.68(0.32)$ & 2.0 & 0.03 \\
Between M.I. (yes/no) & $1.07(0.30)$ & 2.9 & $3.10^{-4}$ \\
Acute operation (versus elective) & $0.69(0.33)$ & 2.0 & 0.03 \\
Emergency operation (versus elective) & $2.46(0.41)$ & 11.7 & $1.10^{-4}$ \\
Time period '87-'92/'93-'98 & $-1.17(0.31)$ & 0.31 & $1.10^{-4}$ \\
\hline
\end{tabular}

Note: area under the $\mathrm{ROC}=0.80$.

The ROC curve gave an area under the curve value of 0.80 . 
The $\mathrm{S}-$ score for an individual patient is calculated as follows: $\mathrm{S}=-2.89-1.17$ (time period) +0.88 (diabetes) +0.69 (vascular disease) +0.68 (lung disease) +1.07 (between myocardial infarction) +0.69 (acute operation) +2.46 (emergency operation)

Table 5. Distribution of the S-scores in group of patients with $(n=75)$ and without $(n=466)$ early mortality (s-score classified into discrete classes).

\begin{tabular}{lcccccccc}
\hline & \multicolumn{7}{c}{ S-score } \\
\cline { 2 - 9 } Group & -4 & -3 & -2 & -1 & 0 & 1 & 2 & \\
\hline No early mortality & $7(16)$ & $171(37)$ & $162(35)$ & $37(8)$ & $19(4)$ & $3(0.6)$ & $0(0)$ & 466 \\
Early mortality & $1(1)$ & $13(17)$ & $16(21)$ & $13(7)$ & $18(24)$ & $9(12)$ & $5(7)$ & 75 \\
\hline
\end{tabular}

Note: score -2 means $(-2.5)-(-1.5)$

Table 6. Distribution of predicted probabilities $(P)$ in group of patients with $(n=75)$ and without $(n=466)$ early mortality. Classes defined as: $0=0 \leq P<0.10 ; 1=0.10 \leq P<0.20 ; \ldots 8=0.80 \leq P<0.90$

\begin{tabular}{llllllllllll}
\hline & \multicolumn{10}{c}{ Predicted probability } \\
\cline { 2 - 12 } & 0 & 1 & 2 & 3 & 4 & 5 & 6 & 7 & 8 \\
\hline No early mortality & 294 & 115 & 25 & 17 & 4 & 7 & 3 & 1 & 0 & 466 \\
(\%) of the total (n=466) & $(63)$ & $(25)$ & $(5)$ & $(4)$ & $(0.9)$ & $(1.5)$ & $(0.6)$ & $(0.2)$ & & \\
Early mortality & 15 & 16 & 8 & 11 & 3 & 7 & 4 & 6 & 5 & 75 \\
$(\%)$ of the total (n=75) & $(20)$ & $(21)$ & $(11)$ & $(15)$ & $(4)$ & $(9)$ & $(5)$ & $(8)$ & $(7)$ \\
Observed mortality (\%) & 4.9 & 12 & 24 & 39 & 43 & 50 & 57 & 86 & 100 \\
\hline
\end{tabular}

The distribution of the S-scores and predicted probabilities P for early mortality in the group with $(\mathrm{n}=75)$ and without $(\mathrm{n}=466)$ early mortality is presented in table 5 and 6 .

The Scores are classified into the following classes: $-4(-4.5)-(-3.5) ;-3:(-3.5)-(-2.50) \ldots$ 2: $(1,5)-(2.5)$. For the probability, following classification is used: $0: 0 \leq \mathrm{P}<0.10 ; 1$ : $0.10 \leq \mathrm{P}<0.20 ; \ldots: 0.80 \leq \mathrm{P}<0.90$. The observed probabilities in these discrete classes compare well with the mid-points of the predicted probabilities (table 5b) (note the number of patients in the classes 4,5,6,7, 8 are very low).

We decide to classify patients in low risk, intermediate risk, high risk and very high risk patients (table 7). The a priori average risk of early mortality is $75 / 541(14 \%)$. Using the $\mathrm{S}$-score and the predicted probability $\mathrm{P}$, we classify patients in low risk (5\%), intermediate risk $(15 \%)$, high risk (30\%), and very high risk (40\%). The observed mortality in these risk groups compare well with the predicted $(4.9 \%, 12 \%, 31 \%, 63 \%)$. 
Table 7. Classification of patients in low risk, intermediate risk, high risk and very high risk patients.

\begin{tabular}{lccccl}
\hline & \multicolumn{5}{c}{ Risk category } \\
\cline { 2 - 6 } & Low & Intermediate & High & Very high & \\
\hline Predicted probability & $5 \%$ & $15 \%$ & $30 \%$ & $\geq 40 \%$ & \\
Class & $0 \leq \mathrm{P}<0.10$ & $0.10 \leq \mathrm{P}<0.20$ & $0.20 \leq \mathrm{P}<0.40$ & $\mathrm{p} \geq 0.40$ & \\
No early mortality & 294 & 115 & 42 & 15 & 466 \\
Early mortality & 15 & 16 & 19 & 25 & 75 \\
TOTAL (\%) & $309(4.9)$ & $131(12)$ & $61(31)$ & $40(63)$ & $541(14)$ \\
\hline
\end{tabular}

We use a predicted probability $\mathrm{P} \geq 0.40$ (risk category very high ) as a cut-off point for constructing a prognostic test for early mortality. The specificity of the test is high (0.97), but a low sensitivity (0.33). The predictive value of a positive respectively negative test are respectively 0.63 and 0.90 (Table 8 ).

Table $8.2 \times 2$ table for the evaluation of the early mortality prediction

\begin{tabular}{lccl}
\hline \multirow{2}{*}{ Early Mortality } & \multicolumn{2}{c}{ Prognostic test } \\
\cline { 2 - 3 } & $\mathrm{T}=0$ & $\mathrm{~T}=1$ \\
$\mathrm{P}<0.40$ & $\mathrm{P} \geq 0.40$ & \\
\hline No $(\mathrm{D}=0)$ & 451 & 15 & 466 \\
Yes $(\mathrm{D}=1)$ & 50 & 25 & 75 \\
& 501 & 40 & 541 \\
\hline
\end{tabular}

Sensitivity $: \mathrm{P}[\mathrm{T}=1 / \mathrm{D}=1]=25 / 75=0.33$

Specificity: $\mathrm{P}[\mathrm{T}=0 / \mathrm{D}=0]=451 / 466=0.99$

Predictive value of positive test: $\mathrm{P}[\mathrm{D}=1 / \mathrm{T}=1]=25 / 40=0.63$

Predictive value of negative test: $\mathrm{P}[\mathrm{D}=0 / \mathrm{T}=0\}=451 / 501=0.90$

\section{Discussion}

The intention of this study is to construct a predictive test to evaluate preoperatively the risk for early mortality of a patient presented for RECABG. A better selection of patients undergoing RECABG is a first step in order to minimize mortality and morbidity. We focussed our study on early mortality because this 6-months-mortality is related to patient variables and therefore a honourable endpoint to do a prediction of mortality risk of the 
operation [7]. In our previous study we analysed risk factors of early mortality in RECABG, and concluded that several pre-and peroperative variables were independent predictor of early mortality, with their there influence on different moments [8]. However in the present study we included only preoperative variables in the analysis, because we want to evaluate and inform the patient preoperatively about his risk.

Cardiovascular causes were the reason of early mortality in 64 patients. In five patients we could not verify the cause of death, cardiac or not cardiac related, these patients were noted as unknown cause of mortality.

Using stepwise logistic regression analysis, the operative period, diabetes, vascularand lung disease, between myocardial infarction, acute and emergency operation were identified as predictive for early mortality. Independently of forwards or backwards performed regression analysis these variables were selected. These variables were comparable with variables selected in other studies [1,3,4]. The positive influence of the time period '93'98 can be related to several factors, growing surgical experiences in redosurgery, changing profile of the patients, as discussed in our previous report [6]. The area under the ROC curve (0.80) indicates that good discrimination remains between yes or no early mortality.

By using these seven variables we created a risk score. We classified patients in low risk (5\%), intermediate risk (15\%), high risk (30\%) and very high risk (40\%) for early mortality. The observed mortality in these risk groups compare well with the predicted (table 7). The specificity of our test is high, as required for a prognostic test, but we have a low sensitivity. Still the test is useful to select patients with a very high risk on mortality. The predictive value of a positive respectively negative test are 0.63 and 0.90 (table 8) respectively. This means that if the test is negative, there is only $10 \%$ risk on early mortality on the other hand, if the test is positive, there is $63 \%$ risk that the patient will die during the first six months.

As for all other prediction-models [9,10], it must be clear, that such a model never predict the specific outcome of an individual patient. Each patient will die or survive. However, with a predictive model we can inform ourselves and the patients about the probability of the risk of mortality.

However, even more than in primary myocardial revascularization, the outcome in RECABG, is also related to perioperative variables. The importance of operative status and perioperative myocardial infraction as independent variables for mortality is documented in almost all studies concerning RECABG [1-6]. We included operative status as a preoperative variable in our predictive model, however, it is impossible to include a perioperative 
myocardial infarction as a preoperative variable in the predictive model. A perioperative myocardial infarction is related to several preoperative variables, such as diseased vein grafts, the native coronary system but also to a lot of operative variables. Route of delivery of cardioplegia, completeness of the revascualization, peroperative spreading of debris from vein grafts in distal coronary arteries, are operative variables related to the occurrence of a perioperative myocardial infarction. The impact of a perioperative myocardial infarction on the early mortality is however, important [1-4]. We must therefore realise that our prediction of likely risk of early mortality after RECABG, flatters the reality if a patient has a perioperative myocardial infarction. Furthermore this is a single institution experience, and several variables are not incorporated in the analysis. Ejection fraction, is not calculated for all patients, and therefore not incorporated in the analysis. However, by using the variables myocardial infarction and between infarction we try to have an idea about ventricular function. Other variables as lack of graft material, a calcified aorta, previous mediastinitis, are certainly variables increasing the operative risk

On the other hand, with our predictive model, we have an evidence-based instrument to identify preoperatively high risk patients for RECABG. This can influence our strategy on several points, the decision to operate or not, operative strategy, type of anaesthesia, postoperative care.

In conclusion; with our predictive model we can stratify patients presented for RECABG, according to their risk for early mortality. Based on this stratification we can not only inform the patient concerning the risk, but also discus the opportunity of the RECABG. At this point we can improve our results by making a better preoperative patient selection.

We thank Johannes M van Druten, PhD, department of Medical Informatics, Epidemiology and Statistics, University of Nijmegen, for the statistical analysis. 


\section{Appendix A. Example of the predictive model}

\section{Formula}

Calculation for the S-Score:

$$
\begin{aligned}
& \mathrm{S}=-2.89-1.17(\text { time period })+0.88(\text { diabetes })+0.69(\text { vascular disease })+0.68 \text { (lung } \\
& \text { disease })+1.07 \text { (between infarction) }+0.69(\text { acute operation })+2.46(\text { emergency }
\end{aligned}
$$
operation)

Calculation of the predicted probability:

$$
\mathrm{P}=1 / 1+\mathrm{e}^{-\mathrm{S}}
$$

\section{Case}

Patient: 73 years old male, insulin dependent diabetes, history of vascular disease, no lung disease, history of a myocardial infarction after the first operation.

First calculation if this patient is presented for an elective operation

Second calculation if this patient is presented is presented for an emergency operation

Elective operation:

$\mathrm{S}=-2.89-1.17(1)+0.88(1)+0.69(1)+0.68(0)+1.07(1)+0.69(0)+2.46(0)=-1.42$

$\mathrm{P}=1 / 1+\mathrm{e}^{-(-1.42)}=1 / 1+4.13=0.19$

Classification: intermediate risk category $(0.10 \leq \mathrm{P}<0.20)$, predicted probabilty $15 \%$

Emergency operation:

$\mathrm{S}=-2.89-1.17(1)+0.88(1)+0.69(1)+0.68(0)+1.07(1)+0.69(0)+2.46(1)=1.04$

$\mathrm{P}=1 / 1+\mathrm{e}^{-(1,04)}=1 / 1+2.8=0.73$

Classification: Very high risk category $(\mathrm{P}>0.40)$, predicted probalility $\geq 40 \%$

\section{References}

1. He G-W, Acuff TE, He Y-H, Ryan WH, Mack MJ. Determinants of operative mortality in reoperative coronary bypass grafting. J Thorac Cardiovasc Surg 1995; 110: 971-978.

2. Yau TM, Borger MA, Weisel RD, Ivanov $J$, The changing pattern of reoperative coronary surgery: trends in 1230 consecutive reoperations. J Thorac Cardiovasc Surg 2000; 120: 156-163. 
3. Weintraub WS, Jones EL, Craver JM, Grosswald R, Guyton RA. In-hospital and longterm outcome after reoperative coronary artery bypass graft surgery. Circulation 1995; 92[suppl II]:II-50-II-57.

4. Christenson JT, Schmuziger M, Simonet F. Reoperative coronary artery bypass procedures : risk factors for early mortality and late survivial. Eur J Cardiothoracic Surg 1997; 11: 129-133.

5. Noyez L, Skotnicki SH, Lacquet LK. Morbidity and mortality in 200 consecutive coronary reoperations. Eur J Cardiothoracic Surg 1997; 11: 528-532.

6. Eck van FM, Noyez L, Verheugt FWA, Brouwer RMHJ. Changing profile of patients undergoing redo-coronary artery surgery. Eur J Cardiothoracic Surg 2002; 21: 205-211.

7. Eck van FM, Noyez L, Verheugt FWA, Brouwer RMHJ. Analysis of mortality within the first six months after coronary reoperation. Ann Thorac Surg 2002; 74: 2106-2112.

8. Eck van FM, Noyez L, Verheugt FWA, Brouwer RMHJ. Preoperative prediction of early mortality in redocoronary artery surgery. Eur J Cardiothoracic Surg 2002; 21: 1031-1036.

9. Blackstone EH. Outcome analysis using hazard functional methodology. Ann Thorac Surg 1996; 61(2suppl) S2-7.

10. Borger MA, Rao V, Weisel RD, Floh AA, Cohen G, Feindel CM, Scully HE, Mickleborough LL, Yau TM. Reoperative coronary bypass surgery: effect of patent grafts and retrograde cardioplegia. J Thorac Cardiovasc Surg 2001; 121 :83-90. 


\title{
CHAPTER VI
}

\section{IDENTIFICATION OF PATIENTS AT RISK FOR EARLY OUT-OF-HOSPITAL MORTALITY AFTER REDOCORONARY ARTERY SURGERY.}

\author{
Frans M. van Eck, Luc Noyez, Freek W.A. Verheugt, Rene M.H.J. Brouwer
}

Netherlands Heart Journal 2003; 11: 394-400. 


\section{Abstract:}

Objective: Analyse risk factors and construct a predictive model for identification of risk patients for early out-of-hospital mortality after coronary reoperations(RECABG).

Methods: 505 patients, discharged from hospital after a RECABG (1987-1998) were studied by uni- and multivariate analysis. A Stepwise selective procedure $(\mathrm{P}<0.05)$ was used to identify a subset of variables with prognostic value for early out-of-hospital mortality. This subset was used to calculate a prognostic score ' $\mathrm{S}$ ' and a predicted probability ' $\mathrm{P}$ ' for early out-of-hospital mortality, $\mathrm{P}=1 / 1+\mathrm{e}^{-\mathrm{S}}$. Sensitivity analysis was used for evaluation.

Results: The best predictive variables for early out-of-hospital mortality were diabetes $(\mathrm{P}=$ 0.002), lung disease $(\mathrm{P}=0.05)$, emergency operation $(\mathrm{P}=0.0001)$ and a perioperative myocardial infarction $(\mathrm{P}=0.0001)$. Emergency operation $(\mathrm{P}=0.001)$ and ante/retrograde cardioplegia $(\mathrm{P}<0.0000)$ were independent predictors of a perioperative myocardial infarction. The prognostic accuracy (ROC area) was $86 \%$. Patients were classified in low risk $(5 \%)$, intermediate risk (15\%), high risk (30\%) and very high risk ( $\geq 40 \%)$. A predicted probability of $\geq 0$. 40 was used as cut-of point. The specificity of this test was $99 \%$, sensitivity $33 \%$, predictive value of a positive test $79 \%$, and $95 \%$ for a negative test.

Conclusion: The results show that patients discharged from hospital after RECABG, can be stratified according to their early out-of-hospital risk. A perioperative myocardial infarction is the major independent risk factor and can be affected by use of retrograde cardioplegia.

\section{Key words}

Coronary reoperation, mortality, out of hospital, prediction 


\section{Introduction}

Mortality of coronary reoperations (RECABG) is still higher than in primary myocardial revascularization. ${ }^{1-6}$ In our previous study we demonstrated that early mortality, six months postoperative, after redosurgery is influenced by several variables at different times. ${ }^{7}$ Based on this time-related insight we constructed a predictive model for this early mortality, on preoperative variables. ${ }^{8}$ The intention of this study, however, is to analyse and predict the early 'out-of-hospital' mortality, defined as mortality within the first six months postoperatively after discharge from the hospital. Because prediction of out-of-hospital mortality is only meaningful for patients surviving the operation, we use the term postoperative prediction. It must be clear that this study is complementary with our previous report, ${ }^{8}$ but different because this study analyse early mortality of the patients surviving the RECABG.

\section{Material and Methods}

\subsection{Patients}

With the aid of our database, Coronary Surgery Database Radboud Hospital (CORRAD), a registry that stores pre-, peri-, postoperative and follow-up data on all patients undergoing isolated coronary bypass grafting, we identified a series of 505 patients discharged from UMC St Radboud Nijmegen hospital after a first coronary reoperation (RECABG) from January 1987 to December 1998. Only patients with an isolated myocardial revascularization at the primary operation and at the RECABG were included in this study. During this period, 541 patients underwent a RECABG at the UMC St. Radboud Nijmegen hospital. $^{7}$ Our hospital mortality, including operative mortality and mortality at the university hospital during hospital stay at the UMC St. Radboud after the RECABG, is $36 / 541(6.7 \%$, 95\% CI 4.6-8.8). The early out-of-hospital mortality, is defined as al cardiac mortality in the first six postoperative months but after discharge from the UMC St Radboud. Our discharge policy is described in our previous report. ${ }^{7}$ It is, however, important to realize that none of the deaths occurring during the post-discharge period occurred after transfer to their cardiac centre and thus would not be considered a hospital death directly related to the operation. The studied variables and their definition were presented in table 1. 
Table 1 Variables and their definition

\begin{tabular}{|c|c|}
\hline Age (years) & 3 groups: age $<60,60 \geq$ age $<70$, age $\geq 70$ years \\
\hline Sex & Male, Female \\
\hline Obesity & Body Surface Area (BSA) $>2.1$ \\
\hline Diabetes & Diet-controlled, oral therapy or insulin dependent diabetes \\
\hline Hypertension & $\begin{array}{l}\text { Systolic blood pressure }>160 \mathrm{mmHg} \text {, or diastolic pressure }>100 \mathrm{mmHg} \text {. } \\
\text { Or antihypertensive medication. }\end{array}$ \\
\hline Hyperlipidemia & Total cholesterol $>250 \mathrm{mg} / \mathrm{dl}$ or triglyceride level $200 \mathrm{mg} / \mathrm{dl}$ \\
\hline Vascular disease & Peripheral -, abdominal vascular pathology or operation \\
\hline Neurological disease & Cerebrovascular accidents and /or transient ischemic attack \\
\hline Renal disease & $\begin{array}{l}\text { Renal failure (creatinine } \geq 150 \mu \mathrm{mol} / \mathrm{L} \text { ) preoperative dialysis, renal } \\
\text { transplantation }\end{array}$ \\
\hline Lung disease & $\begin{array}{l}\text { Chronic obstructive pulmonary disease and/or history of previous lung } \\
\text { disease }\end{array}$ \\
\hline PTCA & History of previous percutaneous transluminal coronary angioplasty \\
\hline $\begin{array}{l}\text { Preoperative myocardial } \\
\text { infarction (MI) }\end{array}$ & History of myocardial infarction before the first operation \\
\hline $\begin{array}{l}\text { Between myocardial } \\
\text { infarction (MI) }\end{array}$ & $\begin{array}{l}\text { History of myocardial infarction between the first operation and the } \\
\text { reoperation. }\end{array}$ \\
\hline Rhythm & Preoperative sinus rhythm \\
\hline $\begin{array}{l}\text { Internal mammary artery } \\
\text { graft (IMA-graft) }\end{array}$ & Patent IMA graft at the reoperation \\
\hline Operative status & $\begin{array}{l}3 \text { groups: Elective: patients with stable cardiac function, usually } \\
\text { scheduled at least one day prior to the surgical procedure. Urgent: } \\
\text { surgery is required within } 24 \text { hours after admission, Emergency: } \\
\text { operation for evolving infarction, ischemia not responding to medical } \\
\text { therapy, or cardiogenic shock. }\end{array}$ \\
\hline Mild valve pathology & Combined valve disease, not requiring surgical intervention \\
\hline ECC & ECC: extra corporal circulation, duration in minutes \\
\hline AoX & AoX; aortic cross clamp, duration in minutes \\
\hline $\begin{array}{l}\text { Perioperative myocardial } \\
\text { infarction (peri-MI) }\end{array}$ & A new $\mathrm{Q}$ wave and a CPK-MB $\% \geq 10 \%$ \\
\hline
\end{tabular}

\subsection{Surgical technique}

Our surgical technique is described in previous papers. ${ }^{5-8}$ Mean bypass time was $140 \pm$ 60.8 minutes (range 25-485), and mean duration of aortic cross-clamping was $70 \pm 33.6$ minutes (range 10-227). There was a mean of $2.4 \pm 0.8$ grafts (range 1-5), and a mean of $3.2 \pm$ 1.2 (range 1-7) distal anastomoses. Of the used grafts $1.0 \pm 0.6$ (range 1-2) were arterial 
grafts with $1.2 \pm 0.9$ (range 1-5) distal anastomoses and 428 patients (79.1\%) received at least one new arterial graft. It is important is to realize that since 1993, cardioplegia has mostly been delivered using retrograde techniques in RECABG.

\subsection{Statistical analysis}

The statistical method is the same as in our previous study. ${ }^{8}$ To test which variables can be considered risk factors for early out-of-hospital mortality, but also for the operative related risk factors, Fisher's exact test (unifactor analysis) was used. Multiple logistic regression analysis was used to identify risk factors that independently contributed to increased or decreased risk. A $p$-value of $p \leq 0.05$ was considered as significant.

To construct a predictive model for early out-of-hospital mortality, the odds ratio's derived from the parameter estimates in the logistic regression analysis were considered estimates of relative mortality risk. To identify a subset of variables with prognostic value for early out-of-hospital mortality a stepwise selective procedure was used at a significance level $\mathrm{p} \leq 0.05$ (significant level for entry respectively stay into the prognostic model). A receiver operating characteristics curve (ROC) was calculated to measure the prognostic value of this subset. This subset was then used to calculated a prognostic score ' $S$ ' and a predicted probability ' $\mathrm{P}$ ' for early out-of-hospital mortality. The prognostic score ' $\mathrm{S}$ ' is a linear function of the variables included in the selected subset. If the variables are selected the ' $S$ 'score is represented by $\mathrm{S}=\mathrm{b} 0+\mathrm{b} 1 \mathrm{X} 1+\mathrm{b} 2 \times 2+\ldots . . \mathrm{bhxh}$. The predicted probability $(\mathrm{P})$ for early out-of-hospital mortality is calculated by $\mathrm{P}=1 / 1+\mathrm{e}^{-\mathrm{s}}$. Sensitivity analysis, $(2 \times 2$ table) was used for evaluating the effect of the initial estimate on the final decision.

\subsection{Perioperative myocardial infarction}

Because of the importance of the variable perioperative myocardial infarction for the early out-of-hospital mortality we performed an uni- and multivariate analysis to identify independent variables for a perioperative myocardial infarction. The total group of 541 patients was used for this analysis. 
Table 2. Unifactor analysis of pre - and perioperative variables.

(Only statistical significant variables were presented)

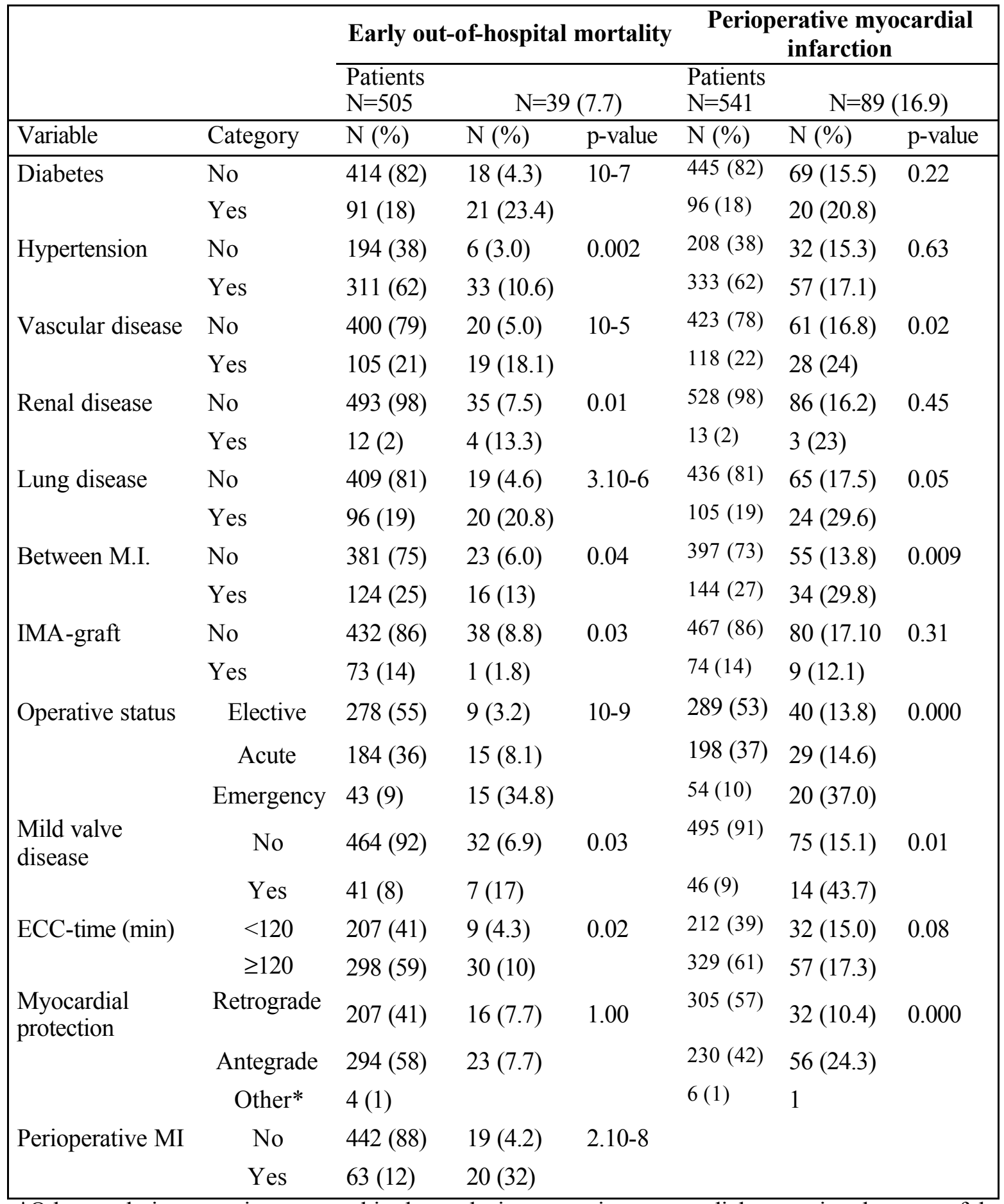

*Other technique, not incorporated in the analysis concerning myocardial protection, because of the limited number of patients.

ECC: extra corporal circulation, MI: myocardial infarction 


\section{Results}

\subsection{Early out-of-hospital mortality}

Early out-of-hospital mortality is $7.7 \%$ (39/505 patients). In 34 patients mortality was cardiovascular related, in five patients the cause of death is noted as uncertain. ${ }^{8}$ Table 2 presents the statistical significant variables of the unifactor risk analysis. Risk factors for early out-of-hospital mortality are: diabetes $\left(\mathrm{p}=10^{-7}\right)$, hypertension $(\mathrm{p}=0.002)$, vascular disease $\left(p=10^{-5}\right)$, renal disease $(p=0.01)$, lung disease $\left(p=3.10^{-6}\right)$, between-myocardial infarction ( $\mathrm{p}=0.02)$, no patent IMA graft $(\mathrm{p}=0.03)$, No-elective operation $\left(\mathrm{p}=10^{-9}\right)$, mild valve disease $(\mathrm{p}=0.03)$, ECC-time $\geq 120$ minute $(\mathrm{p}=0.02)$ and a perioperative myocardial infarction $2.10^{-8}$. Multifactor risk analysis (table 3) identified, in order of importance, perioperative myocardial infarction $(p=0.0001)$, emergency operation $(p=0.0001)$, diabetes $(p=0.002)$, and lung disease $(p=0.05)$ as independent risk factors for early out-of-hospital mortality. The odds ratio's (estimates of relative risk) are 15.6,15.4,5.1 and 2.8. respectively.

Table 3. Multifactor risk analysis, logistic regression analysis, for early out-of-hospital mortality

\begin{tabular}{|lll|}
\hline & $\mathrm{N}=39$ (7,7) \\
Preoperative variable & Odds Ratio & p-value \\
\hline Age $<60$ years & 0.76 & 0.65 \\
Age $\geq 70$ years & 1.3 & 0.70 \\
Sex (female/male) & 0.59 & 0.31 \\
Obesity (yes/no) & 0.70 & 0.54 \\
Diabetes (yes/no) & 5.1 & 0.002 \\
Hypertension (yes/no) & 0.97 & 0.96 \\
Hyperlipidemia (yes/no) & 0.9 & 0.81 \\
Vascular disease(yes/no) & 1.4 & 0.50 \\
Neurological disease (yes/no) & 1.9 & 0.36 \\
Renal disease (yes/no) & 1.9 & 0.52 \\
Lung disease (yes/no) & 2.8 & 0.05 \\
PTCA (yes/no) & 0.89 & 0.85 \\
Previous M.I. (yes/no) & 1.5 & 0.43 \\
Between M.I. (yes/no) & 1.7 & 0.34 \\
Sinus rhythm (yes/no) & 2.9 & 0.19 \\
Patent-IMA-graft (yes/no) & 0.18 & 0.13 \\
Acute operation (versus elective) & 2.1 & 0.17 \\
Emergency operation (versus elective) & 15.4 & 0.0001 \\
Time period '87-'92 /'93-'98 & 0.65 & 0.46 \\
Mild valve disease & 0.62 & 0.56 \\
ECC-time $\geq 120$ minutes & 2.4 & 0.12 \\
Aox-time $\geq 60$ minutes & 0.4 & 0.06 \\
Perioperative myocardial infarction & 15.6 & 0.0001 \\
\hline
\end{tabular}




\subsection{Prediction of early out-of-hospital mortality}

Using stepwise logistic regression analysis, the following variables were selected for prediction of early out-of-mortality: diabetes, lung-disease, emergency operation, and perioperative myocardial infarction. The associated regression coefficients (bi), odds ratio's, and p-values are presented in table 4.

Table 4. Stepwise logistic regression analysis.

Variables selected for prediction of early out-of-hospital mortality.

\begin{tabular}{|llll|}
\hline Preoperative variable & $\begin{array}{l}\text { Regression } \mathrm{b}_{\mathrm{i}} \\
\text { coefficient }( \pm \mathrm{SE})\end{array}$ & Odds Ratio & $\mathrm{p}$-value \\
\hline Intercept & $-4.43(0.39)$ & & \\
Diabetes (yes/no) & $1.54(0.43)$ & 4.7 & $3.10-4$ \\
Lung disease(yes/no) & $1.28(0.43)$ & 3.6 & 0.003 \\
Emergency operation (versus elective) & $2.28(0.48)$ & 9.8 & $1.10^{-4}$ \\
Myocardial infarction & $2.45(0.44)$ & 11.6 & $1.10^{-4}$ \\
\hline
\end{tabular}

Note: area under the $\mathrm{ROC}=0.86$.

The ROC curve gave an area under the curve value of 0.86 . The $\mathrm{S}-$ score for an individual patient is calculated as follows: $\mathrm{S}=-4.43+1.54$ (diabetes) +1.28 (lung disease) +2.28 (emergency operation) +2.45 (perioperative myocardial infarction)

The distribution of the S-scores and predicted probabilities $\mathrm{P}$ for early mortality in the group with $(n=39)$ and without $(n=466)$ early out-of-hospital mortality is presented in table $5 \mathrm{a}$ and $5 \mathrm{~b}$.

Table 5a. Distribution of the S-scores in group of patients with $(n=39)$ and without $(n=466)$ early out-of-hospital mortality (s-score classified into discrete classes).

\begin{tabular}{|llllllllll|}
\hline & \multicolumn{10}{|c|}{ S-score } \\
\hline Group & -4 & -3 & -2 & -1 & 0 & 1 & 2 & 3 \\
\hline No early out-hospital mortality & 285 & 96 & 67 & 9 & 6 & 3 & 0 & 0 & 466 \\
$\%$ & $(61)$ & $(21)$ & $(14)$ & $(1.9)$ & $(1.3)$ & $(0.6)$ & $(0)$ & & \\
Early out-hospital mortality & 5 & 3 & 10 & 5 & 3 & 7 & 2 & 4 & 39 \\
$\%$ & $(13)$ & $(8)$ & $(26)$ & $(13)$ & $(7.7)$ & $(18)$ & $(5.1)$ & $(10)$ & \\
\hline
\end{tabular}

Note: score -2 means $(-2.5)-(-1.5)$

The Scores are classified into the following classes: $-4(-4.5)-(-3.5) ;-3:(-3.5)-(-2.50) \ldots$ 3: $(2,5)-(3.5)$. For the probability, following classification is used: $0: 0 \leq \mathrm{P}<0.10 ; 1$ : 
$0.10 \leq \mathrm{P}<0.20 ; \ldots: 0.90 \leq \mathrm{P}<1.00$. The observed probabilities in these discrete classes compare well with the mid-points of the predicted probabilities (table $5 b$ )

Table 5 b. Distribution of predicted probabilities $(P)$ in group of patients with $(n=39)$ and without ( $(n=466)$ early out-of-hospital mortality. Classes defined as: $0=0 \leq P<0.10 ; 1=$ $0.10 \leq \mathrm{P}<0.20 ; \ldots 8=0.80 \leq \mathrm{P}<0.90$

\begin{tabular}{|lllllllllllll|}
\hline & \multicolumn{10}{c|}{ Predicted probability } \\
\cline { 2 - 7 } & 0 & 1 & 2 & 3 & 4 & 5 & 6 & 7 & 8 & 9 \\
\hline No out-hospital mortality & 381 & 67 & 4 & 10 & 0 & 1 & 2 & 1 & 0 & 0 \\
$(\%)$ of the total (n=466) & $(82)$ & $(14)$ & $(0.9)$ & $(2.2)$ & & $(0.2)$ & $(0.4)$ & $(0.2)$ & & \\
Early out-hospital mortality & 8 & 10 & 1 & 5 & 0 & 2 & 2 & 5 & 2 & 4 \\
$(\%)$ of the total (n=39) & $(21)$ & $(26)$ & $(3)$ & $(13)$ & & $(5)$ & $(5)$ & $(13)$ & $(5)$ & $(10)$ \\
Observed out-hospital mortality & 2.1 & 13 & 20 & 33 & 0 & 67 & 50 & 83 & 100 & 100 \\
$(\%)$ & & & & & & & & & & \\
\hline
\end{tabular}

We decide to classify patients in low risk, intermediate risk, high risk and very high risk patients (table 6). The a priori average risk of early out-of-hospital mortality is 39/505 (7.7\%). Using the S-score and the predicted probability $\mathrm{P}$, we classify patients in low risk $(5 \%)$, intermediate risk $(15 \%)$, high risk (30\%), and very high risk $(40 \%)$. The observed mortality in these risk groups compare well with the predicted $(2.1 \%, 13 \%, 30 \%, 79 \%)$.

Table 6. Classification of patients in low risk, intermediate risk, high risk and very high risk patients.

\begin{tabular}{|lccccc|}
\hline & \multicolumn{5}{c|}{ Risk category } \\
\cline { 2 - 5 } & Low & Intermediate & High & Very high \\
\hline Predicted probability & $5 \%$ & $15 \%$ & $30 \%$ & $\geq 40 \%$ \\
\hline Class & $0 \leq \mathrm{P}<0.10$ & $0.10 \leq \mathrm{P}<0.20$ & $0.20 \leq \mathrm{P}<0.40$ & $\mathrm{p} \geq 0.40$ & \\
No out-hospital mortality & 381 & 67 & 14 & 4 & 466 \\
Early out-hospital mortality & $8(2.1 \%)$ & $10(13 \%)$ & $6(30 \%)$ & $15(79 \%)$ & 39 \\
TOTAL & 389 & 77 & 20 & 19 & 505 \\
\hline
\end{tabular}

We use a predicted probability $\mathrm{P} \geq 0.40$ (risk category very high ) as a cut-off point for constructing a prognostic test for early out-of-hospital mortality. The specificity of the test is high (0.99), but a low sensitivity ( 0.39 ). The predictive value of a positive respectively negative test are respectively 0.79 and 0.95 (Table 7). 
Table 7. $2 \times 2$ table for the evaluation of the early out-hospital mortality prediction

\begin{tabular}{|l|ccc|}
\hline & \multicolumn{3}{|c|}{ Prognostic test } \\
\hline Early Mortality & $\mathrm{T}=0$ & $\mathrm{~T}=1$ \\
& $\mathrm{P}<0.40$ & $\mathrm{P} \geq 0.40$ \\
\hline No $(\mathrm{D}=0)$ & 462 & 4 & 466 \\
Yes $(\mathrm{D}=1)$ & 24 & 15 & 39 \\
& 486 & 19 & 505 \\
\hline & \\
Sensitivity : $\mathrm{P}[\mathrm{T}=1 / \mathrm{D}=1]=15 / 39=0.39$ \\
Specificity: $\mathrm{P}[\mathrm{T}=0 / \mathrm{D}=0]=462 / 466=0.99$ \\
Predictive value of positive test: $\mathrm{P}[\mathrm{D}=1 / \mathrm{T}=1]=15 / 19=0.79$ \\
Predictive value of negative test: $\mathrm{P}[\mathrm{D}=0 / \mathrm{T}=0]=462 / 486=0.95$
\end{tabular}

\subsection{Perioperative myocardial infarction.}

Of the four identified independent predictors of early out-hospital mortality, only a perioperative myocardial infarction is a real influenceable surgical variable. Of the total group of 451 patients, 89 patients $(16 \%)$ had a perioperative myocardial infarction. Table 2 presents the results of the unifactor risk analysis. Vascular disease $(p=0.02)$, betweenmyocardial infarction $(p=0.009)$, emergency operation $(p=0.000)$, mild valve disease $(p=0.01)$ and myocardial protection method $(\mathrm{p}=0.000)$ are statistical significant risk factors for a perioperative myocardial infarction. Multivariate analysis identified emergency operation $(\mathrm{p}=0.001)$ with an Odds Ratio of 1.7 and myocardial protection $(\mathrm{p}=0.0000)$ with an Odds Ratio of 3.7 as independent factors for a perioperative myocardial infarction.

\section{Discussion}

The high mortality rates of RECABG, described in several studies, prove that RECABG remains high risk surgery. ${ }^{1-6}$ Estimation of the risk of these operations is essential not only for the decision as to whether or not to perform the RECABG or not, but also to inform the patient and family about their risk. Important is that based on the work of Blackstone we predict early- six months- mortality, because certainly in high risk patients, the postoperative phase is prolonged and influenced by patient- and procedural- related variables. ${ }^{9}$ In a previous study we discussed a predictive model for early mortality, constructed with preoperative variables. ${ }^{8} \mathrm{We}$ must realize that patients preoperatively 
informed about their risk for early mortality who survive the RECABG, are postoperatively interested in what is changed. But what is even more important for cardiologists, family doctors, and others concerned with these patients in the first months postoperatively, is to know which patients are at risk for mortality during these first months. Additionally we studied the risk factors of this out-of-hospital mortality, and especially a perioperative myocardial infarction, to see if we could decrease this out-of-hospital mortality.

The cause of death of our 39 out-of-hospital deaths was cardiovascular-related in 34 patients $(87 \%)$. In five patients the cause of death was registered as uncertain. This means that we could not trace, even after contacts with cardiologists, family doctor, and the patients family, whether the cause of death is cardiac or not cardiac related. However, we incorporated these five patients in our analysis, because a not-cardiac related death was not proven.

We studied a number of variables, but the list is of course not all-inclusive. Probably the most important variable not discussed is the ejection fraction. The influence of an impaired left ventricular function on the operative result of myocardial revascularization has been proven in several studies. ${ }^{1-6}$ However, in our studied population it was seldom registered preoperatively and therefore not included in the analysis. Left main stenosis and vessel disease, are not incorporated in the analysis, because in RECABG, these variables are difficult to define. What is the meaning of a kft main in a patient with a patent, or even, a diseased graft to the LAD, what is the meaning of three-vessel disease in patients with (diseased) grafts to several coronary arteries? Definition of completeness of revascularization in RECABG, is also a problem. Vessel indication can be difficult: for instance a decision not to replaced old patent, but (minimally?) diseased grafts, because the native coronary artery is in such a bad condition that problems can be expected. These are specific problems of RECABG, but related to the completeness of the revascularization. Other specific variables, not discussed, are, the degree of vein graft stenosis, the number of arterial and vein grafts.

\section{Early Out-of- hospital mortality}

Unifactor analysis identified diabetes, hypertension, lung-, vascular-, renal disease, between MI, No-patent IMA-graft, operative status, mild valve disease, ECC > 120 minutes, and a perioperative myocardial infarction as risk factors for early out-hospital mortality. Premyocardial infarction, no-sinus rhythm, risk factors for early mortality, ${ }^{8}$ were not identified as significant for early out of hospital mortality.

Using stepwise logistic regression analysis, diabetes, lung disease, emergency operation and a perioperative myocardial infarction were identified as independent risk factors 
predictive for early out-of- hospital mortality. The variables were discussed in our previous paper, ${ }^{7}$ there is only a minimal difference in statistical significance because in the present paper, we include only the 505 discharged patients in our analysis.

\section{Predictive model for early out-of-hospital mortality}

Independently of forwards or backwards performed regression analysis the variables, diabetes, lung disease, emergency operation and perioperative myocardial infarction, were selected. The area under the ROC curve (0.86) indicates that good discrimination remains between whether or not early out-of-hospital mortality occurs. In contrast to our predictive model for early mortality, ${ }^{8}$ where we had seven variables, we have only four variables here.

By using these four variables we created a risk score. We classified patients in low risk $(5 \%)$, intermediate risk $(15 \%)$, high risk $(30 \%)$ and very high risk $(40 \%)$ for early mortality. The observed mortality in these risk groups compares well with the predicted (table 6). The specificity of our test is high, as required for a prognostic test, but we have a low sensitivity. Still the test is useful for selecting patients with a very high risk on out-of-hospital mortality. The predictive value of a positive and negative test are respectively 0.79 and 0.95 , respectively (table 7). This means that if the test is negative, there is only $5 \%$ risk on early out-of-hospital mortality on the other hand, if the test is positive, there is $79 \%$ risk that the patient will die during the early out-of- hospital period.

It is important to realize that the specificity of our test is high for very high risk patients, however, this is of course a limited number of patients (15/39). A point of criticism can be that the majority of patients (24/39) were missed. However, the aim of a predictive model is to provide information for us and the patients about the probability of the risk of mortality and in the first place it is this information that is important. It is not the intention to predict the specific outcome of an individual patient, but it can be important to know if a patient has a low or very high risk for mortality in the first coming months. Another interesting point, is that most patients died of a cardiac related cause. This information is retrieved from families, doctors or cardiologists and registered as cardiac-, not cardiac-related, or unknown. More detailed information, can probably result in specific therapy, such as antiarrhythmic therapy if it is known that arrthythmias are responsible for many these cardiac deaths. But this needs further analysis, in a complex and limited patient population. 


\section{Perioperative myocardial infarction}

Of the four identified independent variables, a perioperative myocardial infarction is the only variable that can be influenced by surgery. We exclude emergency operation as an influenceble variable, because we can only take the decision to operate or not to operate an emergency patient and the variables lung-disease and diabetes are patient-characteristics. Unifactor analysis identified vascular disease, between MI, operative status, mild valve disease, and ante/retrograde delivery of cardioplegia as risk factors for a perioperative myocardial infarction. Multivariate analysis identified operative status (as well emergency and urgent operation) and ante/retrograde delivery of cardioplegia as independent factors for a perioperative myocardial infarction. The importance of retrograde delivery of cardioplegic solution in RECABG is wellknown. ${ }^{5-8,10}$ We realize that there are several benefits of retrograde delivery of cardioplegia: better distribution in the myocardium, also distal of arterial grafts, and a decrease in the risk of atheroembolism during manipulation. But we also realize that other factors, as incomplete revascularization, extent of coronary disease, are important and are not incorporated in our study. However, this means that retrograde delivery of cardioplegia, identified as a variable influencing hospital mortality, ${ }^{7}$ is also important for the reduction of out-of-hospital mortality of RECABG. Therefore we agree with Borger et al., ${ }^{10}$ and recommend the routine use of retrograde cardioplegia during RECABG.

This study and our previous analysis of early mortality, ${ }^{8}$ resulted in two predictive models: one preoperatively helpful in decision-making as to whether or not to reoperate, the present, useful for identifying patients at risk for out-of hospital mortality. These two predictive models, provide informations for patients, their families and doctors in two completely different situations.

In conclusion; in this study we identified independent predictors of early out-ofhospital mortality and with our predictive model we can stratify patients surviving the RECABG, according to their risk for early out-of-hospital mortality. To decrease this out-ofhospital mortality we recommend the use of retrograde cardioplegia.

\footnotetext{
* We thank Johannes M van Druten, PhD, department of Medical Informatics, Epidemiology and Statistics, University of Nijmegen, for the statistical analysis.
} 


\section{References}

1. He G-W, Acuff TE, He Y-H, Ryan WH, Mack MJ. Determinants of operative mortality in reoperative coronary bypass grafting. J Thorac Cardiovasc Surg 1995; 110: 971-978.

2. Yau TM, Borger MA, Weisel RD, Ivanov J, The changing pattern of reoperative coronary surgery: trends in 1230 consecutive reoperations. J Thorac Cardiovasc Surg 2000; 120: 156-163.

3. Weintraub WS, Jones EL, Craver JM, Grosswald R, Guyton RA. In-hospital and longterm outcome after reoperative coronary artery bypass graft surgery. Circulation 1995; 92[suppl II]: II-50-II-57.

4. Christenson JT, Schmuziger M, Simonet F. Reoperative coronary artery bypass procedures : risk factors for early mortality and late survivial. Eur J Cardiothoracic Surg 1997; $11:$ 129-133.

5. Noyez L, Skotnicki SH, Lacquet LK. Morbidity and mortality in 200 consecutive coronary reoperations. Eur J Cardiothoracic Surg 1997; 11: 528-532.

6. Eck van FM, Noyez L, Verheugt FWA, Brouwer RMHJ. Changing profile of patients undergoing redo-coronary artery surgery. Eur J Cardiothoracic Surg 2002; 21: 205-211.

7. Eck van FM, Noyez L, Verheugt FWA, Brouwer RMHJ. Analysis of mortality within the first six months after coronary reoperation. Ann Thorac Surg 2002; 74: 2106-2112.

8. Eck van FM, Noyez L, Verheugt FWA, Brouwer RMHJ. Preoperative prediction of early mortality in redocoronary artery surgery. Eur J Cardiothoracic Surg 2002; 21: 1031-1036.

9. Blackstone EH. Outcome analysis using hazard functional methodology. Ann Thorac Surg 1996; 61(2suppl) S2-7.

10. Borger MA, Rao V, Weisel RD, Floh AA, Cohen G, Feindel CM, Scully HE, Mickleborough LL, Yau TM. Reoperative coronary bypass surgery: effect of patent grafts and retrograde cardioplegia. J Thorac Cardiovasc Surg 2001; 121: 83-90. 


\title{
CHAPTER VII
}

\section{LONG TERM CARDIAC SURVIVAL AFTER REOPERATIVE CORONARY} ARTERY BYPASS GRAFTING.

\author{
Luc Noyez, Frans M. van Eck \\ European Journal of Cardio-thoracic Surgery \\ -in press-
}




\begin{abstract}
Objective: Despite advances in cardiac surgery, the risk of reoperative coronary artery bypass surgery (RECABG) still exceeds those of a primary myocardial revascularization and also the late results are not so favourable. In this study long term cardiac survival is analyzed.

Methods: We analyzed long term cardiac survival of 466 patients who survived the first six months after a RECABG between January 1987 and December 1998. Actuarial survival estimates were calculated and pre- and peroperative variables were analyzed to identify predictors of long term cardiac related mortality.
\end{abstract}

Results: Mean follow-up was $7.7 \pm 3.8$ years (1-17 years), and follow-up was 95.6\% complete. One years cardiac survival was 98.2\%, 5-year: 91.0\%, 10-year: 78.7\% and 14-year survival $60.2 \%$. Cardiac survival was only significant superior for patients under 65 years of age at the moment of the RECABG. Impaired left ventricular function was identified as the only independent predictor of late cardiac-related mortality.

Conclusion: The long term survival in patients undergoing RECABG is acceptable. Once patients survived the first six postoperative months, advanced age ( $>65$ years) is affecting long term cardiac survival and impaired left ventricular function is the only independent predictor of late cardiac mortality

\title{
Keywords
}

Coronary, reoperation, cardiac survival, 


\section{Introduction.}

Patients undergoing reoperative coronary artery bypass surgery (RECABG) have higher mortality, perioperative as well as at long term, compared with patients undergoing a primary myocardrevascularization ( CABG). [1-4] Since the study of Blackstone, using hazard function methology for time-related events, it is clear that risk factors must be identified for each phase of hazard. [5] In previous articles we focussed on mortality in the early- 6 months- phase after RECABG. [6,7] The present study concerns the longterm survival of the patients surviving the early postoperative phase after RECABG. This is in contrast with most other studies evaluating long term results starting their 'long-termanalysis' at the moment of the operation or hospital discharge.

\section{Material and methods}

\subsection{Patients}

With the aid of our database, Coronary Surgery Database Radboud Hospital (CORRAD), a registry that stores pre-, peri-, postoperative and follow-up data on all patients undergoing isolated coronary bypass grafting, we identified a series of 541 patients undergoing a first RECABG from January 1987 to December 1998 at the UMC St. Radboud Nijmegen.

The clinical indication for RECABG was angina and proven ischemia despite medical therapy with $\beta$ blockers, calcium antagonists or nitrates, or a combination. We distinguish three groups: (1) elective operations, patients with stable cardiac function, usually scheduled at least one day prior to the surgical procedure; (2) urgent operations, when surgery is required within 24 hours after admission; and (3) emergency operations: in case of operation for evolving infarction, ischemia not responding to medical therapy, or cardiogenic shock. Probably due our restrictive attitude for PTCA of diseased vein grafts, only two patients were operated in emergency after a failed PTCA. Forty-one patients $(7.5 \%)$ were reoperated for early graft failure, 130 patients $(24.1 \%)$ for late graft failure, 49 patients $(9.1)$ for progression of athersosclerosis in the native coronary system, 314 patients $(58.1 \%)$ for a combination of late graft failure and progression of athersosclerosis in the native coronary system, and 7 patients $(1.2 \%)$ for incomplete revascularization. The mean interval between the CABG and RECABG was $141 \pm 59$ months (0-300). 
Table 1. Definitions and frequencies of variables

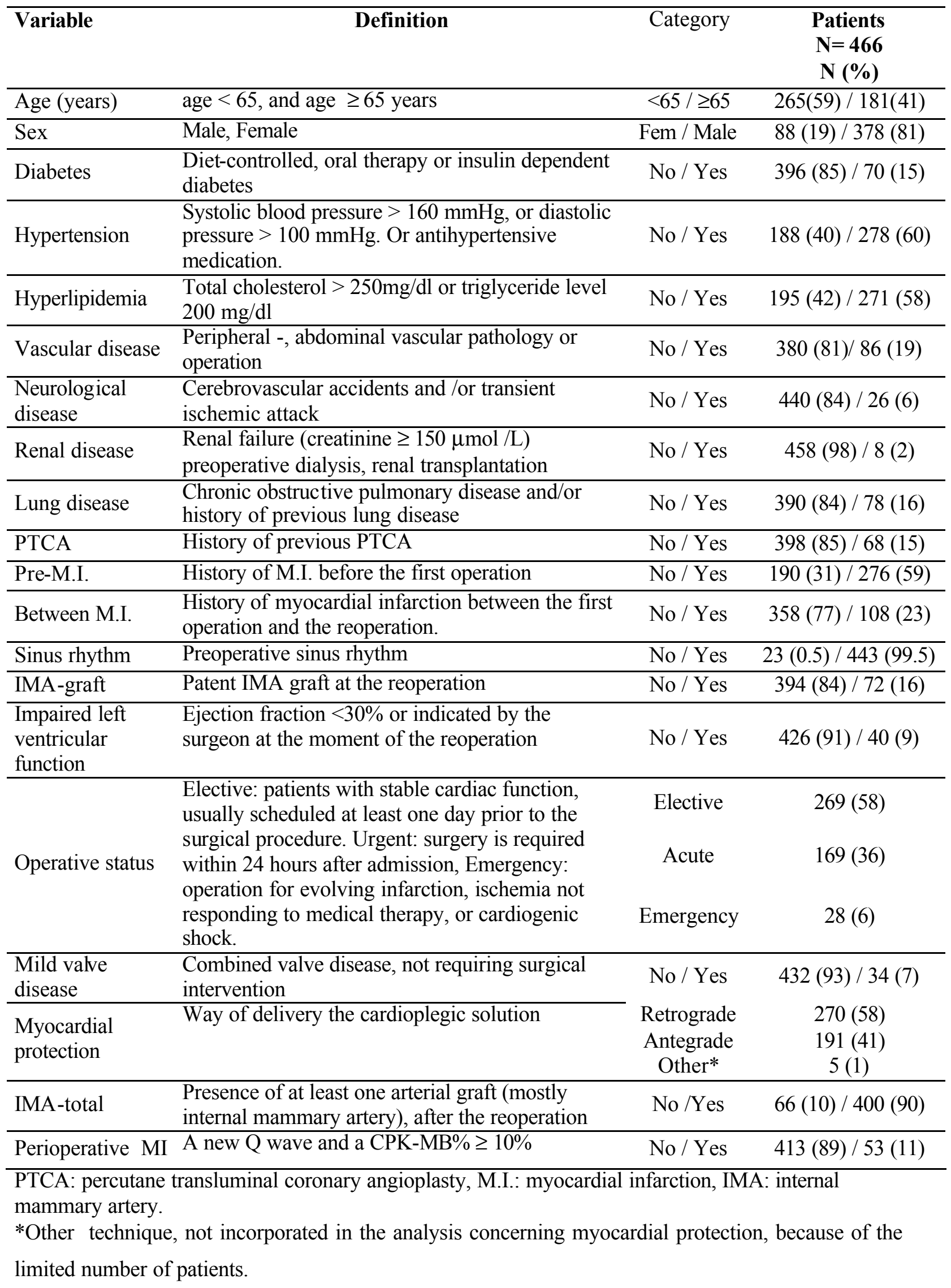


Hospital mortality 36/541 (6.7\%) and early phase - 6-months - mortality 75/541 patients $(13.9 \%)$ were the subject of our previous studies.[6,7] The 466 surviving patients were entered in this follow-up study. The studied pre- and peri-operative variables were listed in table 1.

To be able to compare our survival rates with other studies, we also calculated survival for the total patient population (541 patients) starting from the operation.

\subsection{Follow-up}

Follow-up information is based on data from cardiologists, family doctors, and an annual survey sent directly to the patients. A cross sectional follow-up was performed in December 2002. If there was no response from the patient, the information was traced by telephone contact with the patient, family, doctor, or government records. In case of death, the cardiologist, family doctor, or patients family was contacted to identify the cause of death.

\subsection{Statistical analysis}

Actuarial survival estimates were calculated using Kaplan-Meier method and compared using the log-rank test. Univariate analysis and multiple logistic regression analysis were used to identify risk factors that independently predicted long term cardiac-related mortality. A P-value of 0.05 or less was considered significant.

\section{Results}

Four hundred sixty-six patients with a mean age of $63.4 \pm 8.4$ years (median 64 , range 32-91) were included in the follow-up. Follow-up was 95.6\% complete, 20 patients were lost for follow-up. Mean follow-up was $7.7 \pm 3.8$ years, median 7.0 years and a range of 1-17 years. There were 138 late deaths: in 89 patients there was a proven cardiac related death, in 4 patients the cause of death was unknown, however these deaths were computed as cardiac deaths. Thus, we have 93 patients $(67.4 \%)$ with a cardiac related death. In the other 45 patients $(22.6 \%)$ death was of non-cardiac cause, 21 of them died of cancer.

The total one-year survival is $97.3 \%$, 5-year: $86,8 \%, 10$ year: $68.6 \%$ and a 14 -year survival of $48.1 \%$. The cardiac survival is presented in figure 1 . The one- year cardiac survival is $98.2 \%$, 5-year: $91.0 \%, 10$-year: $78.7 \%$ and a 14 -year survival of $60.2 \%$. 
Figure 1

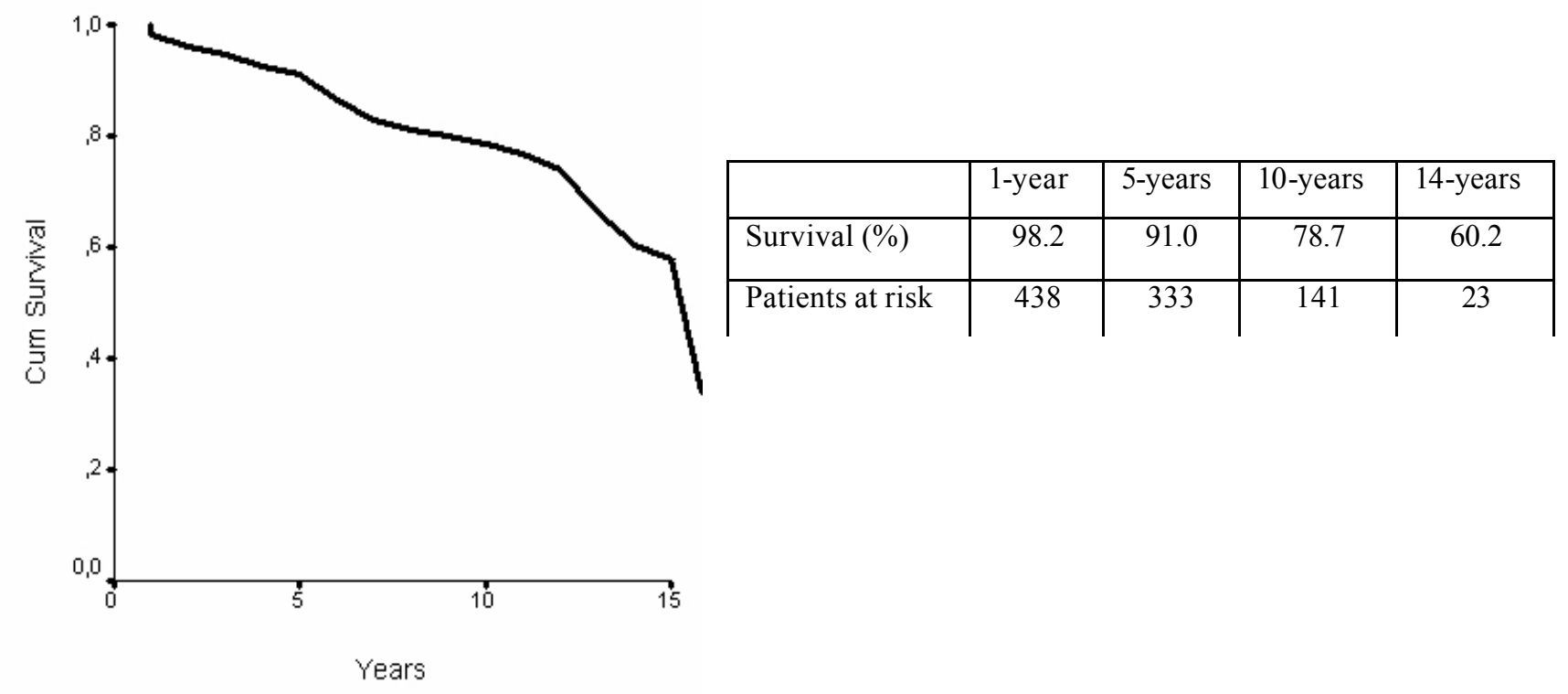

Figure 1. Cardiac survival for survivors of the early postoperative phase after reoperative coronary bypass surgery.

Figure 2

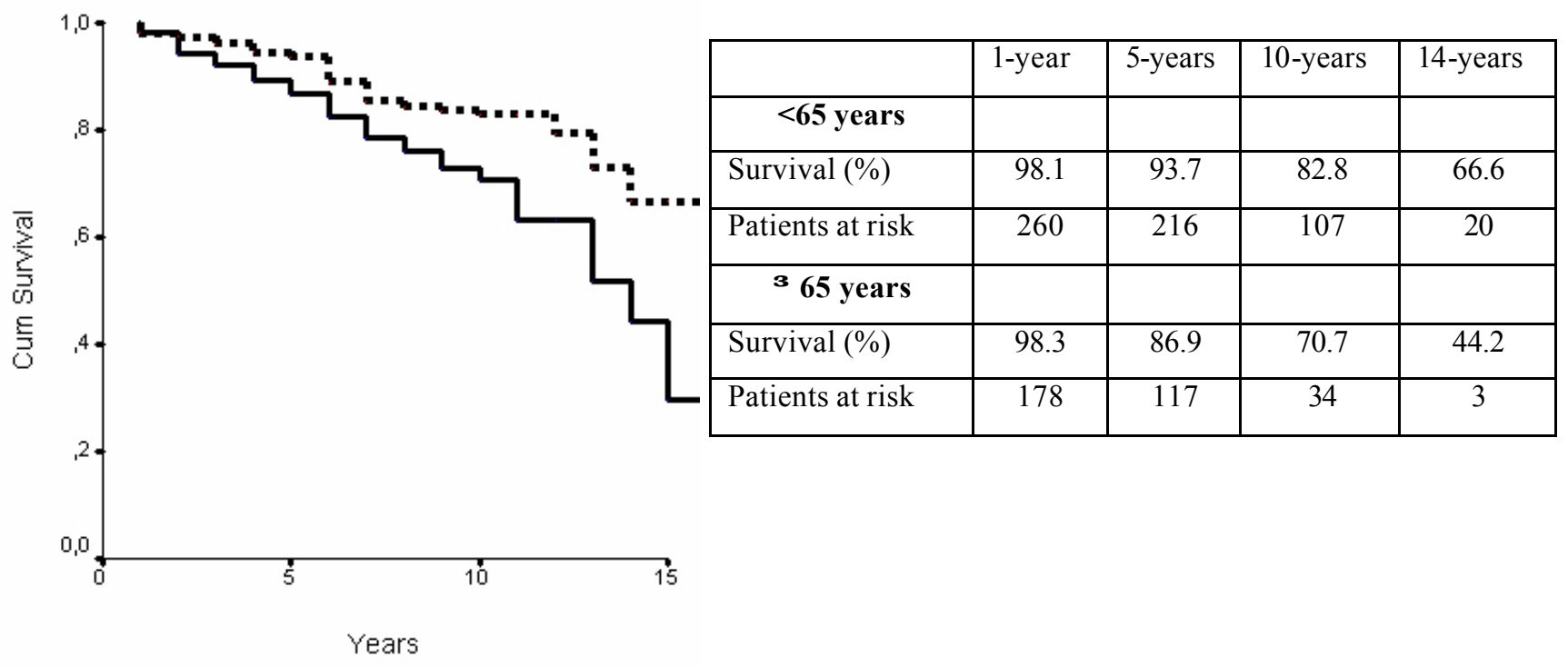

Figure 2. Cardiac survival divided by age. $(\mathrm{P}=\mathbf{0 . 0 0 2}, \log$ rank test $)$

Dotted line patients younger than 65 years

Full line patients aged 65 years or older. 
Cardiac survival was only significantly superior for patients under 65 years old compared to older patients $(\mathrm{P}=0.002)$ (figure 2 ) for the other studied variables (Table 2 ) there was no significant difference in survival.

Table 2. Studied variables tested for their association with long term cardiac survival and Pvalue (log-rank test)

\begin{tabular}{|l|l|l|}
\hline Variable & Category & P-value \\
\hline Age (years) & $<65 / \geq 65$ & 0.002 \\
\hline Sex & Male/ Female & 0.07 \\
\hline Diabetes & Yes / No & 0.06 \\
\hline Hipertensión & Yes / No & 0.65 \\
\hline Hyperlipidemia & Yes / No & 0.12 \\
\hline Vascular disease & Yes / No & 0.12 \\
\hline Neurological disease & Yes / No & 0.21 \\
\hline Renal disease & Yes / No & 0.69 \\
\hline Lung disease & Yes / No & 0.53 \\
\hline PTCA & Yes / No & 0.79 \\
\hline Pre-M.I. & Yes / No & 0.48 \\
\hline Between M.I. & Yes / No & 0.76 \\
\hline Sinus rhythm & Yes / No & 0.65 \\
\hline IMA-graft & Yes / No & 0.18 \\
\hline Impaired left ventricular function & Yes / No & 0.07 \\
\hline Operative status & Elective / acute/ emergency & 0.84 \\
\hline Mild valve disease & Yes / No & 0.31 \\
\hline Myocardial protection & Antegrade / Retrograde & 0.61 \\
\hline IMA-total & Yes / No & 0.35 \\
\hline Perioperative MI & Yes / No & 0.88 \\
\hline
\end{tabular}

To be able to compare our survival rates with other studies, we also calculated survival for the total patients population (541 patients) starting from the operation. This resulted in a one-year survival of $83.8 \%$, 5-year: $76.9 \%$ and a 10 -year survival of $60.6 \%$. Cardiac survival was $84.8 \%, 78.5 \%$, and $66.5 \%$, respectively.

Univariate analysis identified impaired left ventricular function $(\mathrm{P}=0.02)$ and mild valve disease $(\mathrm{P}=0.04)$ as two variables related with late cardiac mortality (Table 3$)$. Impaired left ventricular function is identified by multivariate analysis (Table 4) as the only independent variable for late cardiac mortality $(\mathrm{P}=0.021)$ 
Table 3 Results of uni-variate analysis for long term cardiac related mortality ( $N=446$ patients)

\begin{tabular}{|c|c|c|c|c|}
\hline Variable & Category & Live N (\%) & Mortality N (\%) & P-value \\
\hline \multirow[t]{2}{*}{ Age (years) } & $<65$ & $215(81.1)$ & $50(18.9)$ & 0.21 \\
\hline & $\geq 65$ & $138(76.2)$ & $43(23.8)$ & \\
\hline \multirow[t]{2}{*}{ Sex } & Female & $62(73.8)$ & $22(26.2)$ & 0.18 \\
\hline & Male & $291(80.4)$ & $71(19.6)$ & \\
\hline \multirow[t]{2}{*}{ Diabetes } & No & $306(80.1)$ & 76 (19.9) & 0.22 \\
\hline & Yes & $47(73.1)$ & $17(26.6)$ & \\
\hline \multirow[t]{2}{*}{ Hypertension } & No & $145(81.0)$ & $34(19)$ & 0.42 \\
\hline & Yes & $208(77.9)$ & $59(22.1)$ & \\
\hline \multirow[t]{2}{*}{ Hyperlipidemia } & No & $144(76.6)$ & $44(23.4)$ & 0.25 \\
\hline & Yes & $209(81.0)$ & 49 (19.0) & \\
\hline \multirow[t]{2}{*}{ Vascular disease } & No & $291(80.4)$ & $71(19.6)$ & 0.18 \\
\hline & Yes & $62(73.8)$ & $22(26.2)$ & \\
\hline \multirow[t]{2}{*}{ Neurological disease } & No & $335(79.6)$ & $86(20.4)$ & 0.36 \\
\hline & Yes & $18(72.0)$ & $7(28.0)$ & \\
\hline \multirow[t]{2}{*}{ Renal disease } & No & $347(79.0)$ & $92(21.0)$ & 0.66 \\
\hline & Yes & $6(85.7)$ & $1(14.3)$ & \\
\hline \multirow[t]{2}{*}{ Lung disease } & No & $295(79.3)$ & $77(20.7)$ & 0.85 \\
\hline & Yes & $58(78.4)$ & $16(21.6)$ & \\
\hline \multirow[t]{2}{*}{ PTCA } & No & $300(78.5)$ & $82(21.5)$ & 0.43 \\
\hline & Yes & $53(82.8)$ & $11(17.2)$ & \\
\hline \multirow[t]{2}{*}{ Pre-M.I. } & No & $144(78.7)$ & $39(21.3)$ & 0.84 \\
\hline & Yes & $209(79.5)$ & $54(20.5)$ & \\
\hline \multirow[t]{2}{*}{ Between M.I. } & No & $273(79.8)$ & $69(20.2)$ & 0.52 \\
\hline & Yes & $80(76.9)$ & $24(23.1)$ & \\
\hline \multirow[t]{2}{*}{ Sinus rhythm } & No & $18(78.1)$ & $5(21.9)$ & 0.91 \\
\hline & Yes & $335(79.2)$ & $88(20.8)$ & \\
\hline \multirow[t]{2}{*}{ IMA-graft } & No & $299(79.1)$ & $79(20.9)$ & 0.95 \\
\hline & Yes & $54(79.4)$ & $14(15.1)$ & \\
\hline \multirow{2}{*}{$\begin{array}{l}\text { Impaired left } \\
\text { ventricular function }\end{array}$} & No & $327(80.5)$ & $79(19.5)$ & 0.021 \\
\hline & Yes & $26(65.0)$ & $14(35.0)$ & \\
\hline \multirow[t]{3}{*}{ Operative status } & Elective & $200(78.7)$ & $54(21.3)$ & 0.86 \\
\hline & Acute & $134(80.2)$ & $33(19.8)$ & \\
\hline & Emergency & $19(76)$ & $6(24)$ & \\
\hline \multirow[t]{2}{*}{ Mild valve disease } & No & $328(79.6)$ & $84(20.4)$ & 0.04 \\
\hline & Yes & $25(73.5)$ & $9(9.7)$ & \\
\hline \multirow[t]{2}{*}{ Myocardial protection } & Retrograde & $210(81.4)$ & $48(18.6)$ & 0.35 \\
\hline & Antegrade & $138(75.8)$ & $44(24.2)$ & \\
\hline \multirow[t]{2}{*}{ IMA-total } & No & $32(69.6)$ & $14(30.4)$ & 0.09 \\
\hline & Yes & $321(80.3)$ & $79(19.8)$ & \\
\hline \multirow[t]{2}{*}{ Perioperative MI } & No & $326(79.5)$ & $84(20.5)$ & 0.52 \\
\hline & Yes & $27(75.0)$ & $9(9.7)$ & \\
\hline
\end{tabular}


Table 4 Results of the multivariant analysis of late cardiac-related mortality

\begin{tabular}{|c|c|c|c|}
\hline Variable & Category & Odds Ratio & P-value \\
\hline Age (years) & $\geq 65 /<65$ & 1.3 & 0.28 \\
\hline Sex & Female / Male & 0.7 & 0.99 \\
\hline Diabetes & Yes / No & 1.3 & 0.36 \\
\hline Hipertensión & Yes / No & 1.2 & 0.42 \\
\hline Hyperlipidemia & Yes / No & 0.7 & 0.19 \\
\hline Vascular disease & Yes / No & 1.3 & 0.37 \\
\hline Neurological disease & Yes / No & 1.4 & 0.44 \\
\hline Renal disease & Yes / No & 0.4 & 0.44 \\
\hline Lung disease & Yes / No & 1.0 & 0.99 \\
\hline PTCA & Yes / No & 0.7 & 0.38 \\
\hline Pre-M.I. & Yes / No & 0.8 & 0.55 \\
\hline Between M.I. & Yes / No & 1.2 & 0.53 \\
\hline Sinus rhythm & Yes / No & 1.0 & 0.91 \\
\hline IMA-graft & Yes / No & 1.5 & 0.32 \\
\hline Impaired left ventricular function & Yes / No & 2.5 & 0.02 \\
\hline Operative status & Elective / Acute+ Emergency. & 1.3 & 0.6 \\
\hline Mild valve disease & Yes / No & 1.5 & 0.34 \\
\hline Myocardial protection & Retro- / Ante-grade & 0.7 & 0.83 \\
\hline IMA-total & Yes / No & 0.3 & 0.19 \\
\hline Perioperative $\mathrm{Ml}$ & Yes / No & 1.2 & 0.66 \\
\hline
\end{tabular}

\section{Discussion.}

Based on the work of Blackstone, using hazard function methodology for the occurrence of a time related event, as postoperative death, a three phase hazard function was identified. An early phase, during the first postoperative months, prolonged in high risk patients and influenced by patient and procedural related variables, a constant and a late phase. [5,8] In our previous work we analysed the occurrence of mortality during the early phase after RECABG.[6,7] In the present study we analyzed long term survival of patients undergoing a RECABG, because each phase has his own risk factors. We started our survival analysis at the end of the early phase, six months postoperative. This is different from other survival studies, and consequently it is difficult to compare our results with these studies.[917] Therefore we also calculated survival for our entire patient population.

Table 5 gives a review of different survival studies. Studied period, number of patients, age, mortality, patients included in follow-up, and 5-yrs and 10-years survival are summarized. Because some studies give reviews over different periods, the indicated age is only approximate.[11,12 ] 
Table 5. Review of survival studies.

\begin{tabular}{|c|c|c|c|c|c|}
\hline $\begin{array}{c}\text { Study } \\
\text { (reference) }\end{array}$ & $\begin{array}{c}\text { Studied period } \\
\text { No of patients - Mean age }\end{array}$ & Mortality & $\begin{array}{l}\text { Patients included } \\
\text { in follow-up }\end{array}$ & $\begin{array}{l}\text { Surv } \\
5 \text { yrs }\end{array}$ & $\begin{array}{l}\text { ival \% } \\
10 \mathrm{yrs}\end{array}$ \\
\hline $\begin{array}{l}\text { Salomon et al. } \\
\text { (1) }\end{array}$ & $\begin{array}{c}1970-1988 \\
508 p t s-59 y r s\end{array}$ & $\begin{array}{l}\text { 30-days: } \\
6.9 \%\end{array}$ & $\begin{array}{l}\text { All patients } \\
\text { 30-day-survivors }\end{array}$ & $\begin{array}{l}80 \\
87.4\end{array}$ & $\begin{array}{l}65 \\
70\end{array}$ \\
\hline $\begin{array}{l}\text { Lyttle et al. } \\
\text { (12) }\end{array}$ & $\begin{array}{c}1967-1984 \\
1500 \mathrm{pts}- \pm 56 \mathrm{yrs}\end{array}$ & $\begin{array}{c}\text { Hospital: } \\
\pm: 3.4 \%\end{array}$ & Hospital survivors & 90 & 75 \\
\hline $\begin{array}{l}\text { Yamarmuro et al. } \\
\text { (15) }\end{array}$ & $\begin{array}{c}1983-1993 \\
739 \text { pts }(>70 \text { yrs })-74 y r s\end{array}$ & $\begin{array}{c}\text { Hospital: } \\
7.6 \%\end{array}$ & Hospital survivors & 75 & 49 \\
\hline $\begin{array}{l}\text { Shapira et al. } \\
\text { (17) }\end{array}$ & $\begin{array}{c}1978-1989 \\
498 \mathrm{pts}-64.6 \mathrm{yrs}\end{array}$ & $\begin{array}{c}\text { 30-days: } \\
\text { 3\% }\end{array}$ & All patients & 90 & 74 \\
\hline $\begin{array}{l}\text { Loop et al. } \\
\text { (12) }\end{array}$ & $\begin{array}{c}1967-1987 \\
2500 \mathrm{pts}- \pm 57 \mathrm{yrs}\end{array}$ & $\begin{array}{l}\text { Hospital: } \\
\pm 3 \%\end{array}$ & Hospital survivors & & 63.4 \\
\hline $\begin{array}{l}\text { Blanche et al. } \\
\text { (16) }\end{array}$ & $\begin{array}{c}1983-1996 \\
49 \text { pts }>80 \text { yrs }-82 \text { yrs }\end{array}$ & $\begin{array}{l}\text { Hospital: } \\
8 \%\end{array}$ & Hospital survivors & 58 & \\
\hline $\begin{array}{l}\text { Weintraub et al } \\
{[\mathrm{I}](14)}\end{array}$ & $\begin{array}{c}1975-1993 \\
2030 \text { pts - } 61 \text { yrs }\end{array}$ & $\begin{array}{l}\text { Hospital: } \\
7 \%\end{array}$ & All patients & 76 & 55 \\
\hline $\begin{array}{l}\text { Weintraub et al. } \\
{[\mathrm{II}] \text { (14) }}\end{array}$ & $\begin{array}{c}1975-1993 \\
779 \text { pts - 60-69yrs }\end{array}$ & $\begin{array}{c}\text { Hospital: } \\
8.2 \%\end{array}$ & All patients & 73 & 40 \\
\hline $\begin{array}{l}\text { Noyez, Eck van } \\
\text { (present study) }\end{array}$ & $\begin{array}{c}1987-1992 \\
541 \mathrm{pts}-63.7 \mathrm{yrs}\end{array}$ & $\begin{array}{c}\text { Hospital: } \\
6.7 \% \\
6 \text {-months : } \\
13.9 \%\end{array}$ & $\begin{array}{l}\text { All patients } \\
6 \text { months survivors }\end{array}$ & 86 & 68 \\
\hline
\end{tabular}

Weintraub [I]: total study, Weintraub [II]: only patients between 60-69 years old (reference 14)

It must be clear, however, that several points make the comparison difficult. First the studied patients population are operated in different time frames. This is not only important because of different surgical techniques, patient profile, but also because the indication for RECABG changed over the years.[11,12,18-22] In the early seventies, the majority of RECABG's were performed because of progression of atherosclerosis in the native coronary system or due to incomplete revascularization. Later in the eighties, the reason for RECABG had shifted to predominantly failure of the graft. In recent years, more and more patients are reoperated because of progression of the disease in the native system, in combination with patent arterial grafts.[22] Second, the age of the studied populations is different; varying between 56 and 80 years, or even older.[16] Age is indicated in several studies as an important variable 
influencing survival. $[1,10-12,14,17]$ Third, in several studies the hospital period, mortality, is included or not included in the survival analysis. Fourth, $\dot{t}$ is difficult to compare the risk of the studied patient populations. Risk analysis models as Parsonnet- ,[23] or Euroscore are not use,[24] and the reported operative-, hospital or 30-day mortality, probably an indication of the risk of the operated population, varies in all these studies.

The two studies, most comparable with ours, are from Weintraub et al [14], especially in the section separately evaluating a group of patients aged between 60-69 yrs old, operated between 1975 and 1993( indicated as Weintraub [II] in Table 5). The difference is that this study began in 1975, of the 2030 described patients 471 patients were operated before 1985 , but hospital mortality and long-term survival are comparable with our results for the entire group. The second study is from Shapira,[17] the reported 30-days mortality (3\%) and long term survival ( $90 \%, 74 \%$ ) seems superior to our results. The number of patients and mean age of the studied population are comparable, however, the study starts in 1978 and ends in 1989. Looking to the indications for reoperation, this study shows a high percentage of incomplete revascularization $(11.1 \%)$, a low percentage of combined graft failure and progression of the disease $(22.5 \%)$. If we compare this with our previous study and other studies, it is clear that this patient population, is not comparable with our described population or other recent studies of patients undergoing RECABG.[10,13,14,15,16,22]

Starting our survival analysis at six months postoperatively, cardiac related survival seems only be influenced by age (older or younger than 65 years). Age is identified in several other survival studies, $[1,10,11,12,14,17]$ however in contrast with a majority of these studies, co-morbidity factors and cardiac related variables are not identified as variables with a significant adverse effect on cardiac related longevity. However, diabetes $(\mathrm{P}=0.06)$, female gender $(\mathrm{P}=0.07)$, and impaired left ventricular function $(\mathrm{P}=0.07)$, bend to significance in our analysis. After uni- and multivariate analysis impaired left ventricular function is identified as the only independent predictor of late cardiac related mortality after redo surgery. Impaired left ventricular function is identified by several other studies as a predictor for cardiac related mortality, however, other variables as diabetes, hypertension, emergency surgery and others identified in these reports were not significant in our analysis.[1,2,10-17]

One criticism is that course that some variables are not included in our analysis. The most important is certainly completeness of the revascularization at the moment of the RECABG. In four patients $(0.8 \%)$ it was preoperatively decided to do an incomplete revascularization (two patients with a single graft to the LAD and one patient with a single graft to the right coronary artery, and this despites pathology in the circumflex arteries, in another patient with 
extensive pathology, only an additional IMA graft was constructed to a diseased vein graft to the LAD) All the other RECABG's were performed with as starting point a complete revascularization. However, diffuse pathology, lack of graft material, make definition of completeness of revascularization in RECABG extremely difficult. The question is; is revascularization complete if the surgeon performed all preoperatively planed grafts and distal anastomoses, or if the surgeon performed as much as possible of the preoperatively planned grafts and distal anastomoses, without increasing the risk for complications during the operation. It was even surprising that in our review of the literature, [1,11-17] only in the study of BW Lytle et al. is completeness of revascularization is analyzed.[11]. Completeness of revascularization is, however, not clearly defined and the study describes patients undergoing a RECABG between 1967-1984. As already mentioned in this discussion, it is difficult to compare these patients with our patients. Most of these patients had even not a complete revascularization at the $\mathrm{CABG}$, and even during the RECABG completeness of revascularization varies between $51 \%$ and $75 \%$. It is remarkable that a following study of the Cleveland Clinic, [12] completeness of revascularization is not analyzed. The changing profile of patients undergoing a RECABG, an increase of patients with progression of atherosclerosis in the native coronary arteries and patent arterial grafts, [22] only complicates the definition of complete revascularization. A patient with a patent IMA graft to the LAD, reoperated with new grafts to the distal right coronary artery and to the circumflex . But without a graft to a calcified diagonal branch, because of the risk of peroperative problems. Is this a complete revascularization or not? On the other hand, we realize, that in these patients it would be interesting to know if completeness of revascularization is important. A recent study of Czerny et al showed indirectly that completeness of the revascularization affects significant recurrence of angina but could not show a difference in long term survival(mean follow-up $50 \pm 23$ months).[25]

Another point of criticism is that secondary prevention and certainly medical therapy changed over the years. At our department, patients reoperated before 1992 received mostly no platelet-inhibiting agents, after the CABG. Systematic control of cholesterol or lipoprotein status, use of statins, are important but changed over the years. However, this information is not registered in our database and thus not available.

Inspite of the limitations of our study, the importance is that once patients survive the early postoperative period (six months) after RECABG, their cardiac related survival is influenced by age, and that an impaired left ventricular function is the only independent predictor for cardiac related mortality. These findings confirm the importance of the early 
postoperative period and the identified variables, it seems that the early postoperative period is an executioner, selecting the strongest patients.

In conclusion, the long term survival in patients undergoing reoperative coronary artery surgery are acceptable. Once patients survive the first six postoperative months, only advanced age ( $>65$ years) is affecting long term cardiac survival and impaired left ventricular function is the only independent predictor of late cardiac mortality.

\section{References}

1. Salomon NW, Page US, Bigelow JC, Krause AH, Okies JE, Metzdorff MT Reoperative coronary surgery. Comparative analysis of 6591 patients undergoing primary bypass and 508 patients undergoing reoperative coronary bypass. J Thorac Cardiovasc Surg 1990 ; $100: 250-260$.

2. Schmuziger M, Christenson JT, Maurice J, Mosiman E, Simonet F, Velebit V. Myocardial revascularization for the second time. Analysis of 458 reoperations and 2645 single operations. Cardiovasc Surg $1994 ; 2$ : 623-629.

3. Noyez L, Skotnicki SH, Kaan GL, Hensen AG, de Jong Pl, Lacquet LK. Primaire myocardrevascularisaties versus heroperaties. Een evaluatie van perioperatieve morbiditeit en mortaliteit. Cardiologie $1996 ; 3: 18-21$.

4. Sergeant P, Balckstone E, Meyns B, Stockman B, Jashari R. First cardiological or cardiosurgical reintervention for ischemic heart disease after primary coronary artery bypass grafting. Eur J Cardiothoracic Surg 1998 ; 14 : 480-487.

5. Blackstone EH Outcome analysis using hazard functional methodology. Ann Thorac Surg $1996 ; 61(2$ suppl) : S2-7.

6. Eck van FM, Noyez L, Verheugt FWA, Brouwer RMHJ. Analysis of mortality within the six months after coronary reoperation. Ann Thorac Surg $2002 ; 74$ : 2106-2112.

7. Eck van FM, Noyez L, Verheugt FWA, Brouwer RMHJ. Preoperative prediction of early mortality in redocoronary artery surgery. Eur J Cardiothoracic Surg $2002 ; 21$ : 10311036.

8. Sergeant P, Blackstone E, Meyns B. Validation and interdependence with patientvariables of the influence of procedural variables on early and late survival after CABG. KU Leuven Coronary Surgery Program. Eur J Cardiothorac Surg 1997 ; 12 : 1-19. 
9. Loop FD, Lytle BW, Gill CC, Golding LAR, Cosgrove DM, Taylor PC. Trends in selection and results of coronary artery reoperations. Ann Thorac Surg $1983 ; 36$ : 380388.

10. Akins CW, Buckley MJ, Dagget WM, Hilgenberg AD, Vlahakes GJ, Torchiana DF, Austen WG. Reoperative coronary grafting: changing patient profiles, operative indications, techniques, and results. Ann Thorac Surg 1994 ; 58 : 359-365.

11. Lytle BW, Loop FD, Cosgrove DM, Taylor PC, Goormastic M, Peper W, Gill CC, Golding LAR. Fifteen hundred coronary reoperations. J Thorac Cardiovasc Surg 1987 ; 93 :847-859.

12. Loop FD, Lytle BW, Cosgrove DM, Woods EL, Stewart RW, Golding LAR, Goormastic M, Taylor PC. Reoperation for coronary atherosclerosis. Changing practice in 2059 consecutive patients. Ann Surg $1990 ; 212$ : 378-386.

13. Christenson JT, Schmuzinger M, Simonet F. Reoperative coronary artery bypass procedures: risk factors for early mortality and late survival. Eur J Cardiothoracic Surg $1997 ; 11: 129-133$.

14. Weintraub WS, Jones EL, Craver JM, Grosswald R, Guyton RA. In-hospital and longterm outcome after reoperative coronary artery bypass surgery. Circulation 1995 ; $92[$ suppl II] : II-5-II-57.

15. Yamamuro M, Lytle BW, Sapp SK, Cosgrove DM, Loop FD, McCarthy PM. Risk factors and outcomes after coronary reoperation in 739 elderly patients. Ann Thorac Surg 2000 ; 69 : 464-474.

16. Blanche C, Kahn SS, Chaux A, Denton TA, Sandu M, Tsai T-P, Trento A. Cardiac reoperations in octogenarians: Analysis of outcomes. Ann Thorac Surg 1999 ; 67 : 93-98.

17. Shapira I, Isakov A, Heller I, Topilsky M, Pines A. Long-term follow-up after coronary artery bypass grafting reoperation. Chest $1999 ; 115: 1593-1597$.

18. Abramov D, Tamariz MG, Fremes SE, Guru V, Borger MA, Christakis GT, Bhatnagar G, Sever JY, Goldman BS.Trends in coronary artery bypass surgery results: a recent,9-year study. Ann Thorac Surg $2000 ; 70: 84-90$.

19. Noyez L, Lacquet LK. Cardiac reoperations with a patent internal mammary artery graft. A double challenge? Cardiovascular Surgery 1995; $36: 13-15$.

20. Borger MA, Rao V, Weisel RD, Floh AA, Cohen G, Feindel CM, Scully HE, Mickleborough LL, Yau TM. Reoperative coronary bypass surgery: effect of patent grafts and retrograde cardioplegia. J Thorac Cardiovasc Surg $2001 ; 121$ : 83-90. 
21. Brener SJ, Loop FD, Lytle BW,Ellis SG, Cosgrove DM, Topol EJ. A profile of candidates for repeat myocardial revascularization: implications for selection of treatment. J Tho rac Cardiovasc Surg 1997 ; 114 : 153-161.

22. Eck van FM, Noyez L, Verheugt FWA, Brouwer RMHJ. Changing profile of patients undergoing redo-coronary artery surgery. Eur J Cardiothoracic Surg $2002 ; 21$ : 205-211.

23. Parsonnet V, Dean D, Bernstein AD. A method of uniform stratification of risk for evaluating the results of surgery in acquired adult heart disease. Circulation 1989 ; 79(suppl I) : I-3-I-12.

24. Nashef SAM, Roques F, Michel P Gauducheau E, Lemeshow S, Salamon R. European system for cardiac opertive risk evaluation (EUROscore). Eur J Cardio-thorac Surg 1999 ; $16,9-13$.

25. Czerny M, Zimpfer D, Kilo J, Gottardi R, Dunkler D, Wolner E, Grimm M. Coronary reoperations: recurrence of angina and clinical outcome with and without cardiopulmonary bypass. Ann Thorac Surg $2003 ; 75: 847-852$. 


\section{CHAPTER VIII}

EVALUATION OF LONG TERM QUALITY OF LIFE AFTER REOPERATIVE CORONARY ARTERY SURGERY. PRELIMINARY RESULTS.

Luc Noyez, Astrid Schultz, Stefan M. van der Heide,

Frans M. van Eck, René M.H.J. Brouwer

Netherlands Heart Journal 2003; 11: 500-505.. 


\begin{abstract}
Objective: The risks of reoperative coronary artery bypass surgery (RECABG) still exceed those of a primary revascularization and late results are not so favourable either. The subject of the present study is an evaluation of the long term quality of life after RECABG.

Methods: We studied the outcome of 541 patients who underwent a RECABG from January 1987 to December 1998. The endpoint of the study was December 2002, or patients death. Quality of life, using the EuroQol registration was evaluated.

Results: Hospital mortality was $6.7 \%$. Follow-up was $95.6 \%$ complete, mean 7.7 years. There were 177 late deaths. The cumulative survival rates were $83.8 \%, 76.9 \%$, and $60.6 \%$, cardiac survival rates: were $84.8 \%, 78.5 \%$, and $66.5 \%$, at the 1-year, 5-years, and 10-year follow-ups, respectively. For 255 patients (89\%) NYHA and EuroQol information was complete. In total $23 \%$ of the patients were in NYHA class I, $51 \%$ in class II, $21 \%$ in class III and $5 \%$ were in class IV. In the EuroQol registration $54 \%$ of the patients declared they have no mobility problems, $85 \%$ no problems with self-care, and $65 \%$ no problems with usual activities. However, $60 \%$, suffered from moderate pain, or discomfort, and 33\% from anxiety or depression. On the visual analogue scale (mean 63.5 ), $13 \%$ of the patients scored $>90$, $68 \%$ between 50 and 90 and $19 \%$ of the patients $<50$.
\end{abstract}

Conclusion: The long-term results of cumulative survival and cardiac survival,NYHA class in our patient population who underwent RECABG are comparable with other studies. Quality of life is acceptable regarding to the high risk of a RECABG.

\title{
Key words:
}

Myocardial revascularization, reoperation, follow-up, quality of life, EuroQol 


\section{Introduction.}

The risks of reoperative coronary artery bypass surgery (RECABG) still exceed those of a primary revascularization. Several reports discuss late survival and related variables ando late results are not very favourable either. However, little or nothing has been reported concerning long term quality of life after RECABG, an important issue in a 'high risk' patient population. $^{1-8}$

The intention of this study is to evaluate long-term quality of life of patients undergoing a RECABG, using the EuroQol registration, ${ }^{9}$ and also the feasibility of this EuroQol survey in our data registration.

\section{Patients and methods.}

\subsection{Patients}

With the aid of our database, Coronary Surgery Database Radboud Hospital (CORRAD), we identified a series of 541 patients undergoing a first RECABG from January 1987 to December 1998 at the UMC St. Radboud Nijmegen. Hospital mortality was 36/541 $(6.7 \%)$ and the 505 surviving patients were entered into our follow-up. ${ }^{10}$

\subsection{Follow-up.}

Follow-up information is based on data from cardiologists, family doctors and an annual survey sent directly to the patients. A cross sectional follow-up was performed in December 2002. If there was no response from the patient, the information was traced by telephone contact with the patient, family, doctor, or government records. When death had occurred, the cardiologists, family doctor, or patients family was contacted to identify the cause of death. During the cross sectional follow-up patients were asked to inform us about their functional, New York Heart Association, classification and quality of life by using the EuroQol registration. ${ }^{9}$ The EuroQol-method is a standardised, generic (not disease specific) method for describing and evaluating health-related quality of life. It collects data about physical, mental and social functioning. The questionnaire (Table 1) consists of questions about mobility, self-care, normal day activities, anxiety and depression, pain and discomfort and a Visual Analogue Scale (VAS), a gauge by which the patient can express his current state of health on a scale of 0 (worst imaginable health state) to 100 (best imaginable health state) The relation between quality of life and several pre- and perioperative variables was studied (Appendix 1) 
Table 1. Results of the EuroQol registration at follow-up.

\begin{tabular}{|lll|}
\hline EuroQol Registration & Number of patients (n=255) & \% \\
Mobility & 139 & 54.5 \\
I have no problems in walking about & 104 & 40.8 \\
I have some problems in walking about & 14 & 5.5 \\
I can not walk alone - I am confined to bed & 217 & 85.1 \\
Self-care & 30 & 11.8 \\
I have no problems with self-care & 8 & 3.1 \\
I have some problems washing or dressing myself & & 64.7 \\
I am unable to wash or dress myself & 165 & 31.4 \\
Usual activities (work, study, housework, family, leisure activities) & 3.9 \\
I have no problems with performing my usual activities & 10 & 27.1 \\
I have some problems with performing my usual activities & 80 \\
I am unable to perform my usual activities & 69 & 60.4 \\
Pain/discomfort & 154 & 19.2 \\
I have no pain or discomfort & 49 & 63.5 \\
I have moderate pain or discomfort & & 32.5 \\
I have extreme pain or discomfort & 162 & 3.9 \\
Anxiety / Depression & 83 & \\
I am not anxious or depressed & 10 & \\
I am moderately anxious or depressed & & \\
I am extremely anxious or depressed & & \\
&
\end{tabular}

\subsection{Statistical analysis.}

Data were presented as frequency distribution and simple percentages, the VAS as mean \pm standard deviation. Survival was calculated using Kaplan-Meier method. To test which patient variables were associated with the different domains of the EuroQoregistration, univariant analysis, was used. A p-value of 0.05 or less was considered significant.

\section{Results.}

A total of 505 patients with a mean age $63.6 \pm 8.5$, mean 64.1 , range $32-91$ years were included in the follow-up, mean follow-up was $7.7 \pm 3.8$ years. Follow-up was $96 \%$ complete, 20 patients were lost for follow-up. The cumulative survival rates for the total patient population (541 patients) were $83.8 \%, 76.9 \% 60.6 \%$ at the one-year, five-year, and ten-year follow-up respectively. Cardiac event-free survival rates were $84.8 \%, 78.5 \%$ and $66.5 \%$ respectively. (figure 1)

At the moment of the cross-sectional follow-up, December 2002, 287 patients were registered as alive. Of 255 patients (89\%), NYHA and EuroQol information was complete. 


\section{Figure 1. Cardiac event-free survival of the total patient population.}

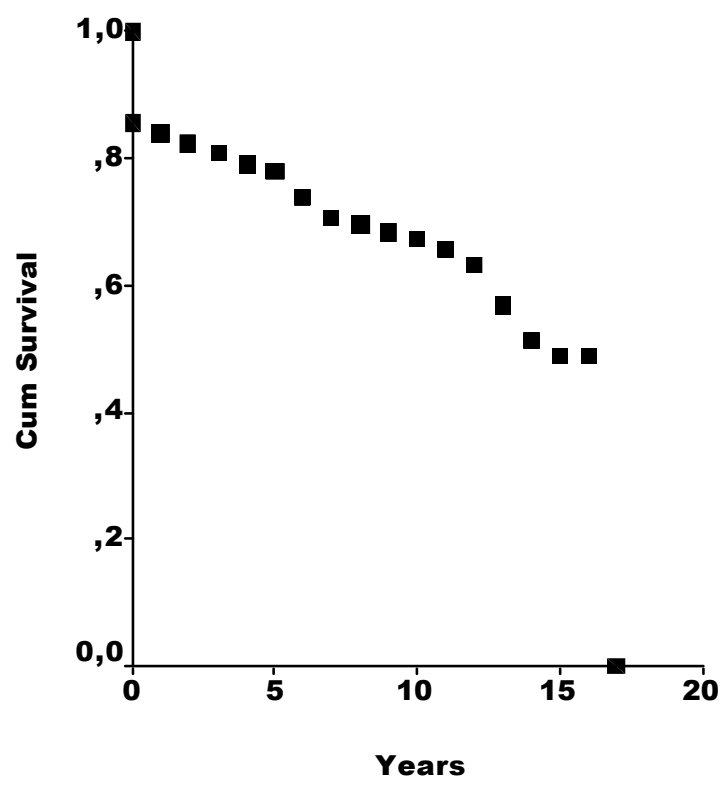

\begin{tabular}{|l|l|l|l|}
\hline & 1-year & 5 -years & 10 -years \\
\hline Survival (\%) & 84.8 & 78.5 & 66.5 \\
\hline Patients at risk & 446 & 333 & 141 \\
\hline
\end{tabular}

The results of the pre and post NYHA registration of this patient population are presented in figure 2 .

Figure 2. New York Heart Association functional class of 255 patients preoperatively (Pre -op) and at follow-up.

$\square$ Pre-op $\square$ Follow-up

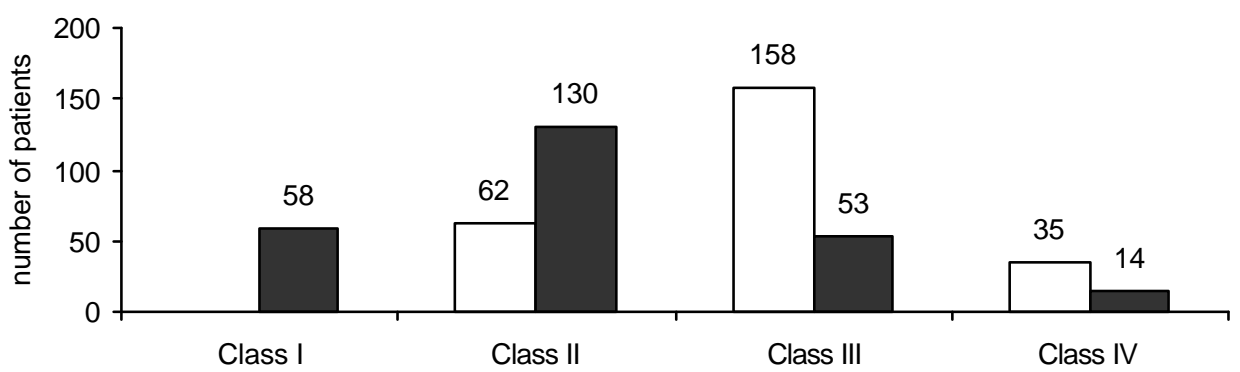

The results of the EuroQol registration are summarized in table 1. Interesting is that despite the fact that most patients have no problems with mobility $(54 \%)$, self-care $(85 \%)$, usual activities (65\%), and anxiety or depression (63\%), about $60 \%$ declare that they are suffering form moderate pain and discomfort. Univariate analysis identified several variables related to this EuroQol registration (table 2). Women, have a significant lesser quality of life regarding to mobility $(\mathrm{p}=0.031)$, normal activities $(\mathrm{p}=0.011)$, pain, discomfort $\left(\mathrm{p}=<10^{-4}\right)$, and anxiety and depression $(\mathrm{p}=0.02)$. Diabetics $(\mathrm{p}=0.004)$, patients with peripheral vascular 
pathology $(p=0.019)$ and a between myocardial infarction $(p=010)$ have significant more problems with mobility. Hypertensive patients $(\mathrm{p}=0.033)$ and patients with a history neurological disease $(p=0.03)$ have a significant lesser mobility postoperative. Patients with a history of a renal disease have more problems with normal activities $(p=0.008)$.

Table 3. Studied variables tested for their aossciation with the EuroQol registration (univariate analysis) -significant p-values are marked bold

\begin{tabular}{|lccccc|}
\hline \multicolumn{1}{|c}{ Variable } & Mobility & Self-care & $\begin{array}{c}\text { Usual } \\
\text { activities }\end{array}$ & $\begin{array}{c}\text { Pain } \\
\text { discomfort }\end{array}$ & $\begin{array}{c}\text { Anxiety } \\
\text { Depression }\end{array}$ \\
\hline Age & 0.61 & 0.31 & 0.14 & 0.64 & 0.31 \\
Sex & $\mathbf{0 . 0 3 1}$ & 0.54 & $\mathbf{0 . 0 1 1}$ & $<\mathbf{1 0}$ & $\mathbf{0 . 0 2}$ \\
Diabetes & $\mathbf{0 . 0 0 4}$ & 0.08 & 0.40 & 0.11 & 0.07 \\
Hypertension & 0.23 & $\mathbf{0 . 0 3 3}$ & 0.29 & 0.14 & 0.27 \\
Hyperlipidemia & 0.71 & 0.39 & 0.99 & 0.82 & 0.36 \\
Vascular disease & $\mathbf{0 . 0 1 9}$ & 0.70 & 0.29 & 0.63 & 0.47 \\
Neurological disease & 0.47 & $\mathbf{0 . 0 3 3}$ & 0.61 & 0.84 & 0.46 \\
Renal disease & 0.062 & 0.056 & $\mathbf{0 . 0 0 8}$ & 0.41 & 0.72 \\
Lung disease & 0.74 & 0.47 & 0.41 & 0.39 & 0.88 \\
PTCA & 0.96 & 0.27 & 0.76 & 0.62 & 0.43 \\
Preoperative MI & 0.18 & 0.88 & 0.73 & 0.10 & 0.75 \\
Between-MI & $\mathbf{0 . 0 1 0}$ & 0.19 & 0.26 & 0.12 & 0.94 \\
Sinus rhythm & 0.68 & 0.17 & 0.38 & 0.24 & 0.73 \\
IMA-graft & 0.17 & 0.39 & 0.76 & 0.33 & 0.38 \\
Impaired left ventricular function & 0.12 & 0.91 & 0.68 & 0.42 & 0.31 \\
Operative status & 0.47 & 0.19 & 0.26 & 0.39 & 0.16 \\
Mild valve disease & 0.99 & 0.13 & 0.89 & 0.89 & 0.74 \\
Myocardial protection & 0.98 & 0.72 & 0.54 & 0.52 & 0.68 \\
Perioperative MI & 0.54 & 0.32 & 0.95 & 0.88 & 0.64 \\
\hline
\end{tabular}

The Visual Analogue Score had a mean of 63.5 20.5 (median 65 , range 10-100). Thirty-two patients $(12.5 \%)$ had a VAS $>90,49$ patients $(19.2 \%)$ a VAS of $<50,174$ patients $(68.2 \%)$ indicated a score between 50 and 90 . Figure 3 presents the result as a histogram.

\section{Discussion.}

Reoperative coronary artery surgery is still high-risk surgery. Despite advances in surgical techniques and myocardial protection, mortality and morbidity rates of RECABG still exceeds those of CABG. This concerns not only the perioperative results but also the longterm results. Most studies deal with perioperative and long term survival results and only a few of these reports discuss quality of life, mostly by mean of the functional status. ${ }^{1-8,10}$ 


\section{Figure 3. Results of the Visual Analogue Score.}

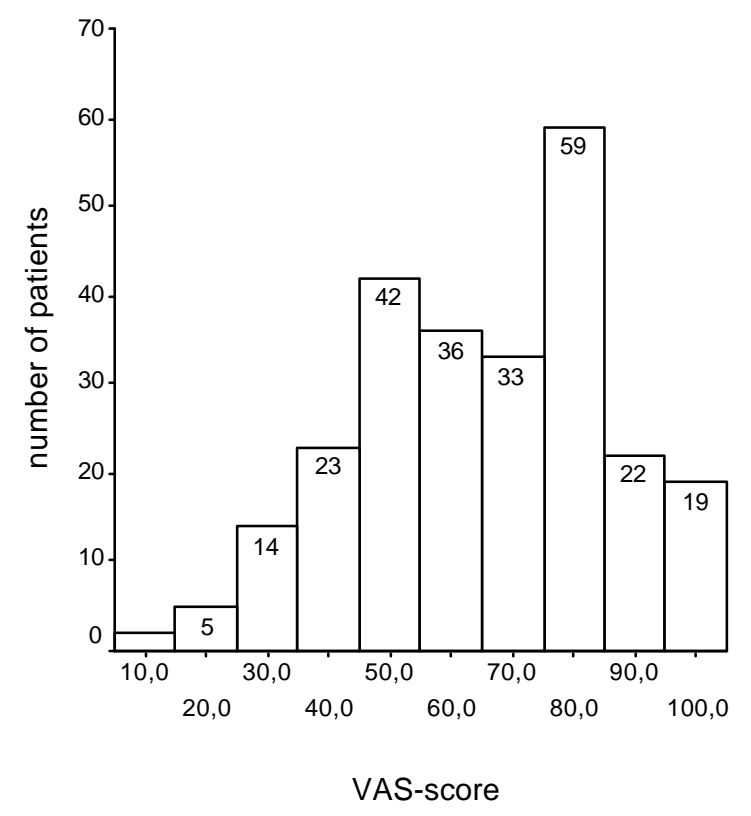

The ACC/AHA guidelines for CABG surgery suggest that improvement in quality of life is a primary indication for CABG surgery. ${ }^{11}$ The importance of quality of life was recognized and referred to as "not just the absence of death but life with the vibrant quality that we associate with the vigour of youth" by Elkington in $1966 .{ }^{12}$ Quality of life constitutes a person's perceptions of his personal physical and mental well-being, health, and symptoms rather than the surgeon's view of technical success. It is generally accepted that patients with larger preoperative health status deficits were more likely to have an improvement in their quality of life, but also that these patients have a higher perioperative mortality and morbidity risk. Therefore evaluation of quality of life in high-risk patients, such as patients undergoing a RECABG, is important and must seen as a complementary approach to the usual evaluations.

Our long term survival and cardiac-event free, were comparable with other reports and discussed in a previous study. ${ }^{1-8,10}$ Registration of functional NYHA class shows that even in long term, patients benefit of the RECABG. ${ }^{1-8}$ It is known that angina can affect quality of life, but it is also known that health status is much more than an evaluation of angina. $^{13}$

There is however no consensus on the best approach to asses quality of life, particularly after open heart surgery. In previous reports we evaluated quality of life using the Duke Activity Status index in young people, ${ }^{14}$ and the Barthel index in an elderly population. ${ }^{15}$ In literature, numerous questionnaires have been used, tested. However, none 
has been accepted as the gold standard. In this study we use the EuroQol registation. ${ }^{9}$ This EuroQol registration addresses various aspects of quality of life, is standardised, widely accepted, but not disease specific,. The questions are simple and the questionnaire is easy to complete.

At our cross sectional follow-up we had a good response, $89 \%$ of the returned questionnaires were complete. It must be noted that some patients only completed the NYHAclassification or only the EuroQol registration; these are not, however, incorporated in our study. Interpretation of our results is of course difficult, we have no other study for comparison. In our search of literature we did not find any specific studies concerning quality of life after RECABG, and after such a long follow-up period. Eighty-five percent of patients without problems with self-care is certainly a good result in this patient population. More difficult is the interpretation of the results of mobility and usual activities, anxiety or depression. Interesting however, is that about $60 \%$ of the patient suffer from moderate pain or discomfort. This is an important results and it is imperative that this point is discussed preoperatively with patients undergoing a RECABG. The visual analogue scale, asking the patients how they evaluate their own health state, shows that most patients accept their life quality as good. More interesting in this EuroQol registration is, however, that we identified, female gender, diabetes, vascular pathology, hypertension, renal pathology, neurological pathology and a between myocardial infarction as preoperative variables related to the post operative quality of life. As said, comparison of these results is difficult because of the lack of similar studies. However, in a prospective study of quality of life before and after open heart operations using the Nottingham health profile, ${ }^{16}$ female gender was even identified as an independent predictor of less improvement of quality of life. The relation of several variables on the different domains of quality of life seems logical, namely diabetes, vascular pathology on mobility, neurological disease on self-care, renal disease on usual activity. On the other hand, it is surprising that left ventricular function and operative status are not related to the EuroQol registration. However, operative status (acute and emergency) was identified as an independent variables for early mortality, and impaired left ventricular function as an independent variable for late cardiac mortality. ${ }^{8,10}$ So only a limited number of these patients were included in the cross sectional follow-up of December 2002.

We realize that our study has many shortcomings and is not complete. Most important is of course the lack of preoperative registration of quality of life. However, the aim of the study was to gain an idea of quality of live of patients undergoing a RECABG. Because of the good response on the EuroQol registration questionnaire during this study, we now 
include this questionnaire preoperatively in our CORRAD-data registration and also in our annual follow-up. Certainly in high-risk patients, as those undergoing RECABG, but also in other high risk populations, such as elderly, this "subjective" information can augment clinical decision-making by helping to identify those who will have a quality of life benefit from the operation. For instance, in a female diabetic patient, with vascular comorbidity, presenting for a RECABG, and identified as a high risk patient, complaining in the first place of mobility-problems, we can be more restrictive because, female gender, diabetes and vascular pathology seems to be related to a lesser improvement of mobility postoperative.

In conclusion this study show acceptable long term results concerning quality of life at long term after RECABG. Further analysis of this subject, can be helpful in making the decision to operate or not. Important is also that the EuroQol registration for quality of life, seems us very practical and will be used as well preoperative as postoperative in our cardiac surgery data registration.

*We thank Dr. Eric Roberston, anaesthesiologist, for his correction of the English text

\section{References.}

1. Salomon NW, Page US, Bigelow JC, Krause AH, Okies JE, Metzdorff MT Reoperative coronary surgery. Comparative analysis of 6591 patients undergoing primary bypass and 508 patients undergoing reoperative coronary bypass. J Thorac Cardiovasc Surg 1990 ; $100: 250-260$.

2. Lytle BW, Loop FD, Cosgrove DM, Taylor PC, Goormastic M, Peper W, Gill CC, Golding LAR. Fifteen hundred coronary reoperations. J Thorac Cardiovasc Surg 1987 ; 93 : 847-859.

3. Weintraub WS, Jones EL, Craver JM, Grosswald R, Guyton RA. In-hospital and longterm outcome after reoperative coronary artery bypass surgery. Circulation 1995 ; 92[suppl II] : II-5-II-57.

4. Yamamuro M, Lytle BW, Sapp SK, Cosgrove DM, Loop FD, McCarthy PM. Risk factors and outcomes after coronary reoperation in 739 elderly patients. Ann Thorac Surg 2000 ; 69 : 464-474.

5. Blanche C, Kahn SS, Chaux A, Denton TA, Sandu M, Tsai T-P, Trento A. Cardiac reoperations in octogenarians: Analysis of outcomes. Ann Thorac Surg 1999 ; 67 : 93-98. 
6. Shapira I, Isakov A, Heller I, Topilsky M, Pines A. Long-term follow-up after coronary artery bypass grafting reoperation. Chest $1999 ; 115: 1593-1597$.

7. Loop FD, Lytle BW, Cosgrove DM, Woods EL, Stewart RW, Golding LAR, Goormastic M, Taylor PC. Reoperation for coronary atherosclerosis. Changing practice in 2059 consecutive patients. Ann Surg 1990 ; 212 : 378-386.

8. Noyez L. Eck van FM. Longterm cardiac survival after reoperative coronary artery bypass grafting . - in press- European Journal of Cardio-thoracic Surgery

9. Brooks R, the EuoQol Group. EuroQol: the current state of play. Health Policy; 1996;37:53-72.

10. Eck van FM, Noyez L, Verheugt FWA, Brouwer RMHJ. Analysis of mortality within the six months after coronary reoperation. Ann Thorac Surg $2002 ; 74$ : 2106-2112.

11. American Heart Association. 2001 heart and stroke statistical update. May 2001

12. Elkington JR. Medicine and quality of life. Ann Intern Med 1996;64:711-714.

13. Pocock SJ, Henderson RA, Seed P. Quality of life, employment status, and anginal symptoms after coronary angioplasty or bypass surgery. Circulation 1996;94:135-142.

14. Noyez L, JW Onundu, DPB Janssen, SH Skotnicki, LK Lacquet. Myocardial revascularization in patients $\leq 45$ years old: evaluation of caridal and functional capacity, and return to work. Cardiovascular Surgery 1999;7:128-133.

15. Noyez L, Eck van FM, Janssen DPB, Skotnicki SH, Lacquet LK. Myocardial revascualrization in octogenarians: evaluation by the Barthel index. Cardiologie 1997;4:378-381.

16. Chocron S. Etievent J-P, Viel J-F, Dussaucy A, Clement F, Alwan K, Neidhardt M, Schipman N. Prospective study of quality of life before and after open heart operations. Ann Thorac Surg 1996;61:153-157. 


\begin{tabular}{|c|c|}
\hline Variable & Definition \\
\hline Age (years) & age $<65$, and age $\geq 65$ years \\
\hline Sex & Male, Female \\
\hline Diabetes & Diet-controlled, oral therapy or insulin dependent diabetes \\
\hline Hypertension & $\begin{array}{l}\text { Systolic blood pressure }>160 \mathrm{mmHg} \text {, or diastolic pressure }>100 \mathrm{mmHg} \text {. Or } \\
\text { antihypertensive medication. }\end{array}$ \\
\hline Hyperlipidemia & Total cholesterol $>250 \mathrm{mg} / \mathrm{dl}$ or triglyceride level $200 \mathrm{mg} / \mathrm{dl}$ \\
\hline Vascular disease & Peripheral -, abdominal vascular pathology or operation \\
\hline $\begin{array}{l}\text { Neurological } \\
\text { disease }\end{array}$ & Cerebrovascular accidents and /or transient ischemic attack \\
\hline Renal disease & Renal failure (creatinine $\geq 150 \mu \mathrm{mol} / \mathrm{L}$ ) preoperative dialysis, renal transplantation \\
\hline Lung disease & Chronic obstructive pulmonary disease and/or history of previous lung disease \\
\hline PTCA & History of previous percutaneous transluminal coronary angioplasty \\
\hline Pre-M.I. & History of myocardial infarction before the first operation \\
\hline Between M.I. & History of myocardial infarction between the first operation and the reoperation. \\
\hline Sinus rhythm & Preoperative sinus rhythm \\
\hline IMA-graft & Patent Internal Mammary Artery graft at the reoperation \\
\hline $\begin{array}{l}\text { Impaired left } \\
\text { ventricular } \\
\text { function }\end{array}$ & $\begin{array}{l}\text { Ejection fraction }<30 \% \text { or indicated by the surgeon at the moment of the } \\
\text { reoperation }\end{array}$ \\
\hline Operative status & $\begin{array}{l}\text { Elective: patients with stable cardiac function, usually scheduled at least one day } \\
\text { prior to the surgical procedure. Urgent: surgery is required within } 24 \text { hours after } \\
\text { admission, Emergency: operation for evolving infarction, ischemia not responding } \\
\text { to medical therapy, or cardiogenic shock. }\end{array}$ \\
\hline $\begin{array}{l}\text { Mild valve } \\
\text { disease }\end{array}$ & Combined valve disease, not requiring surgical intervention \\
\hline $\begin{array}{l}\text { Myocardial } \\
\text { protection }\end{array}$ & Way of delivery the cardioplegic solution \\
\hline Perioperative MI & A new $\mathrm{Q}$ wave and a CPK-MB $\% \geq 10 \%$ \\
\hline
\end{tabular}

PTCA : percutane transluminal coronary angioplasty, M.I. myocardial infarction, IMA : internal mammary artery. ${ }^{*}$ Other technique, not incorporated in the analysis, because of the limited number op patients (5) . 
CHAPTER IX

SUMMARY AND CONCLUSIONS

SAMENVATTING EN BESLUITEN 


\section{Chapter I}

After a review of the complexity of hazards related to reoperative coronary artery bypass grafting, the objectives of this thesis are outlined.

- What is changing in the patient population undergoing reoperative myocardial revascularization especially regarding strategies in primary myocardial revascularization?

- Which variables are responsible for the persistently elevated mortality of reoperative myocardial revascularization, and how can we inform patients and family about this risk?

\section{Chapter II}

In this chapter the changing profile of patients undergoing reoperative myocardial revascularization are studied. A series of 582 patients undergoing a first redo, between January 1987 and June 2000 at the University Medical Center Nijmegen, St. Radboud is described. There is a shift to an increasing number of older patients, with more coexisting disease, and with more patent arterial grafts. The increasing number of patients reoperated for isolated progression of atherosclerosis in the native coronary arteries confirms the palliative aspect of bypass surgery.

\section{Chapter III}

This chapter deals with the increasing number of patients undergoing a redo with a patent internal mammary artery graft. The good survival in patients when return of angina is the only symptom suggests a more restrictive approach. An analysis of short and long time results, clinical, functional and subjective status of 71 patients with a patent internal mammary artery graft undergoing RECABG is presented. Despite a perioperative mortality of $7 \%$, we conclude that the improved clinical, functional and subjective status of the patients justify this kind of surgery.

\section{Chapter IV}

High mortality rates remains in RECABG. In Chapter IV we focus on mortality within the first six months - the so-called 'early post-operative phase' following reoperative myocardial revascularization. Mortality is assessed at three different points: hospital mortality, mortality at six months and outpatient perioperative mortality, as death occurring from the time of hospital discharge to six months postoperatively. This study emphasized that 
early mortality is influenced by several variables at different times. Insight in this time-related influence of variables help point out factors contributes to hospital mortality and death after hospital discharge.

\section{Chapter V}

Chapter $\mathrm{V}$ is a result of the analysis in the previous chapter. Because the high risk for early mortality after reoperative myocardial revascularization we constructed a predictive model based on preoperative variables. The best predictive variables for early mortality are diabetes, vascular-, lung-disease, a myocardial infarction between the primary and the RECABG, acute- and emergency operation and the operative period. Evaluation of our predictive model shows a specificity of $97 \%$, a sensitivity of $33 \%$ and a predictive value of a positive test $63 \%$ and $90 \%$ for a negative test. This study shows that patients can be stratified according to their early mortality risk. Information that can be used to inform patients, and to discuss the opportunity of RECABG.

\section{Chapter VI}

Because it is not only important to discuss preoperatively the risk, but also to identify high risk patients for early postoperative mortality, the analysis performed in chapter $\mathrm{V}$ is repeated for the patients surviving the operation and includes also peroperative variables. Diabetes, lung disease, emergency operation and a perioperative myocardial infarction are the best predictive variables. The predictive value of a positive test is $79 \%$ and $95 \%$ for a negative test. With this model we can inform not only patients but also family, family doctors and cardiologists about the risk for early mortality, after hospital discharge.

\section{Chapter VII}

In this chapter, we analyzed long term cardiac survival of the 466 patients who survived the first six months after a RECABG. Mean follow-up was $7.7 \pm 3.8$ years (1-17 years), and follow-up was 95.6\% complete. One year cardiac survival was 98.2\%, 5-year: 91.0\%, 10-year: $78.7 \%$ and 14-year survival $60.2 \%$. Cardiac survival was only significantly better for patients aged 65 years or less at the time of RECABG. Impaired left ventricular function was identified as the only independent predictor of late cardiac-related mortality. This chapter confirms again the importance of the first six postoperative months after RECABG. 


\section{Chapter VIII}

This chapter concerns quality of life after RECABG. Although improvement of quality of life is accepted as a primary indication for myocardial revascularization, little or nothing is reported concerning quality of life after RECABG in literature. Our results of quality of life analysis after reoperative coronary artery surgery using the EuroQol score are presented. Despite all the limitations of this study, we conclude that patients have an improved functional status and quality of life. On the other hand, the EuroQol registration seems a very useful system and is now integrated pre- and postoperatively in our CORRAD ( Coronary Surgery Database Radboud) registry.

* Dr. Eric N. Robertson, Anesthesiologist, is thanked for his correction of the English text. 


\section{Hoofdstuk I}

$\mathrm{Na}$ een overzicht van de complexe problematiek bij coronaire heroperaties, worden de hoofdlijnen van dit proefschrift naar voor gebracht.

- In welke mate is de populatie van patiënten, die een heroperatie ondergaan veranderd en dit in relatie tot de veranderde strategieën bij de primaire ingrepen?

- Welke factoren spelen een rol in de hoge mortaliteit bij heringrepen en kunnen we deze mortaliteit inschatten? Op deze manier kunnen we tot een betere selectie van goede operatiekandidaten komen maar ook betere informatie verschaffen aan patiënt en familie.

\section{Hoofdstuk II}

In dit hoofdstuk wordt het profiel van patiënten die een coronaire heringreep ondergaan bestudeerd. En groep van 582 patiënten, die een heringreep ondergingen tussen januari 1987 en juni 2000 in het Universitair Medisch Centrum Nijmegen, St. Radboud wordt beschreven. Steeds meer en meer ouderen, risico-patiënten, en patiënten met een goed functionerende arteriële graft ondergaan een heroperatie. Tevens blijkt er een stijgend aantal patiënten te zijn met recidief klachten ten gevolge van het verder aantasten van de eigen coronair arteriën.

\section{Hoofdstuk III}

Dit hoofdstuk analyseert de resultaten van patiënten met een goed functionerende arteriële graft die een heroperatie ondergaan. In deze studie zijn 71 patiënten betrokken. De perioperatieve mortaliteit bedraagt 7\%, maar de goede klinische, functionele en subjectieve resultaten, zowel op korte als op langere termijn verantwoorden de heringreep bij deze populatie.

\section{Hoofdstuk IV}

De hoge mortaliteit bij heringrepen is een blijvend punt van discussie en onderzoeksthema. In dit hoofdstuk wordt de vroegtijdige mortaliteit - binnen de eerste zes maanden na de operatie geanalyseerd. Specifiek in deze analyse is dat de mortaliteit wordt geanalyseerd op drie momenten. Ten eerste: de mortaliteit zes maanden na de ingreep, ten tweede: de ziekenhuis mortaliteit, zijnde de peroperatieve en alle mortaliteit tijdens het postoperatieve ziekenhuisverblijf en ten derde: de vroegtijdige 'out-of-hospital 'mortaliteit, 
dwz alle mortaliteit die optrad na het ziekenhuisontslag maar binnen de eerst zes maanden postoperatief. Onze analyse toont aan dat verschillende factoren op verschillende tijdstippen en met een verschillend belang de vroegtijdige mortaliteit beïnvloeden.

\section{Hoofdstuk V}

Dit hoofdstuk is een resultaat van de analyse verricht in hoofdstuk IV. Op basis van deze gegevens wordt in hoofdstuk $\mathrm{V}$ een model gepresenteerd voor het preoperatief inschatten van de vroegtijdige mortaliteit. Diabetes, vasculaire-, long-problematiek, een hartinfarct tussen de primaire operatie en de heringreep, acute en spoedingrepen, alsmede de operatieve periode, zijn variabelen die onafhankelijk bijdragen tot de vroegtijdige mortaliteit na heringrepen. Het ontworpen model heeft een specificiteit van $97 \%$, sensitiviteit van $33 \%$, de voorspelende waarde van een positief resultaat is $63 \%$ en $90 \%$ bij een negatieve test. Deze informatie kan gebruikt worden om patiënten, familie, huisartsen en cardiologen preoperatief te informeren omtrent het risico van hun heringreep.

\section{Hoofdstuk VI}

In dit hoofdstuk wordt de analyse van het vorige hoofdstuk hernomen, maar met het verschil dat nu enkel patiënten die de heroperatie overleefden, en een aantal operatieve variabelen in de analyse zijn betrokken. Het belang is tweeërlei: ten eerste is het niet alleen belangrijk om patiënten en familie preoperatief te informeren over het mortaliteit risico, maar ook om na de operatie opnieuw hun kansen te bespreken. Ten tweede, zeker voor behandelende cardiologen, kan men op deze manier patiënten met een verhoogde kans op een out-of-hospital mortaliteit identificeren en eventueel specifiek gaan behandelen.

Diabetes, longproblematiek, een spoedingreep en het optreden van een perioperatief myocardinfarct zijn factoren die onafhankelijk bijdragen tot een verhoogde kans op vroegtijdige out-of-hospital mortaliteit. Opnieuw, in analogie met hoofdstuk V, werd een voorspellend model gemaakt. De voorspellende waarde van een positieve test bedraagt $79 \%$ en $95 \%$ voor een negatieve test. In de marge van deze analyse bleek dat het gebruik van retrograde toediening van de cardioplegische vloeistof een significante rol speelt bij het beperken van een perioperatief myocardinfarct.

\section{Hoofdstuk VII}

De lange termijn cardiale overleving van de 466 patiënten, die de eerste zes postoperatieve maanden overleefden wordt beschreven. De gemiddelde follow-up bedroeg 7.7 
\pm 3.8 jaren (1-17 jaar), en de follow-up was voor 95.6\% volledig. De 1-jaars cardiale overleving was $98.2 \%$, 5-jaars: $91.0 \%, 10$-jaars: $78.7 \%$ en de 14 -jaars overleving $60.2 \%$. Deze overleving wordt significant beïnvloed door de leeftijd op het ogenblik van de RECABG ( 65 jaar) en een verminderde linker ventrikel functie is de enige onafhankelijke predictor voor cardiale dood. Dit hoofdstuk geeft nogmaals aan hoe belangrijk de eerste zes postoperatieve maanden na RECABG zijn.

\section{Hoofdstuk VIII}

In dit hoofdstuk ligt de nadruk op de kwaliteit van leven. Het verbeteren van de levenskwaliteit is een primaire behandelingsindicatie bij mensen met ischemische hartklachten. Des ondanks is er in de literatuur weinig of niets beschreven over de kwaliteit van leven na coronaire heroperaties. Onze resultaten, waarbij kwaliteit van leven werd geregistreerd door middel van de EuroQol registratie worden gepresenteerd. Het is een studie met heel wat beperkingen maar toch besluiten we dat deze patienten zowel op functioneel gebied als in kwaliteit van leven het goed stellen. Daarnaast lijkt de EuroQol registratie een goed hanteerbare en betrouwbare methode om de kwaliteit van leven te evalueren. In de huidige CORRAD-registratie ( Coronary Surgery Database Radboud) wordt deze EuroQol zowel preoperatief als postoperatief geregistreerd. 


\section{DANKWOORD}

Dat de vraag van een student, om "een werkje", uiteindelijk resulteert in een proefschrift heeft natuurlijk te maken met de inzet van velen.

De secretaresses van de afdeling Thorax-hartchirurgie, met name mevrouw Els van Hulzen en mevrouw Jose Meys. Dank voor de koffie, voor de mogelijkheid om in de avond- en weekenduren op het secretariaat te kunnen werken. Mevrouw Lisette Peters, voor het invoeren van heel wat follow-up data in de CORRAD databank.

Dr. Hans Van Druten, voor mij de 'onbekende' statisticus, maar wel de man die niet alleen door de statistische analyses, maar ook door de tips voor verdere uitwerking van de globale analyse naar predictiemodellen de basis vormde voor dit proefschrift.

Dr. Eric Robertson, voor het nalezen en corrigeren van de engelse teksten

Professor Dr. Leo Booij, niet alleen omdat ik onder zijn leiding mijn opleiding anesthesie kon starten, maar ook omdat hij mij aanspoorde om deze studie af te ronden.

Professor Dr. Rene Brouwer, die de taak als promotor op zich nam.

De professoren Dr. A. Stalenhoef, Dr. J. van der Hoeven, Dr. B. Mochtar, Dr. G.J. Scheffer, Dr. P. Sergeant, als leden van de manuscriptcommissie

Dr. Marcel Hasenbos en Drs. Dirk van Diejen voor het honoreren van de aangevraagde studiedagen om zodoende de puntjes op de i te kunnen zetten.

Dr. Jacques Driessen voor zijn politieke adviezen 
Mijn collegae assistenten en stafleden anesthesiologen, stafleden en assistenten van de afdeling Thorax-hartchirurgie. Reoperaties zijn nu niet direct de meest gemakkelijk ingrepen, en het was ( is) niet steeds een pretje om ingedeeld te zijn op OK 83. Ook hun werk zit in dit proefschrift vervat.

Reoperaties duren langer, patiënten liggen langer op de IC, vragen meer zorg. Vandaar mijn speciale dank aan het verplegend- en ondersteunend personeel van de afdelingen Thoraxhartchirurgie, cardiologie, operatiekamer, en intensieve zorg, alsook de operatieassistenten, anesthesiemedewerkers en perfusionisten. Hun inspanningen en zorg hebben bijgedragen tot de resultaten beschreven in dit proefschrift.

Dank aan de - verwijzende - cardiologen, mag dit proefschrift een bewijs zijn dat binnen het UMCN St Radboud, meer gebeurt dan alleen opereren.

Een speciaal woord van dank is er uiteraard voor mijn co-promotor en vriend Dr. Luc Noyez. Luc, coronaire heroperaties zijn jouw interessepunt. De indicatiestelling, de operatie en zorg. En nu ook het opzetten van een specifieke polikliniek voor deze patiëntenpopulatie. Bij het aanleveren van ieder werkje, ieder artikel, begon je met "ik kan niet beloven dat dit iets wordt". Dat het uiteindelijk dit proefschrift geworden is heeft zeker te maken met jouw motto 'eerst nog even nadenken, dan werken, niet opgeven of zeuren, maar doorwerken en eventueel zelfs wat harder'.

Tot slot, maar zeker niet in de geringste mate, dank ik

Mijn moeder, die mij de mogelijkheid heeft geboden om te kunnen studeren.

Mijn vrouw, Sabina, die steeds opnieuw begrip toonde voor van mijn afwezigheid gedurende de weekenden en de avonden dat ik aan dit proefschrift werkte. 


\section{CURRICULUM VITAE}

Frans Matthijs van Eck werd geboren op 4 februari 1972 te Ede. Na de lagere school te hebben doorlopen werden achtereenvolgens de MAVO, een kappersopleiding en een opleiding voor automonteur gevolgd. Na deze omzwervingen werd het tijd voor een wat meer gestructureerde aanpak en werd vervolgens het HAVO en VWO diploma aan het Luzac college te Arnhem behaald. Hierna begon hij zijn studie Geneeskunde aan de Katholieke Universiteit te Nijmegen. Gedurende zijn studie kwam hij. via het keuzeblok 'Hart in nood' en later als keuze-co-assistent, terecht op de afdeling Thorax-hartchirurgie van het Universitair Medisch Centrum Nijmegen, St. Radboud. Dit was de plek waar hij zijn eerste onderzoekservaring opdeed, en waar de basis werd gelegd voor dit proefschrift. Vervolgens werd op 10 november 2000 het artsexamen met goed gevolg afgelegd.

Van 2000 tot en met 2001 was hij als AGNIO werkzaam op de afdeling Thorax hartchirurgie van het UMCN St. Radboud. Tijdens deze periode maakte hij kennis met het vakgebied van de anesthesiologie, en per 1 januari 2002 maakte hij de overstap naar de afdeling anesthesiologie alwaar hij eerst als AGNIO werkzaam was en sinds 1 augustus 2002 in opleiding tot anesthesioloog onder leiding van Prof. Dr. L.H.D.J. Booij en Prof. Dr. G. J. Scheffer.

Frans is getrouwd met Sabina Kippersluys en samen hebben ze twee kinderen, Lucas en Lisa. 
